\title{
Characterization of Eastern Filbert Blight-resistant Hazelnut Germplasm Using Microsatellite Markers
}

\author{
Megan F. Muehlbauer, Josh A. Honig, John M. Capik, Jennifer N. Vaiciunas, \\ and Thomas J. Molnar ${ }^{1}$ \\ Department of Plant Biology and Pathology, Foran Hall, 59 Dudley Road, Rutgers University, New \\ Brunswick, NJ 08901
}

\begin{abstract}
AdDitional INDEX words. Anisogramma anomala, Corylus avellana, disease resistance, filbert, nut crops, simple sequence repeat markers, tree breeding

Abstract. The development of new cultivars resistant to the disease eastern filbert blight (EFB), caused by Anisogramma anomala, is of primary importance to hazelnut (Corylus sp.) breeders in North America. Recently, a large number of EFB-resistant cultivars, grower selections, and seedlings from foreign germplasm collections were identified. However, for a significant number of these, little is known of their origin, relationships, or genetic background. In this study, 17 microsatellite markers were used to investigate the genetic diversity and population structure of 323 unique accessions, including EFB-resistant and tolerant germplasm of uncertain origins, in comparison with a panel of known reference accessions representing a wide diversity of Corylus cultivars, breeding selections, and interspecific hybrids. The resulting allelic data were used to construct an unweighted pair group method using arithmetic averages (UPGMA) dendrogram and STRUCTURE diagram to elucidate relationships among the accessions. Results showed 11 consensus groups with EFB-resistant or tolerant accessions in all, providing strong evidence that EFB resistance is relatively widespread across the genus Corylus. Furthermore, open-pollinated seedlings tended to group together with reference accessions of similar geographic origins, providing insight into their genetic backgrounds. The results of this study add to the growing body of knowledge of hazelnut genetic resources and highlight recently introduced EFB-resistant seedling germplasm as new, unrelated genetic pools of resistance.
\end{abstract}

The genus Corylus $(2 \mathrm{n}=2 \mathrm{x}=22)$ is widely distributed across temperate regions of the Northern Hemisphere. Various species can be found in Japan, Korea, and China, through Tibet, India, northern Iran, Turkey, and the Caucuses as well as in much of Europe and North America (Mehlenbacher, 1991). Most taxonomists place Corylus in the subfamily Coryloideae of the family Betulaceae, order Fagales, with recent work supporting the inclusion of 11 species placed in four subsections (Bassil et al., 2013; Chen et al., 1999; Erdogan and Mehlenbacher, 2000; Yoo and Wen, 2002). Across the genus, plants range from small, multistemmed shrubs to tall, singletrunk trees. All species produce edible nuts and are windpollinated, self-incompatible, and deciduous (Mehlenbacher, 1991). The most well-studied and commercially important member of the genus is the european hazelnut (C. avellana), which ranks fifth in world tree nut production behind cashew (Anacardium occidentale), almond (Prunus dulcis), walnut (Juglans regia), and chestnut (Castanea sp.). Turkey produces $\approx 70 \%$ of the world's hazelnut crop $(742,997 \mathrm{t}$ in 2011) followed by Italy $(\approx 15 \%)$ and the United States $(\approx 5 \%)$ (Food and Agriculture Organization of the United Nations, 2013). Ninetynine percent of U.S. production comes from the Willamette Valley of Oregon.

\footnotetext{
Received for publication 6 Jan. 2014. Accepted for publication 16 Apr. 2014. Funding for this research comes from the New Jersey Agricultural Experiment Station, the Rutgers Center for Turfgrass Science, and the U.S. Department of Agriculture Specialty Crops Research Initiative Competitive Grant 200951181-06028.

We thank S.A. Mehlenbacher, V.R. Sathuvalli, and the USDA-ARS National Clonal Germplasm Repository, Corvallis, OR, for contribution of plant materials and simple sequence repeat primers.

${ }^{1}$ Corresponding author. E-mail: molnar@aesop.rutgers.edu.
}

The lack of commercial hazelnut production in the eastern United States is largely the result of the disease EFB caused by the fungus Anisogramma anomala (Thompson et al., 1996). This pathogen is found naturally occurring on the wild american hazelnut (C. americana), where it causes little damage (Capik and Molnar, 2012; Fuller, 1908; Weschcke, 1954). However, EFB is devastating to most plants of $C$. avellana, on which it causes stem cankers, branch dieback, and subsequent tree death (Johnson and Pinkerton, 2002). The disease was originally restricted to regions east of the Rocky Mountains, allowing commercial hazelnut production to thrive in the Pacific northwestern United States for many decades (Thompson et al., 1996). Unfortunately, A. anomala was inadvertently introduced into southwestern Washington in the 1960s and subsequently overwhelmed hazelnut orchards, because control measures had not yet been developed and cultivars in production were generally very susceptible (Davison and Davidson, 1973; Gottwald and Cameron, 1980). The disease has since spread throughout the Willamette Valley of Oregon. Its management adds considerable expense to hazelnut production as a result of the need for copious fungicide sprays, scouting for cankers, and pruning of infected wood. Breeding for resistance to EFB is considered to be the most cost-effective means of control (Johnson et al., 1996; Julian et al., 2008, 2009; Thompson et al., 1996).

In the Pacific northwestern United States, the first EFBresistant cultivar identified was $C$. avellana Gasaway, a lateblooming pollenizer that produces low yields of small nuts. 'Gasaway' was shown to transmit resistance to its offspring in a ratio of one resistant to one susceptible, which is indicative of a dominant allele at a single locus in the heterozygous state (Cameron, 1976; Mehlenbacher et al., 1991). It has since been widely used in the Oregon State University (OSU, Corvallis, 
OR) hazelnut breeding program, leading to the development of the EFB-resistant cultivars Santiam (Mehlenbacher et al., 2007), Yamhill (Mehlenbacher et al., 2009), Jefferson (Mehlenbacher et al., 2011), and Dorris (Mehlenbacher et al., 2013).

Since the discovery of 'Gasaway', additional C. avellana cultivars and seedling selections have been shown to be resistant to EFB in Oregon. These include 'Ratoli' (Lunde et al., 2000; Sathuvalli et al., 2011a) and 'Culpla' (Chen et al., 2007) from Spain; 'Uebov' and 'Crvenje' from Serbia (Sathuvalli et al., 2010); Moscow \#1, 2, 26, 27, and 37 from Moscow Province, Russia; OSU 495.072 believed to be from southern Russia (Sathuvalli et al., 2010); OSU 759.010 from the Republic of Georgia (Sathuvalli et al., 2011b); Finland CCOR 187.001 from Finland (Chen et al., 2007); and OSU 408.040 from the University of Minnesota (Chen et al., 2005; Sathuvalli et al., 2012). Today, in addition to continued use of 'Gasaway', these resistant plants are being incorporated into breeding efforts at OSU (S.A. Mehlenbacher, personal communication).

Hazelnut breeding in the eastern United States began in the early 1900s with the goal of developing better-adapted, coldhardy, and EFB-resistant plants. These efforts have been previously discussed in detail in Molnar (2011), Molnar et al. (2005), and Thompson et al. (1996). Briefly, most of the breeding efforts were unsuccessful in identifying or developing hazelnuts capable of supporting a commercial hazelnut industry in the eastern United States, primarily because of a lack of the combination of EFB resistance, cold-hardiness, high nut yield, and kernel quality. However, some progress was made in developing improved EFB-resistant hybrids from first-generation controlled crosses of $C$. avellana and $C$. americana as well as better selections from open-pollinated (OP) seedling populations of those original hybrids (Molnar et al., 2005).

A hazelnut genetic improvement program was initiated at Rutgers University in 1996. To search for additional sources of EFB resistance in C. avellana - the species with the largest nuts and highest quality kernels (Mehlenbacher, 1991) - germplasm collections were made in Russia, Ukraine, and Poland. The resulting seedlings, spanning numerous seed lots across all three countries, were exposed to $A$. anomala at Rutgers University (a subset was also grown at OSU) and later evaluated for their response to the disease. From more than 2400 seedlings, nearly $100(\approx 4 \%)$ EFB-resistant (plants remaining free of disease symptoms) and -tolerant (plants with few small cankers) plants were identified that add to the pool of genetic resources now available for breeding. Some of these plants have improved nut yield and quality compared with earlier EFB-resistant selections, particularly 'Gasaway' (Capik et al., 2013; Molnar et al., 2007).

Adding this new EFB-resistant material to the resistant accessions identified in Oregon and the clonal and seedpropagated interspecific hybrid selections previously developed by eastern U.S. breeders results in a significant amount of disease-resistant germplasm (Capik et al., 2013; Capik and Molnar, 2012). However, with the exception of the known cultivars (Ratoli, Culpla, etc.), much of this material came as seed of unknown or uncertain origin. In regard to many of the grower selections derived from early breeding efforts in the eastern United States, in general, there was little or no control of the pollen parent and records of female parents were often lost, including species designations. Furthermore, as a result of extensive exchange of plant materials in the United States, especially among members of the Northern Nut Growers Association (NNGA, 2013), selections from different states and provinces likely share the same genetic base. This uncertainty in relationships and genetic backgrounds of the EFB-resistant germplasm presents problems when planning long-term breeding efforts to develop durable resistance in this long-lived, perennial species.

Fortunately, molecular tools are now available to characterize hazelnut germplasm. Microsatellite, or simple sequence repeat (SSR), markers are particularly valuable for fingerprinting accessions, examining relationships, and assessing genetic diversity in hazelnut (including across species) as a result of their abundance, polymorphic nature, and codominance (Bassil et al., 2005a, 2005b, 2013; Boccacci et al., 2005, 2006, 2008; Gökirmak et al., 2009; Gürcan et al., 2010a, 2010b; Gürcan and Mehlenbacher, 2010a, 2010b). Collectively, these studies have provided significant insight into the genetic diversity and population structure existing in cultivated and wild hazelnuts, including the domestication and spread of cultivated hazelnut in Europe. Gökirmak et al. (2009) examined 270 accessions of $C$. avellana spanning the world's production regions, of which 198 were unique. Their analysis organized the accessions into groups based on their SSR profiles and place of origin, revealing four major geographic groups (Central European, Black Sea, English, and Spanish-Italian) with subgroups resolved within them. Their work, as well as that of the others listed previously, provides a framework in which to place previously uninvestigated clonal accessions and seedlings in relation to known cultivars using SSR markers. The objective of our study was to use SSR markers to investigate the genetic diversity and population structure of new EFB-resistant and tolerant hazelnut germplasm in comparison with a wide diversity of known Corylus cultivars, accessions, breeding selections, and interspecific hybrids.

\section{Materials and Methods}

Plant material. A total of 323 Corylus accessions from Rutgers University, OSU, and the U.S. Department of Agriculture (USDA) National Clonal Germplasm Repository (NCGR) were examined in this study (Table 1). These accessions include 84 clonal accessions of $C$. avellana, 142 selections derived from OP seed of $C$. avellana from new germplasm introductions, 11 representatives of wild Corylus species, and 86 putative Corylus hybrids. The 84 clonal $C$. avellana accessions comprise a reference panel of known cultivars grown across much of the world's production regions and also include most of the known C. avellana sources of EFB resistance. Nearly all of these clonal accessions were previously characterized in Gökirmak et al. (2009) and were selected for incorporation in this study to represent the geographic groups described in their work.

The 142 seed-derived $C$. avellana accessions include 86 EFB-resistant and 33 EFB-tolerant plants identified from germplasm collections made in Russia, Ukraine, and Poland, as described in Capik et al. (2013) and Molnar et al. (2007), with the remainder comprised of susceptible seedlings from these regions as well as Estonia and Moldova. The 86 putative Corylus hybrid accessions consist of EFB-resistant and -tolerant plants developed from earlier U.S. breeding efforts, including that of J. Gellatly, C. Farris, J. Gordon, and E. Grimo. Most of these were selected from seedlings produced by OP (Molnar, 2011; Molnar et al., 2005; Thompson et al., 1996). Collectively, the seed-derived $C$. avellana accessions and the putative Corylus 


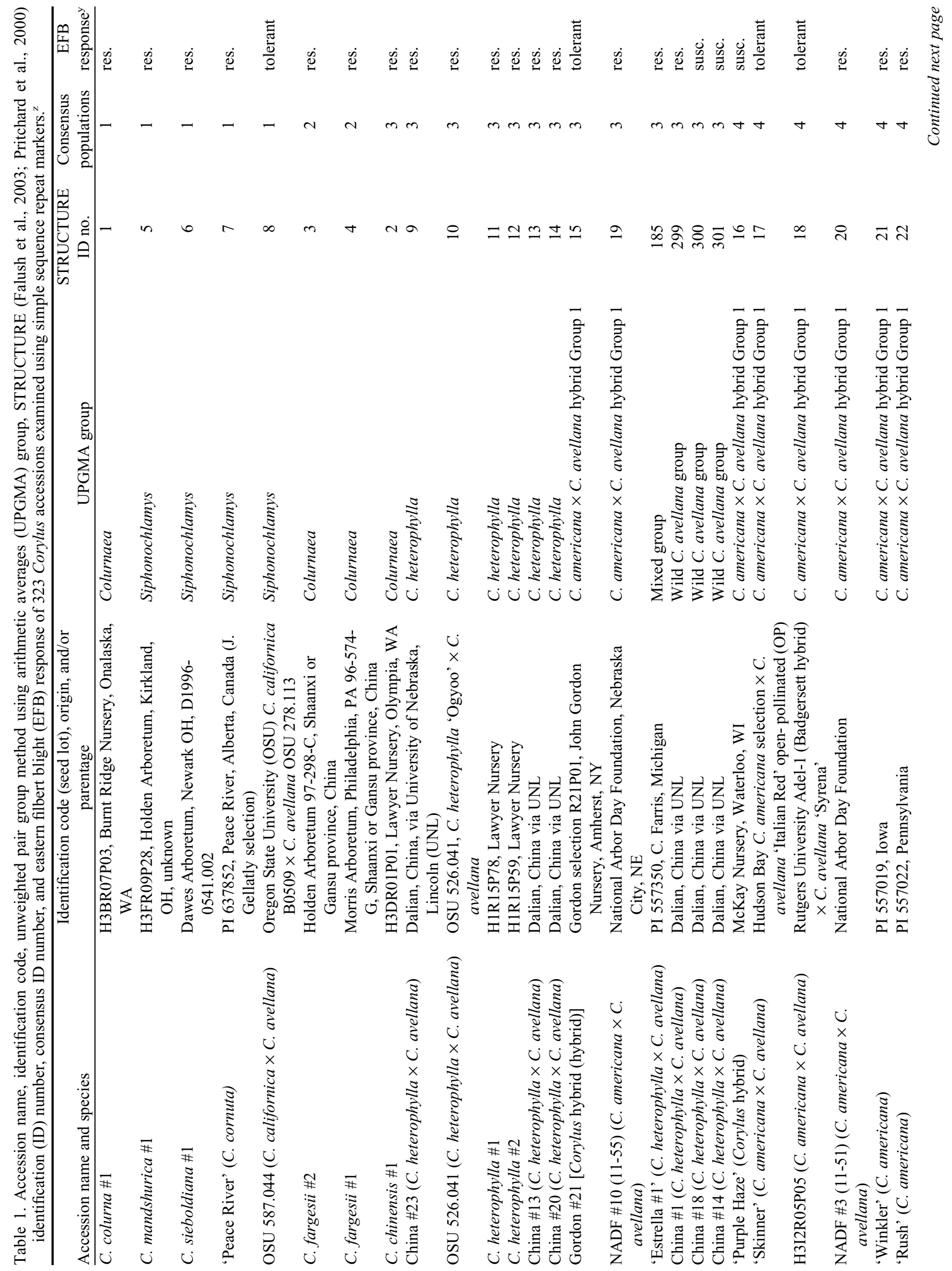




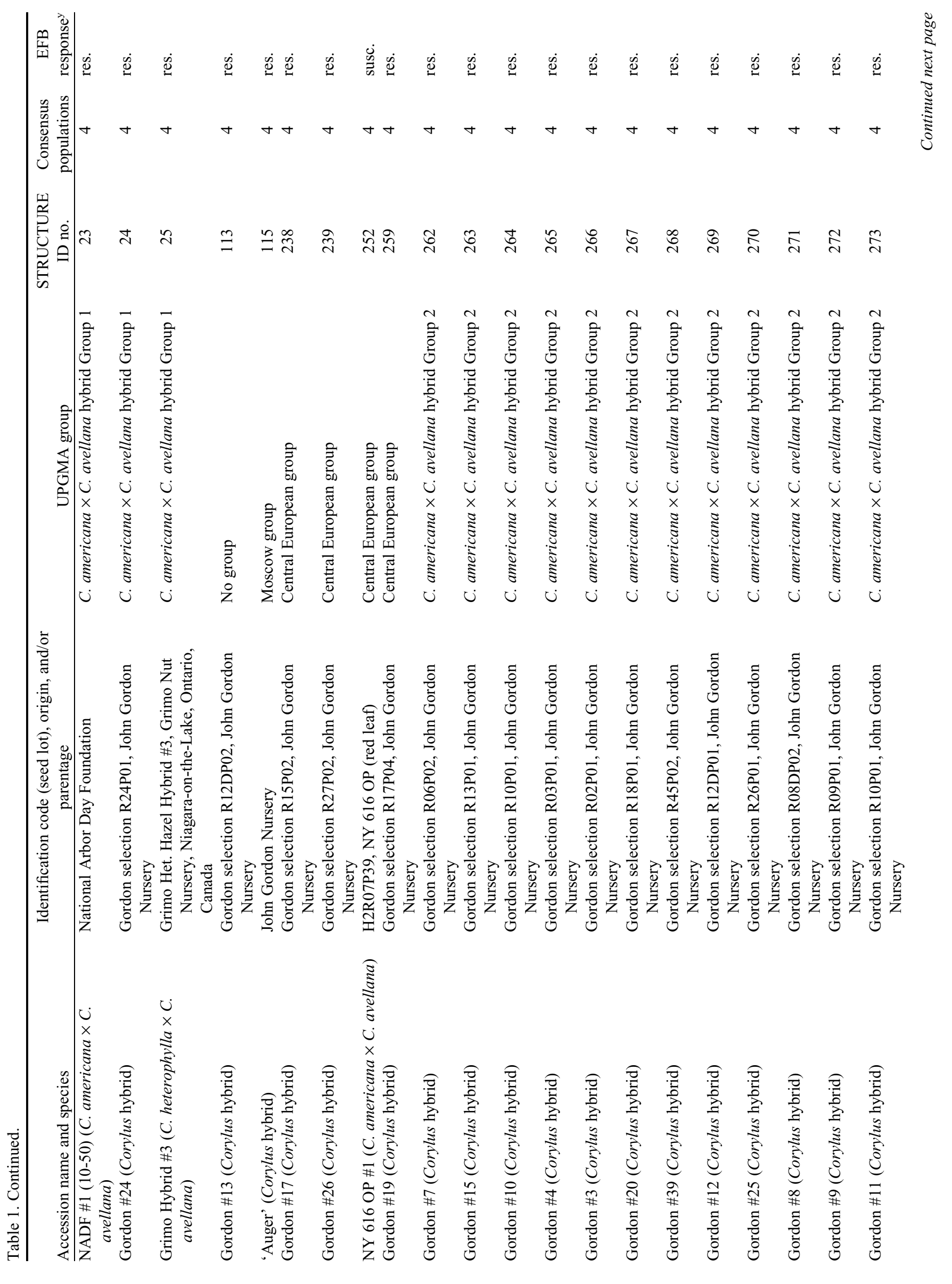




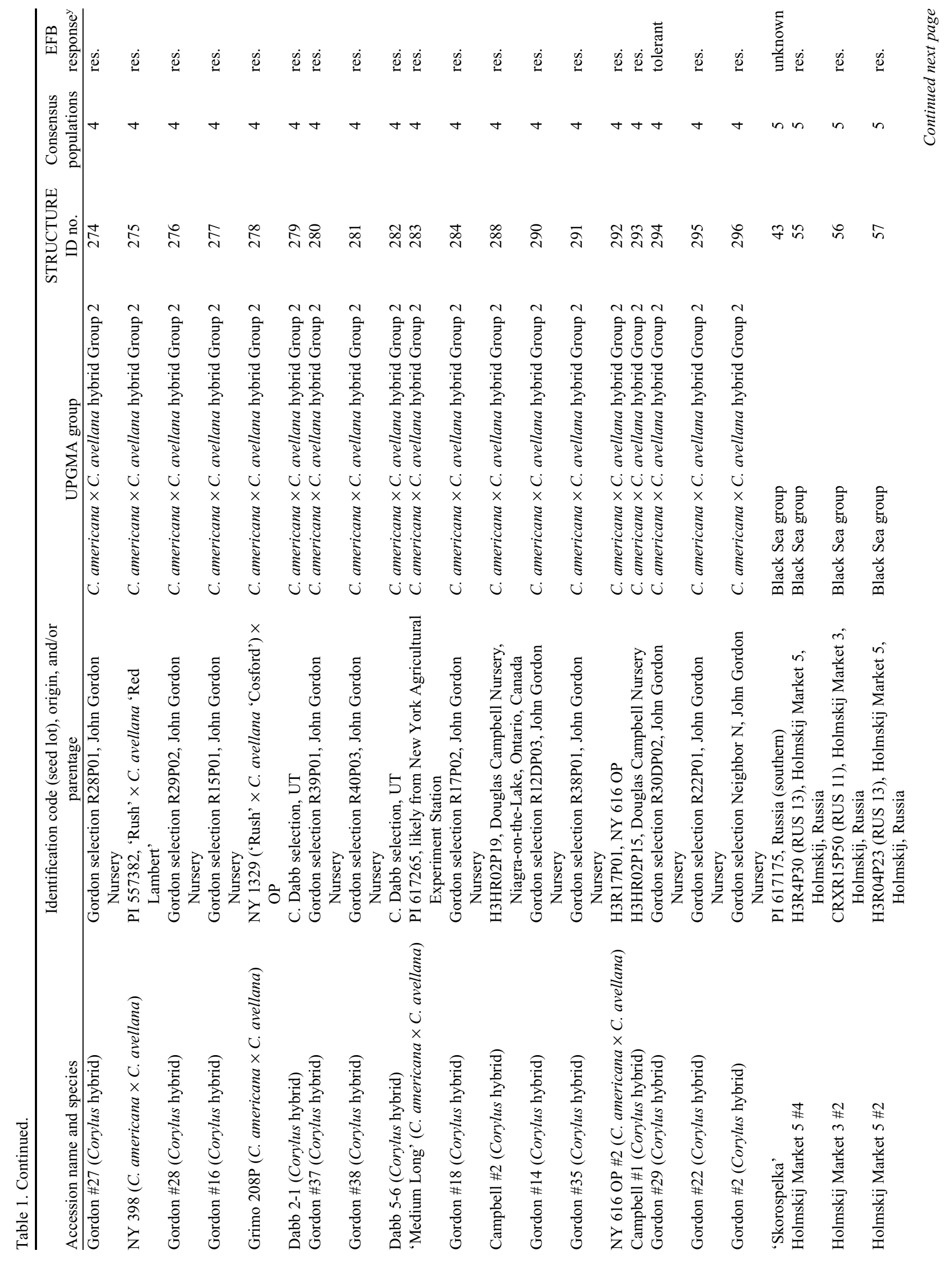




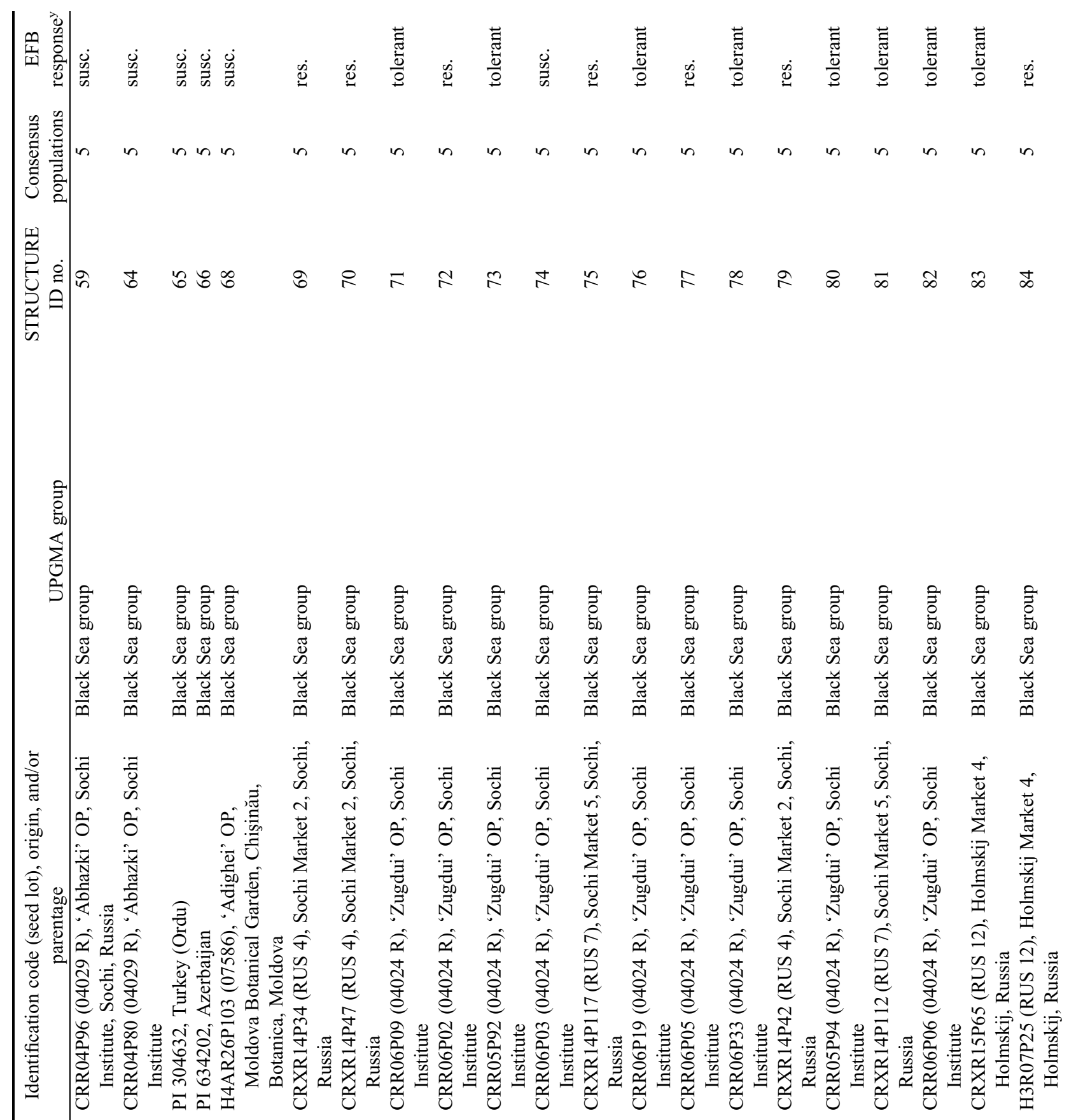

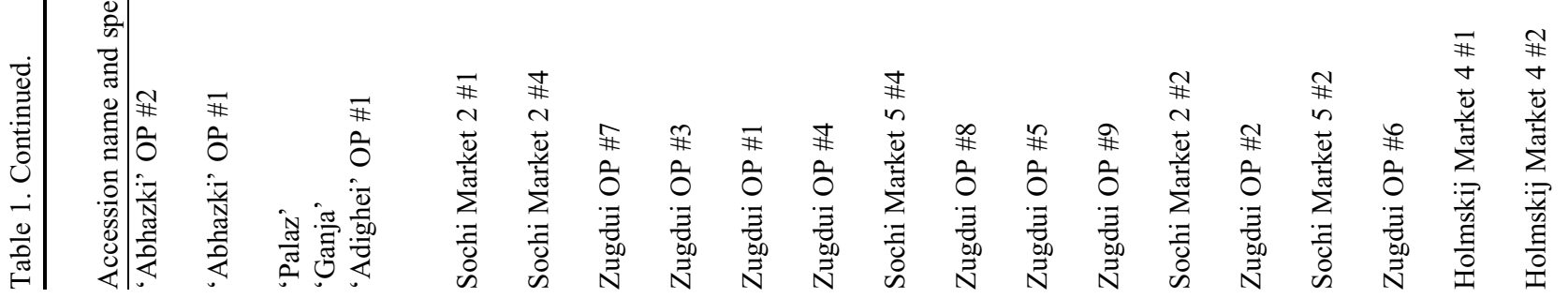




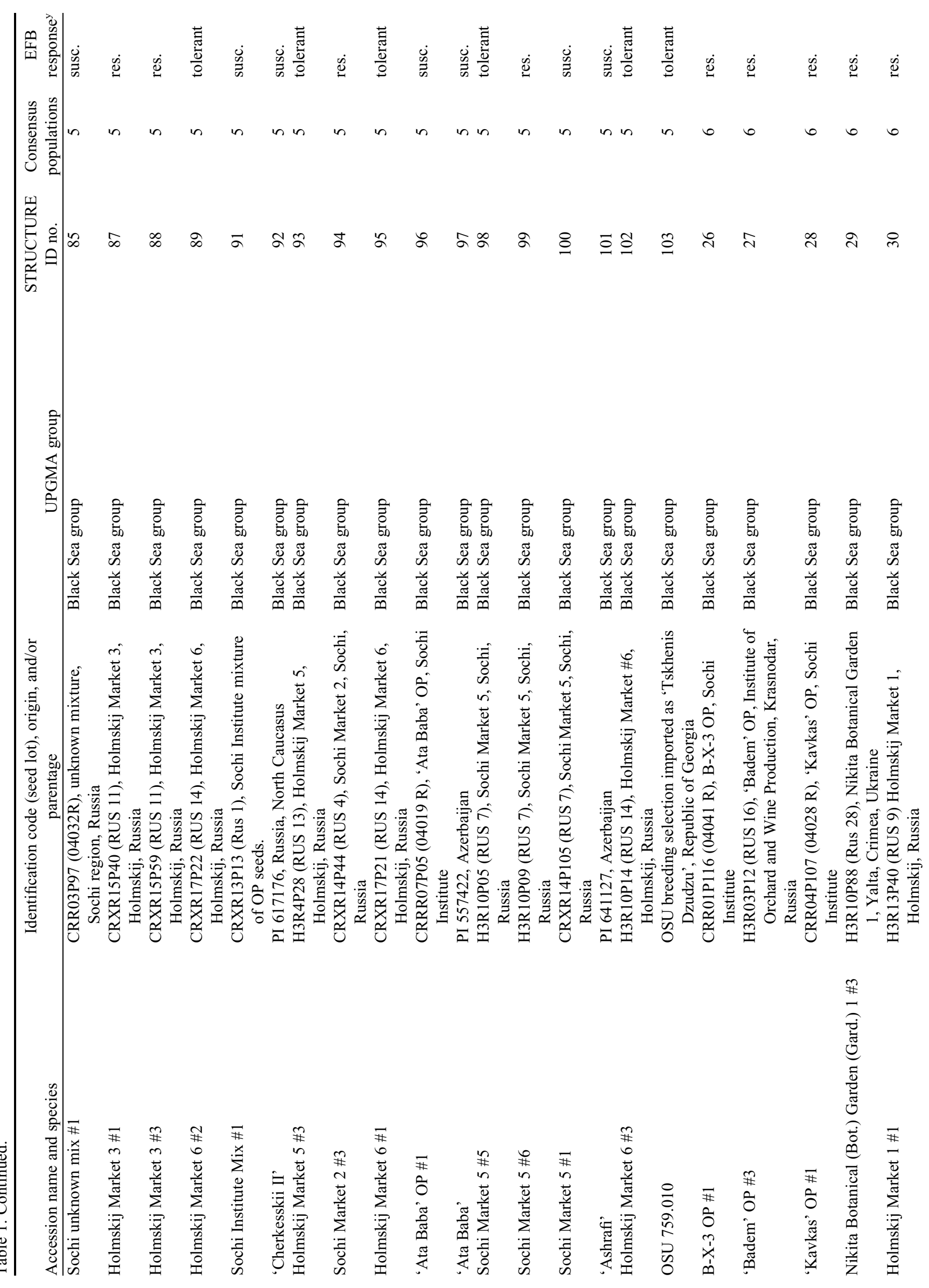




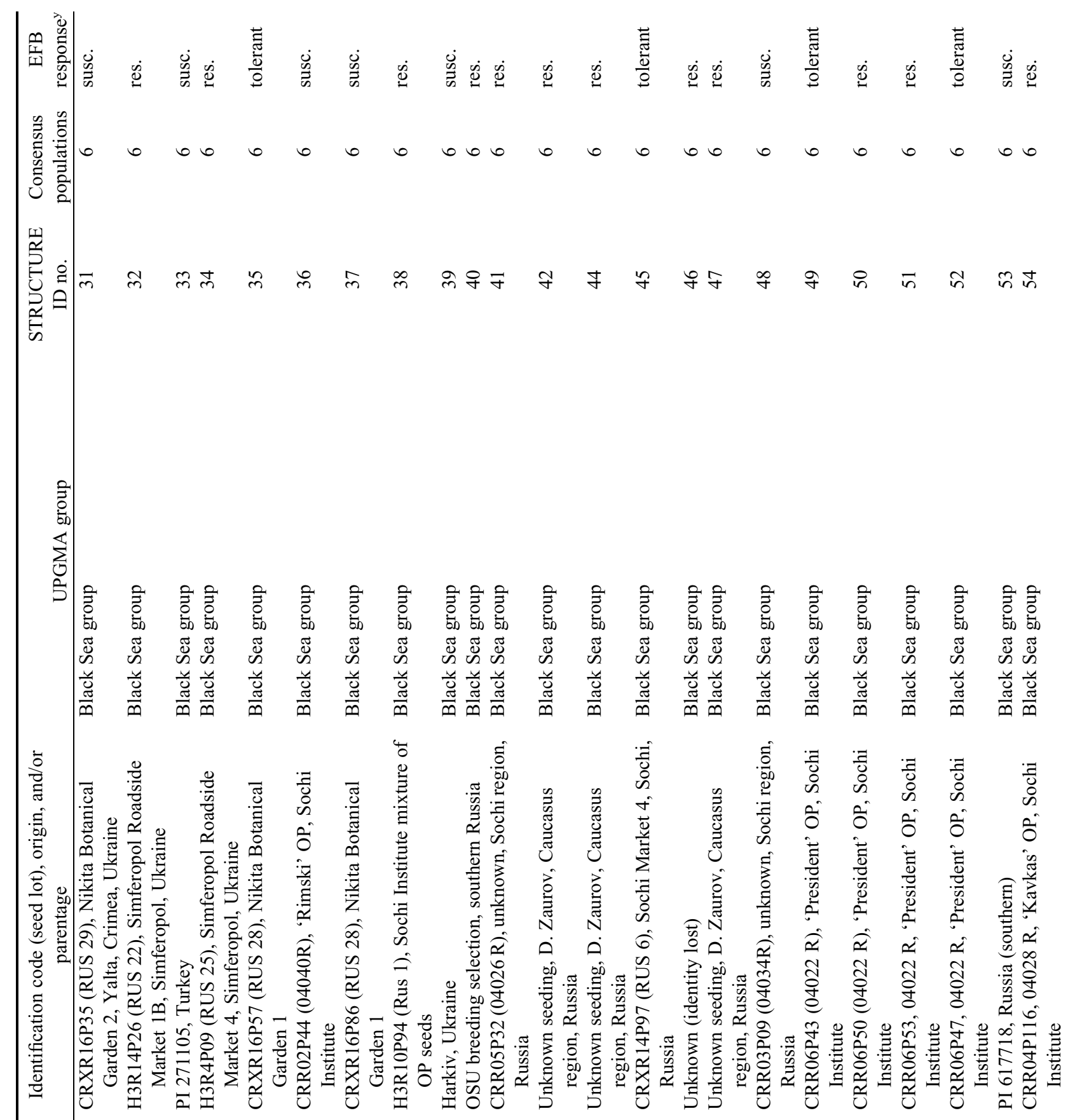




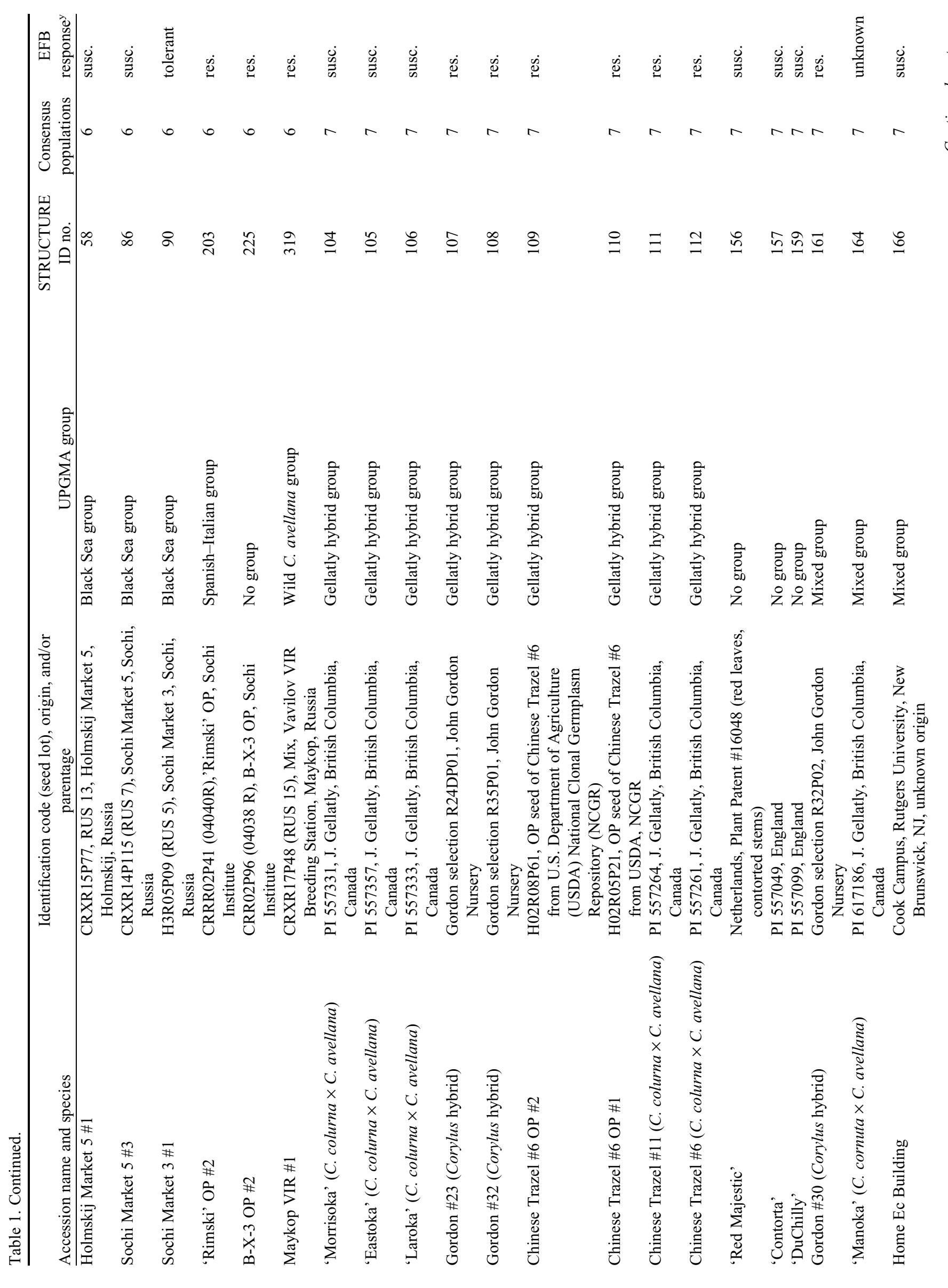




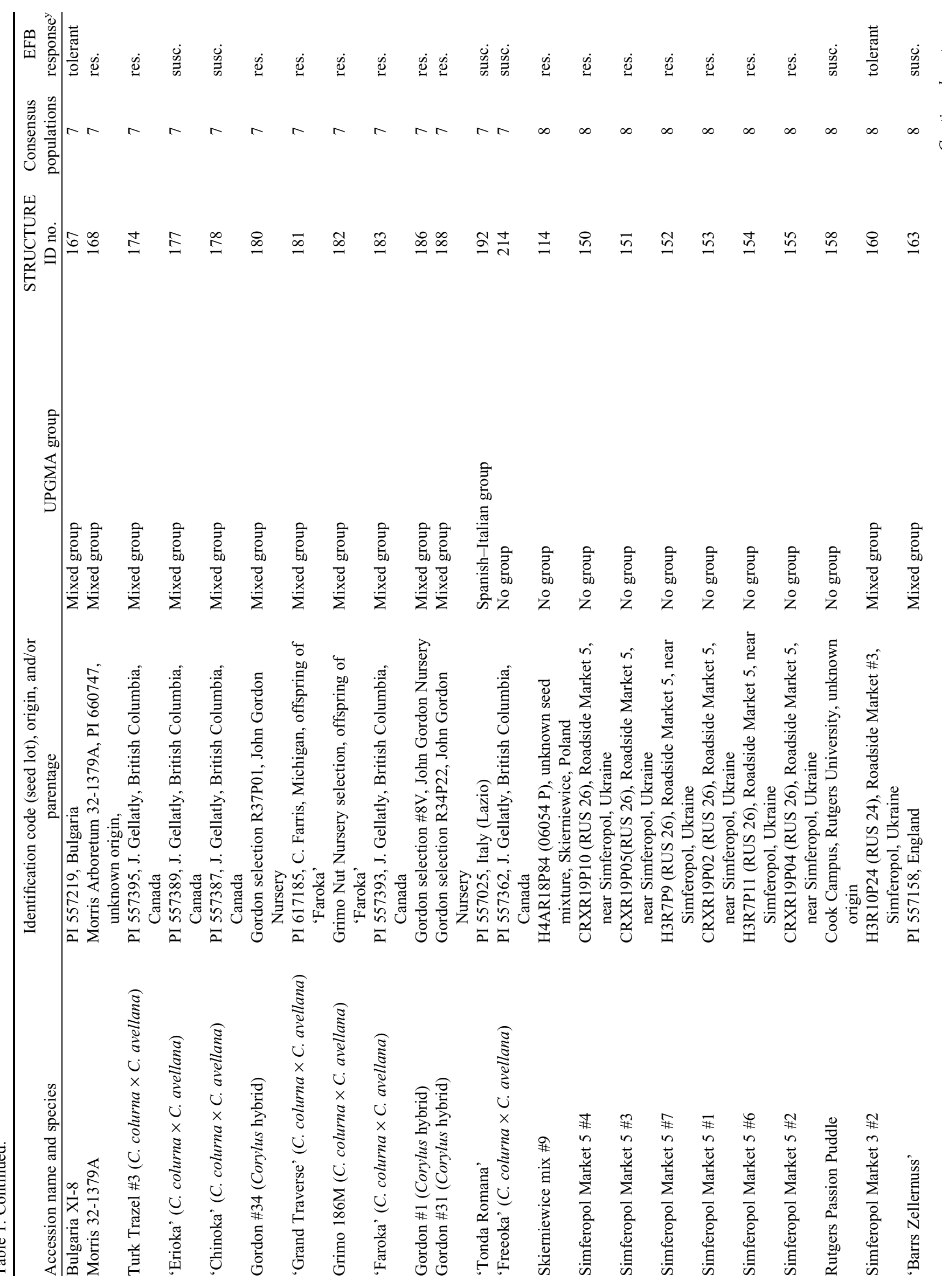




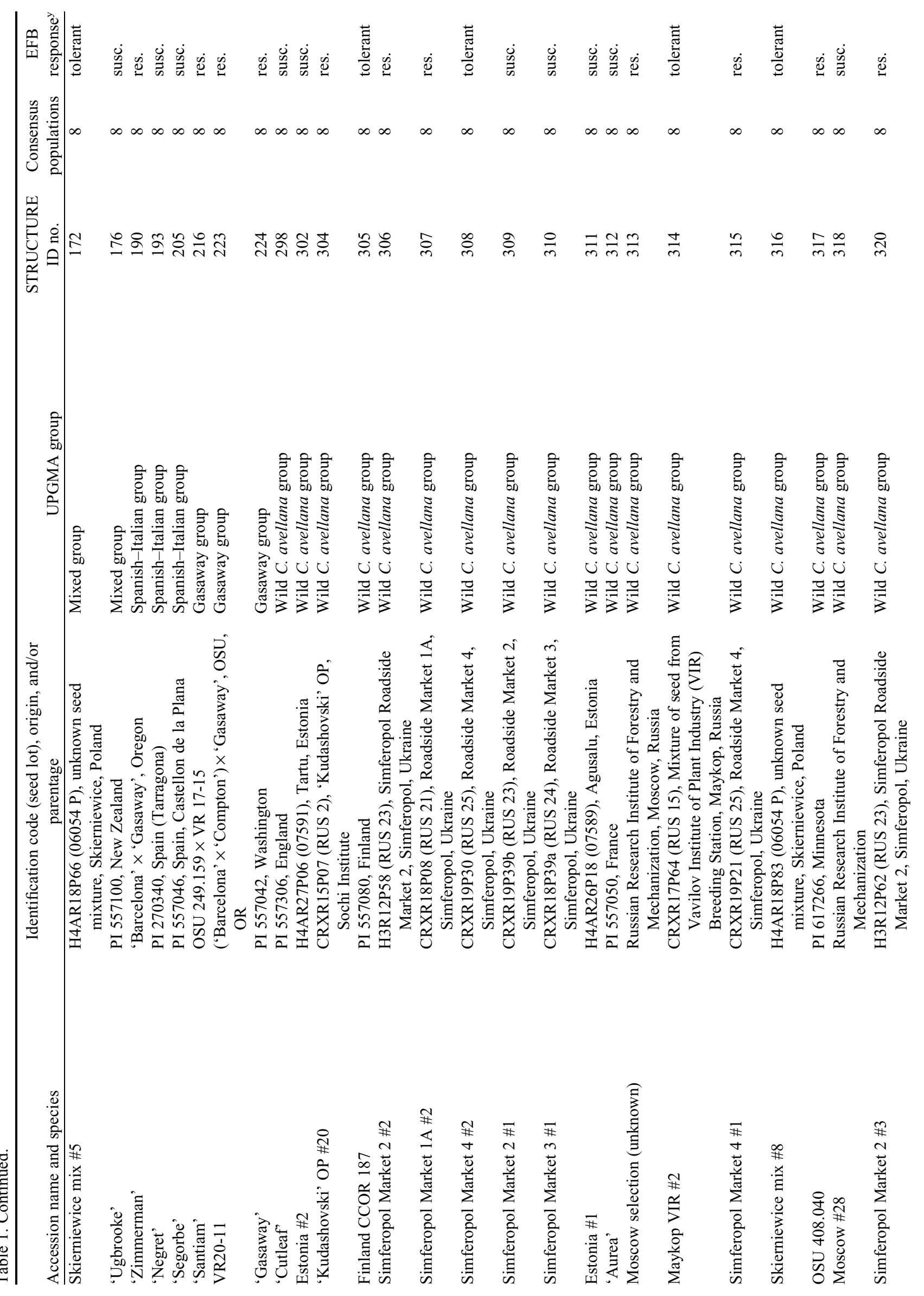




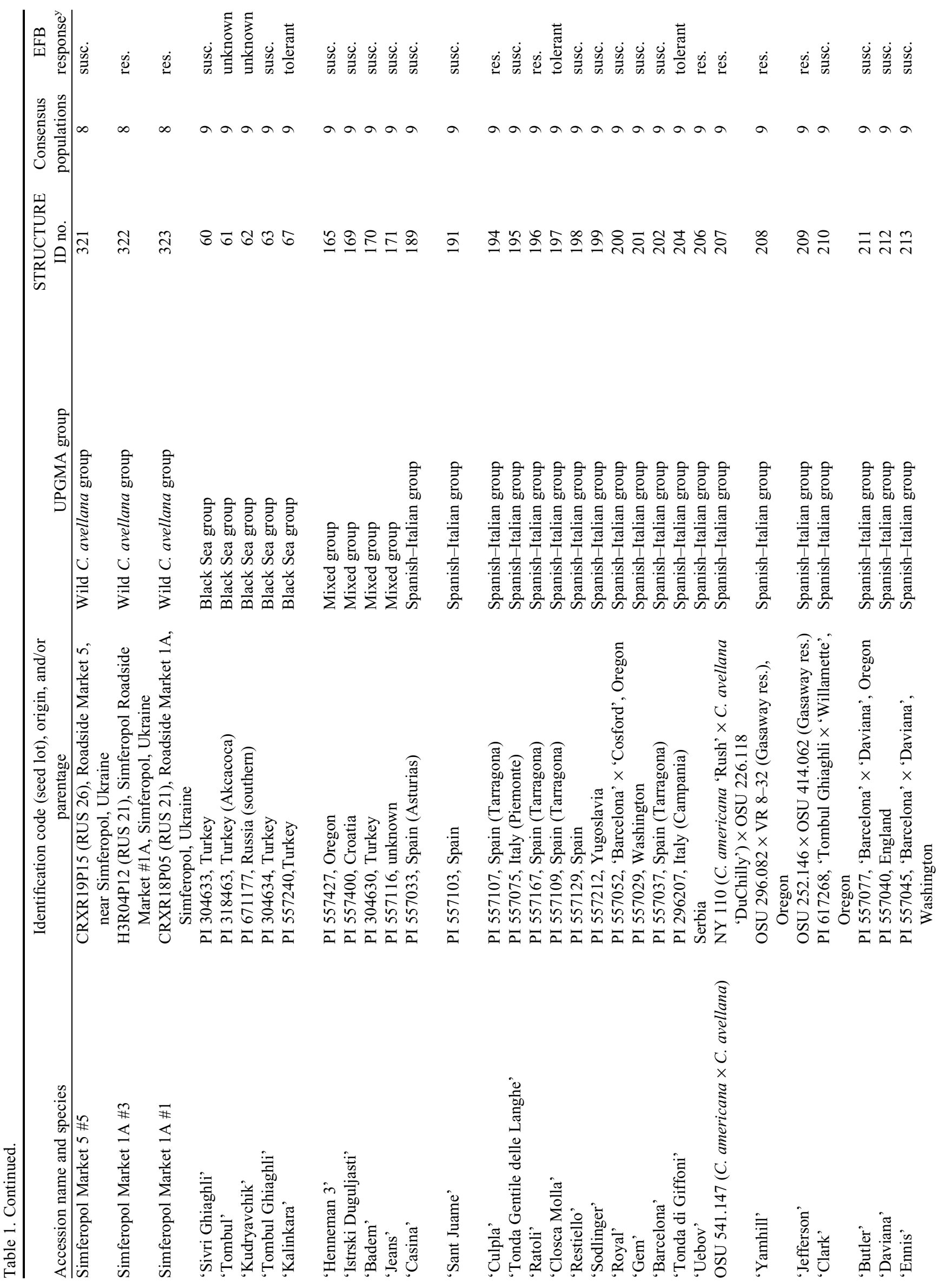




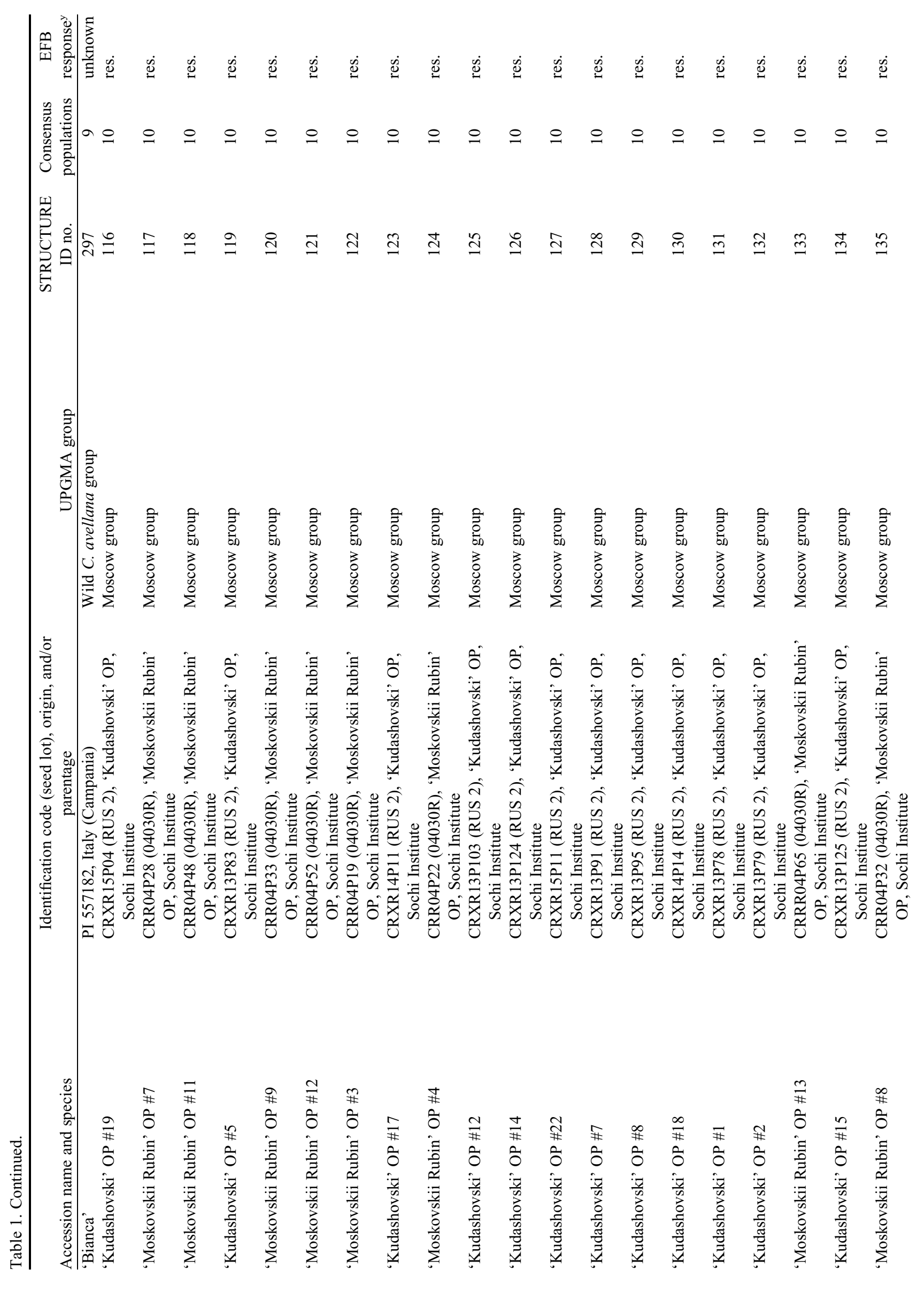




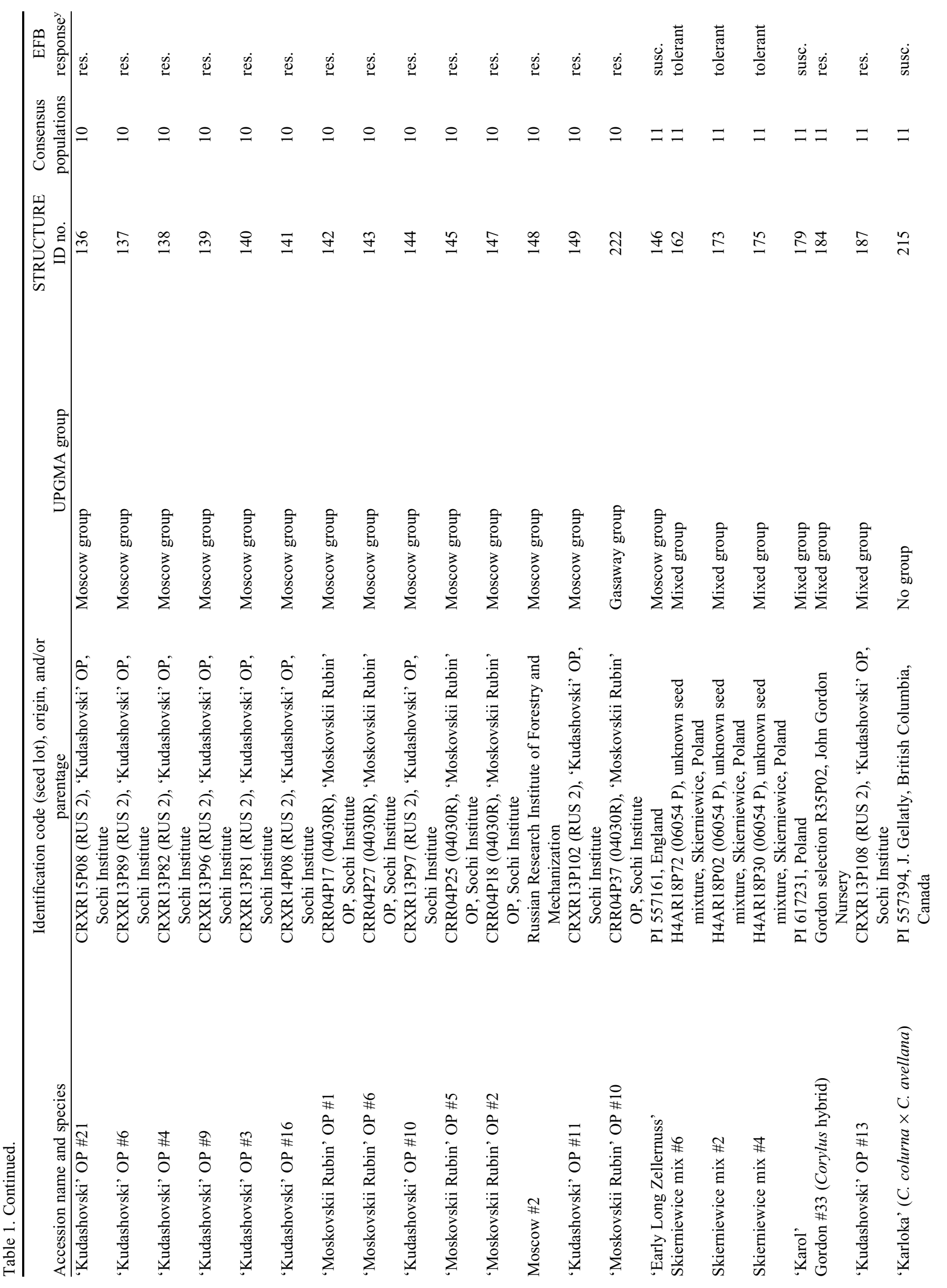




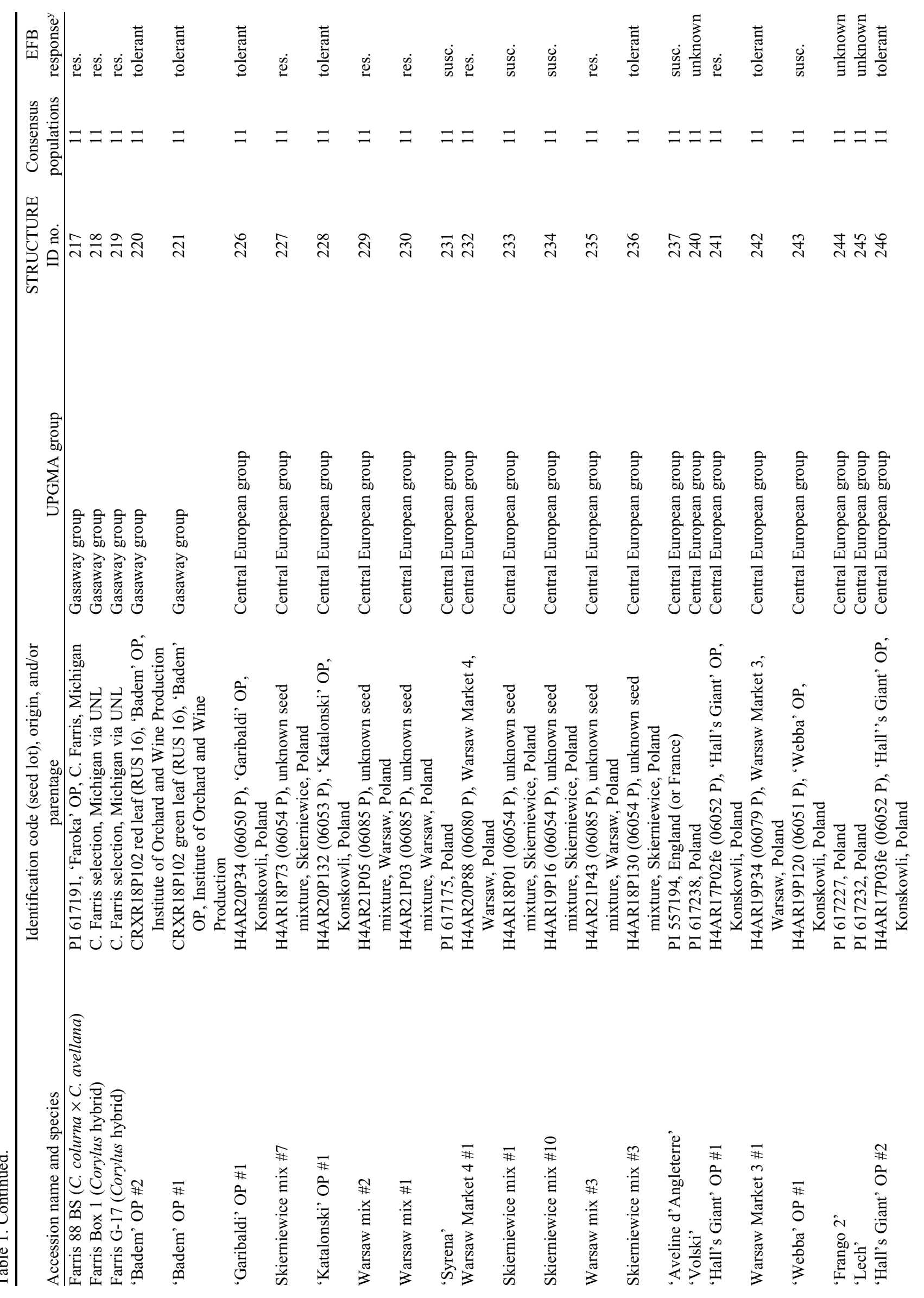




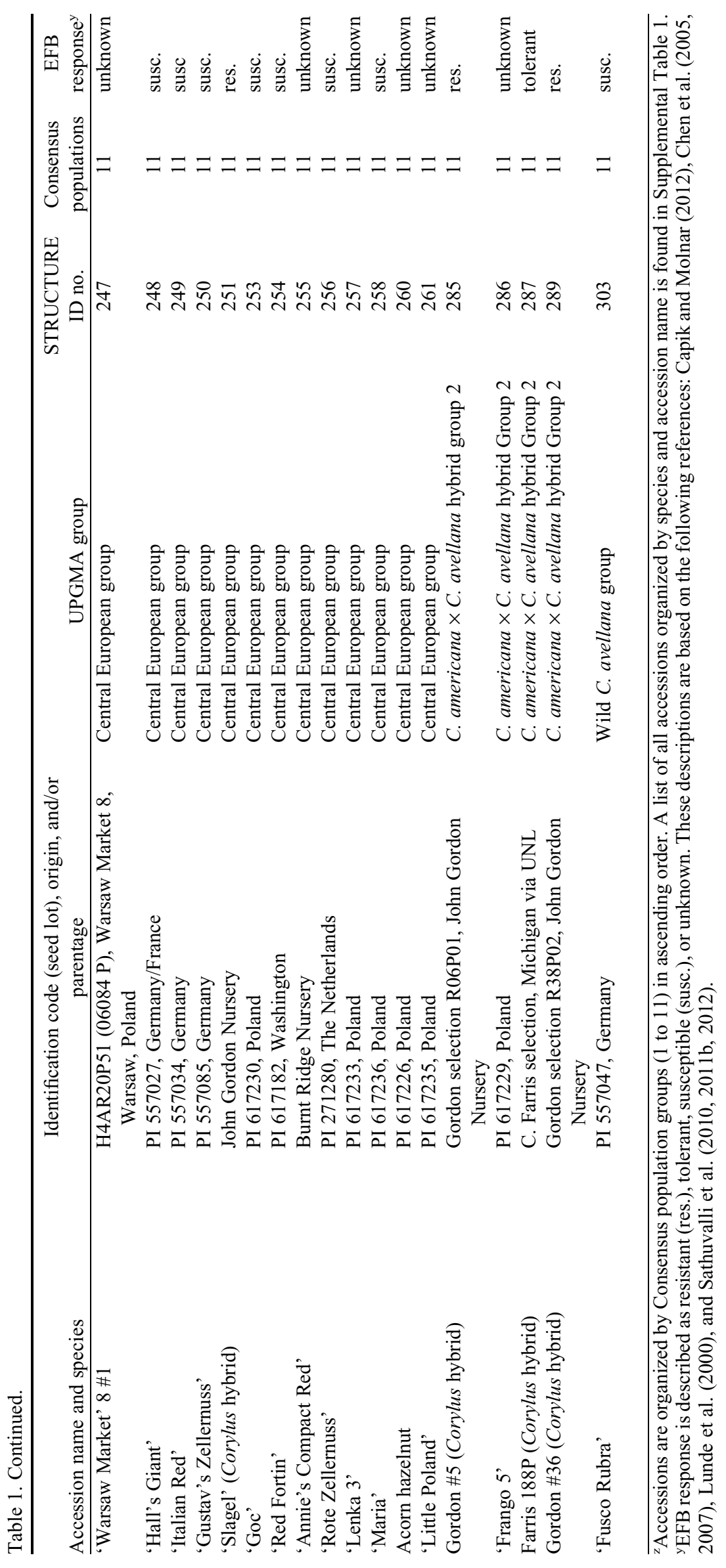


hybrid accessions have largely unknown pedigrees/origins and have not been previously characterized. The 11 wild accessions include plants of $C$. americana, $C$. californica, $C$. colurna, $C$. chinensis, $C$. cornuta, $C$. heterophylla, $C$. mandshurica, and $C$. sieboldiana to serve as outgroup accessions for the phylogenetic analysis and to help place putative hybrids. Finally, three additional accessions (Home Ec Building, Rutgers Passion Puddle, and Morris 32-1379A) have unknown origins and one (Unknown-EFB res.) is an EFB-resistant grafted C. avellana tree that had its identity lost at Rutgers and was included in an attempt to name it.

Genomic DNA extraction and microsatellite GENOTYPING. Young leaves were collected from accessions growing at Rutgers University or the USDA NCGR in Corvallis, OR, during Spring 2011 or 2012 and stored at $-80{ }^{\circ} \mathrm{C}$ until ground in liquid nitrogen. Plant genomic DNA was extracted using the CTAB method adapted from protocols described by Cullings (1992) and Doyle and Doyle (1987). Extracted DNA was quantified with a spectrophotometer (NanoDrop ND-1000; Thermo Scientific, Waltham, MA) and diluted to a concentra- tion of $5 \mathrm{ng} \cdot \mu \mathrm{L}^{-1}$. Seventeen well-characterized SSR markers (Table 2) were used to genotype all of the hazelnut accessions. These 17 SSR markers were chosen by screening a subset of 35 SSR markers (selected from more than 200 currently available for hazelnut) based on their level of polymorphism in the current data set, coverage of previously determined genetic linkage groups (10 out of 11 represented), high-quality amplification, reproducibility, low frequency of null alleles, and cross-species utility (Bassil et al., 2005a, 2005b; Boccacci et al., 2005; Gökirmak et al., 2009; Gürcan et al., 2010b; Gürcan and Mehlenbacher, 2010a, 2010b; Mehlenbacher et al., 2006). Amplification of all SSR polymerase chain reaction (PCR) products was assumed to be allelic for the current analysis, but this does not preclude the possibility that some amplification products were from paralogous loci. The M13 (-21) 18-bp sequence was added to the $5^{\prime}$ end of all forward primers as an economical method for the fluorescent labeling of PCR fragments (Schuelke, 2000), and the "PIG-tailing" sequence (GTTTCTT) was added to the 5' end of all reverse primers to reduce uncertainty in scoring "true" vs. "plus-A"

Table 2. Characteristics of the 17 simple sequence repeat markers used to assess the genetic diversity and relationships of 323 Corylus accessions.

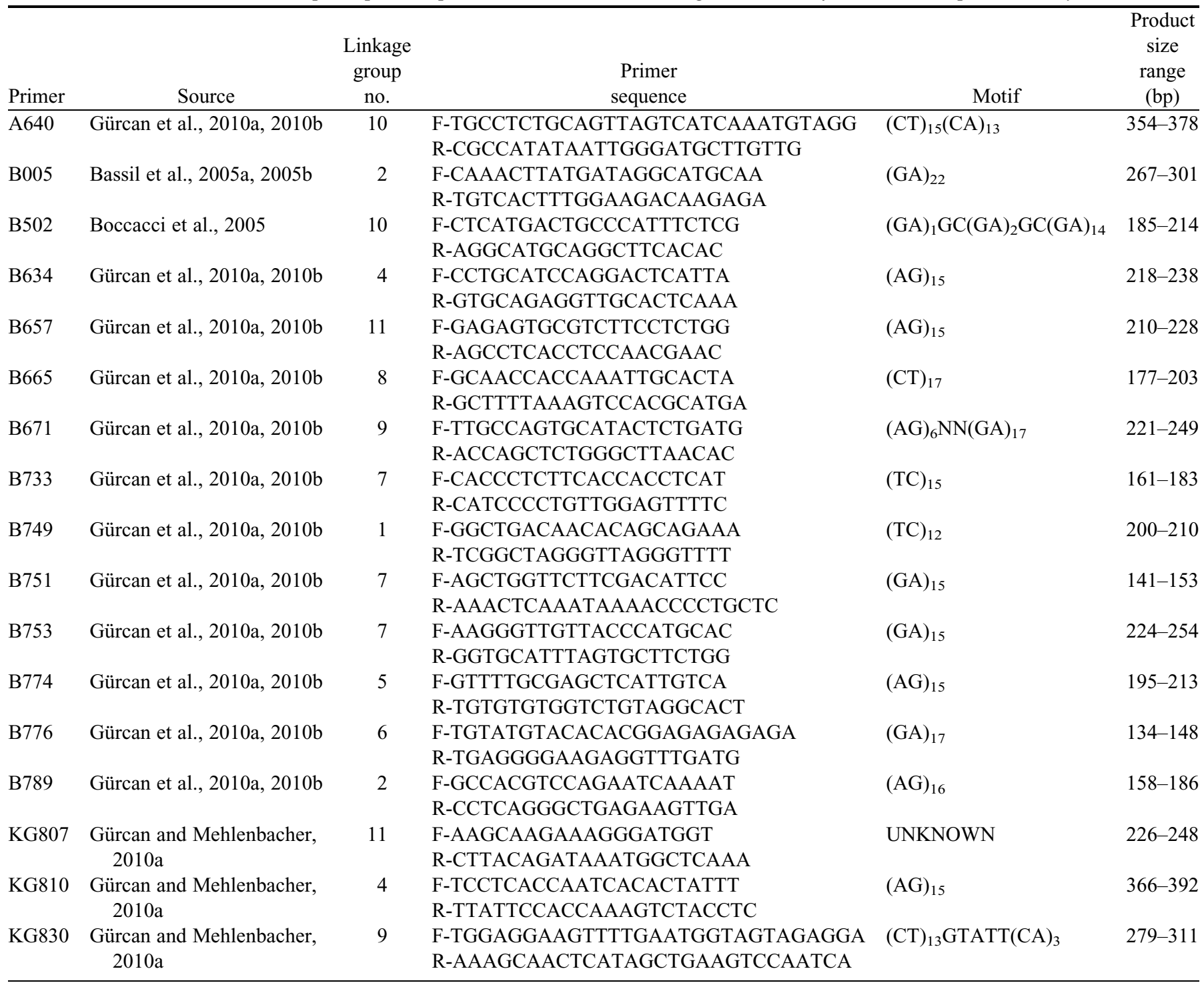


alleles (Brownstein et al., 1996). Primers were synthesized by Integrated DNATechnologies (Coralville, IA). PCR genotyping reactions were performed in 96-well plates in $13-\mu \mathrm{L}$ reaction volumes. PCR reactions were composed of $5.0 \mathrm{ng}$ genomic DNA, 10× Ramp-Taq PCR buffer (Denville Scientific, Metuchen, NJ), $2.0 \mathrm{~mm} \mathrm{MgCl}_{2}, 0.25 \mathrm{~mm}$ each dNTP (Denville Scientific), 0.5 U Ramp-Taq DNA polymerase (Denville Scientific), 0.5 pmol forward primer with 5' M13 (-21) addition, 1.0 pmol reverse primer with 5' PIG-tail addition, and 1.0 pmol FAM, NED, PET, or VIC fluorescently labeled M13(-21) primer. PCR cycling was conducted in thermocyclers (GeneAmp 9700; Applied Biosystems, Foster City, CA) using the following parameters: initial denaturation of $94^{\circ} \mathrm{C}$ for $5 \mathrm{~min}$ followed by 30 cycles of $94^{\circ} \mathrm{C}$ for $30 \mathrm{~s}, 55^{\circ} \mathrm{C}$ for $45 \mathrm{~s}, 72{ }^{\circ} \mathrm{C}$ for $45 \mathrm{~s}$, followed by 20 cycles of $94{ }^{\circ} \mathrm{C}$ for $30 \mathrm{~s}, 53^{\circ} \mathrm{C}$ for $45 \mathrm{~s}$, $72^{\circ} \mathrm{C}$ for $45 \mathrm{~s}$, followed by a final extension of $72^{\circ} \mathrm{C}$ for $10 \mathrm{~min}$. PCR products were run on a capillary electrophoresis genetic analyzer (ABI 3500xl; Applied Biosystems) and were sized using a LIZ600 size standard (Applied Biosystems). Two additional controls were added to each 96-well plate: a sample of $C$. avellana 'Barcelona', a widely grown, EFB-susceptible cultivar in Oregon; and the GeneScan Installation Standard DS33 (Applied Biosystems). Genotyping results were scored and analyzed using Genemapper 4.0 (Applied Biosystems).

DAta ANALYsis. The frequency of null alleles [F(null)] per loci was calculated using Cervus Version 3.0 (Kalinowski et al., 2007). The numbers of alleles for each locus, allele frequencies, observed heterozygosity $\left(\mathrm{H}_{\mathrm{o}}\right)$, expected heterozygosity $\left(\mathrm{H}_{\mathrm{e}}\right)$, and polymorphism information content (PIC) values were calculated using Powermarker Version 3.25 (Liu and Muse, 2005). Based on the allele frequencies, a distance matrix was then computed using the same software. A dendrogram based on an UPGMA was then constructed from the frequency-based distance matrix, and bootstrap values for the tree were calculated with a minimum support value of 0.500 . The UPGMA dendrogram was visualized using Mega 5.01 (Tamura et al., 2011).

A Bayesian model-based clustering method, STRUCTURE 2.3.3 (Falush et al., 2003; Pritchard et al., 2000), was used to elicit population structure by assigning each accession to a population or populations based on 17-locus genotypes. Software run parameters included the assumption that all loci were independent and in linkage equilibrium. The admixture ancestry model, with correlated allele frequencies, was used for the analysis with a burn-in length of 20,000 iterations followed by 50,000 Markov chain Monte Carlo run iterations at each $(K)$ value. An individual assigned to multiple populations (several colors in its bar) was considered evidence of admixture or hybridization. A preliminary program run, with $(K)$ set for $(K)=2$ through 50 , was used to estimate the most parsimonious value of $(K)$ by finding the maximal value of the estimated log probability $\operatorname{Pr}(X \mid K)$ output at each $(K)$ value. The STRUCTURE analysis was then run $10(K)$ values above and below the estimated most parsimonious $(K)$ value with 20 replicate runs per $(K)$. The most parsimonious value of $(K)$ was then chosen based on the maximal value of the average estimated $\log$ probability $\operatorname{Pr}(X \mid K)$ across all replicates and runs of $(K)$.

Using information derived from the UPGMA dendrogram and the STRUCTURE output, the accessions were assigned to consensus populations. Interpretations of clusters/relationships among accessions in the UPGMA dendrogram were resolved by considering all accessions grouped within a node to be more closely related than to those not included in that node. For the STRUCTURE analysis, accessions were interpreted as belonging to a group/population based on their degree of admixture, where a given accession was considered a group member when exhibiting greater than $50 \%$ identity to one group (shown as greater than $50 \%$ one solid color). Data for unique accessions in these consensus populations were then subjected to an analysis of molecular variation (AMOVA) using GenAlEx 6.5 (Peakall and Smouse, 2006, 2012). This analysis was used to assess genetic variation within and among the consensus populations and to determine the interpopulation pairwise genetic distance $\left(F_{s t}\right)$.

\section{Results and Discussion}

\section{SSR markers}

The 17 SSR markers amplified 308 alleles in the current data set. As expected with a diploid species, each of the 17 SSR markers was inherited as a separate multiallelic, codominant locus. The number of alleles for individual SSRs ranged from 12 to 26 alleles per locus with a mean of 18 alleles per locus. The number of genotypes per locus ranged from 27 to 80 with a mean of 53 genotypes per locus. The frequency of null alleles per locus ranged from 0.0071 to 0.2577 , which were comparable to previously reported values for hazelnut (Gökirmak et al., 2009). Mean values for $\mathrm{H}_{\mathrm{e}}, \mathrm{H}_{\mathrm{o}}$, PIC and inbreeding coefficient were $0.81,0.73,0.79$, and 0.103 , respectively (Table 3 ). These results were also similar to previously reported values of $\mathrm{H}_{\mathrm{e}}, \mathrm{H}_{\mathrm{o}}$, PIC, and inbreeding coefficient for hazelnut (Bassil et al., 2005b; Boccacci et al., 2005; Gürcan et al., 2010a; Gürcan and Mehlenbacher, 2010a).

\section{UPGMA clustering}

The UPGMA clustering analysis placed the wild Corylus outgroup accessions in the most basal position of the dendrogram in groups that reflected their taxonomic subsections within Corylus (Fig. 1) (Yoo and Wen, 2002). The four "tree hazel" accessions (subsection Colurnaea) - C. colurna \#1, C. chinensis \#1, and C. fargesii \#1 and \#2-were placed in a group at the very top, most basal position of the dendrogram. Immediately interior to this group was placed a cluster of the four "beaked-hazel" accessions (subsection Siphonochlamys clade). These include C. mandshurica \#1, C. sieboldiana \#1, C. cornuta 'Peace River', and OSU 587.044 (a hybrid of $C$. californica $\times C$. avellana). It should be noted that $C$. mandshurica and $C$. sieboldiana are considered synonyms (Mehlenbacher, 1991). Placed interior to this cluster are $C$. heterophylla accessions, which include $C$. heterophylla \#1 and $\# 2$ and the $C$. heterophylla $\times C$. avellana hybrids China \#13, $\# 20$, and \#23. Also included is OSU 526.041, which is the result of a cross of $C$. heterophylla 'Ogyoo' and a mixture of three $C$. avellana pollens (OSU 55.129, Birk 5-6, and OSU 226.122), where the male parent has yet to be determined (S.A. Mehlenbacher, personal communication).

The remainder of the accessions in the study [all from subsection Corylus (leafy-husk hazels), with the exception of a few putative interspecific hybrids with $C$. colurna] were placed interior to these outgroup accessions. They were divided into 10 distinct groups that largely reflected the origin of the reference cultivars held within them. These groups were given names based on their origins while also taking into account their 
Table 3. Summary statistics, including observed heterozygosity $\left(\mathrm{H}_{\mathrm{o}}\right)$, expected heterozygosity $\left(\mathrm{H}_{\mathrm{e}}\right)$, polymorphism information content (PIC), and inbreeding coefficient (f) for 323 Corylus accessions assessed with 17 simple sequence repeat markers.

\begin{tabular}{lcccccccc}
\hline Locus & Alleles (no.) & Major allele frequency & Genotypes (no.) & $\mathrm{H}_{\mathrm{o}}$ & $\mathrm{H}_{\mathrm{e}}$ & PIC & $\mathrm{f}$ & Frequency of null alleles \\
\hline A640 & 16 & 0.24 & 52 & 0.83 & 0.85 & 0.83 & 0.026 & 0.0106 \\
B005 & 15 & 0.32 & 40 & 0.64 & 0.78 & 0.75 & 0.184 & 0.1050 \\
B502 & 17 & 0.33 & 58 & 0.66 & 0.82 & 0.80 & 0.196 & 0.1061 \\
B634 & 19 & 0.29 & 53 & 0.80 & 0.83 & 0.81 & 0.038 & 0.0189 \\
B657 & 20 & 0.18 & 55 & 0.86 & 0.88 & 0.87 & 0.027 & 0.0120 \\
B665 & 20 & 0.19 & 64 & 0.52 & 0.89 & 0.87 & 0.41 & 0.2577 \\
B671 & 21 & 0.24 & 67 & 0.81 & 0.86 & 0.85 & 0.065 & 0.0299 \\
B733 & 12 & 0.32 & 39 & 0.73 & 0.77 & 0.74 & 0.058 & 0.0297 \\
B749 & 18 & 0.39 & 40 & 0.60 & 0.71 & 0.67 & 0.171 & 0.0921 \\
B751 & 13 & 0.39 & 38 & 0.72 & 0.78 & 0.76 & 0.079 & 0.0418 \\
B753 & 22 & 0.28 & 75 & 0.83 & 0.87 & 0.86 & 0.043 & 0.0191 \\
B774 & 17 & 0.33 & 47 & 0.79 & 0.82 & 0.80 & 0.046 & 0.0189 \\
B776 & 21 & 0.47 & 71 & 0.57 & 0.71 & 0.68 & 0.202 & 0.1205 \\
B789 & 26 & 0.36 & 27 & 0.80 & 0.81 & 0.80 & 0.018 & 0.0071 \\
KG807 & 13 & 0.37 & 80 & 0.67 & 0.74 & 0.70 & 0.104 & 0.0472 \\
KG810 & 21 & 0.26 & 50 & 0.80 & 0.86 & 0.84 & 0.076 & 0.0379 \\
KG830 & 17 & 0.31 & 53.11 & 0.73 & 0.81 & 0.79 & 0.103 \\
Mean & 18.12 & 0.31 & & & 0.82 & 0.80 & 0.029 &
\end{tabular}

previous assignment, where applicable, into the major geographic groups described by Gökirmak et al. (2009). The names assigned to groups in the current UPGMA clustering analysis include three previous groups from Gökirmak et al. (2009)_the Black Sea group, Spanish-Italian group, Central European group - as well as seven new groups referred to as $C$. americana $\times$ C. avellana hybrid Groups 1 and 2, Gellatly hybrid group, Moscow group, Mixed group, Gasaway group, and wild C. avellana group. Each group is discussed subsequently, in the order in which they appear in the UPGMA dendrogram, starting at the top (Fig. 1).

C. AMERICANA $\times$ C. AVELLANA HYBRID Group 1. The UPGMA clustering analysis placed both of the wild $C$. americana accessions, 'Rush' from Pennsylvania and 'Winkler' from Iowa, adjacent to one another within a small group near the top of the dendrogram. This group holds several other accessions known to be of $C$. americana interspecific hybrid origin, including 'Skinner'; the National Arbor Day Foundation (NADF) selections \#1, \#3, and \#10; and the Rutgers University selection H3I2R05P05 (Fig. 2). Also placed in this group are several accessions with largely unknown parentage, including Gordon \#21 and \#24, Grimo Hybrid \#3, and 'Purple Haze'.

'Skinner' was selected by F. Ashworth from a cross of a Hudson Bay wild C. americana seedling with an OP seedling of $C$. avellana 'Italian Red' (Ashworth, 1970). It is one of the two known $\mathrm{F}_{1} C$. americana $\times C$. avellana hybrids included in the study (NY 398 is the other) and is likely placed close to 'Rush' and 'Winkler' based on having a high genomic contribution from $C$. americana.

NADF \#1, \#3, \#10, and H3I2R05P05 share a common origin that trace in part to germplasm originating from Badgersett Research Corp., Canton, MN, which in turn traces back to $C$. americana 'Winkler'. In brief, C. Weschcke of River Falls, WI, used 'Winkler' as well as local wild C. americana selections in a sizable interspecific hybridization program with $C$. avellana spanning several decades (Weschcke, 1954, 1970). Whereas Weschcke released a number of cultivars, including Carlola, Delores, and Magdalene (Brooks and Olmo, 1997), none proved commercially viable (Weschcke, 1970). However,
Weschcke's germplasm was later used as a foundation for breeding efforts at Badgersett Research Corp. (Rutter, 1987, 1991). Seedlings from Badgersett were then used to plant a 3.6-ha research field at the farm of NADF in Nebraska City, NE, from which the EFB-resistant NADF \#1, \#3, and \#10 were selected (Capik and Molnar, 2012; Hammond, 2006; Xu and Hanna, 2010). H3I2R05P05 was selected from a cross of Rutgers Adel-1, an EFB-resistant seedling selection originating from a plant purchased from Badgersett Research Corp., with C. avellana 'Syrena' from Poland (Molnar and Capik, 2012).

Sathuvalli and Mehlenbacher (2012) also used 'Winkler', 'Rush', and many NADF selections, including \#1, \#3, and \#10 (listed as ADF10.050, ADF11.055, and ADF11.051, respectively), in their SSR study of $C$. americana and known interspecific hybrids. In their study, NADF \#1, \#3, and \#10 were placed close together within a larger group of accessions from the NADF, whereas 'Winkler' was placed within a second group of NADF accessions. However, 'Rush' was placed in a separate clade, comprised largely of its known hybrid offspring.

'Rush' has a history of use in breeding interspecific hybrids, which may provide some explanation for the placement of Gordon \#21 and \#24 in this group. In the early 1900s, 'Rush' was crossed with various $C$. avellana cultivars and improved, EFB-resistant $F_{1}$ hybrids were selected (Crane et al., 1937; Reed, 1936; Slate, 1961). Although several cultivars were released from this work, none was commercially successful. However, progress was made, with some plants, including 'Potomac' and several of the Slate NY numbered selections (e.g., NY 104, NY 398, NY 616), representing improvements over 'Rush' (Capik and Molnar, 2012; Coyne et al., 1998; Lunde et al., 2000). In 1963, J. Gordon of Amherst, NY, began planting hundreds of OP seedlings of NY 104 ('Rush' $\times C$. avellana 'DuChilly') and NY 200 ('Rush' $\times C$. avellana 'Hall's Giant') (Gordon, 1993; J. Gordon, personal communication). He grew several generations of plants, selecting EFB-resistant individuals to plant successive generations, although few pedigree records were kept. From his efforts, more than 40 EFBresistant clonal selections were established at Rutgers University 


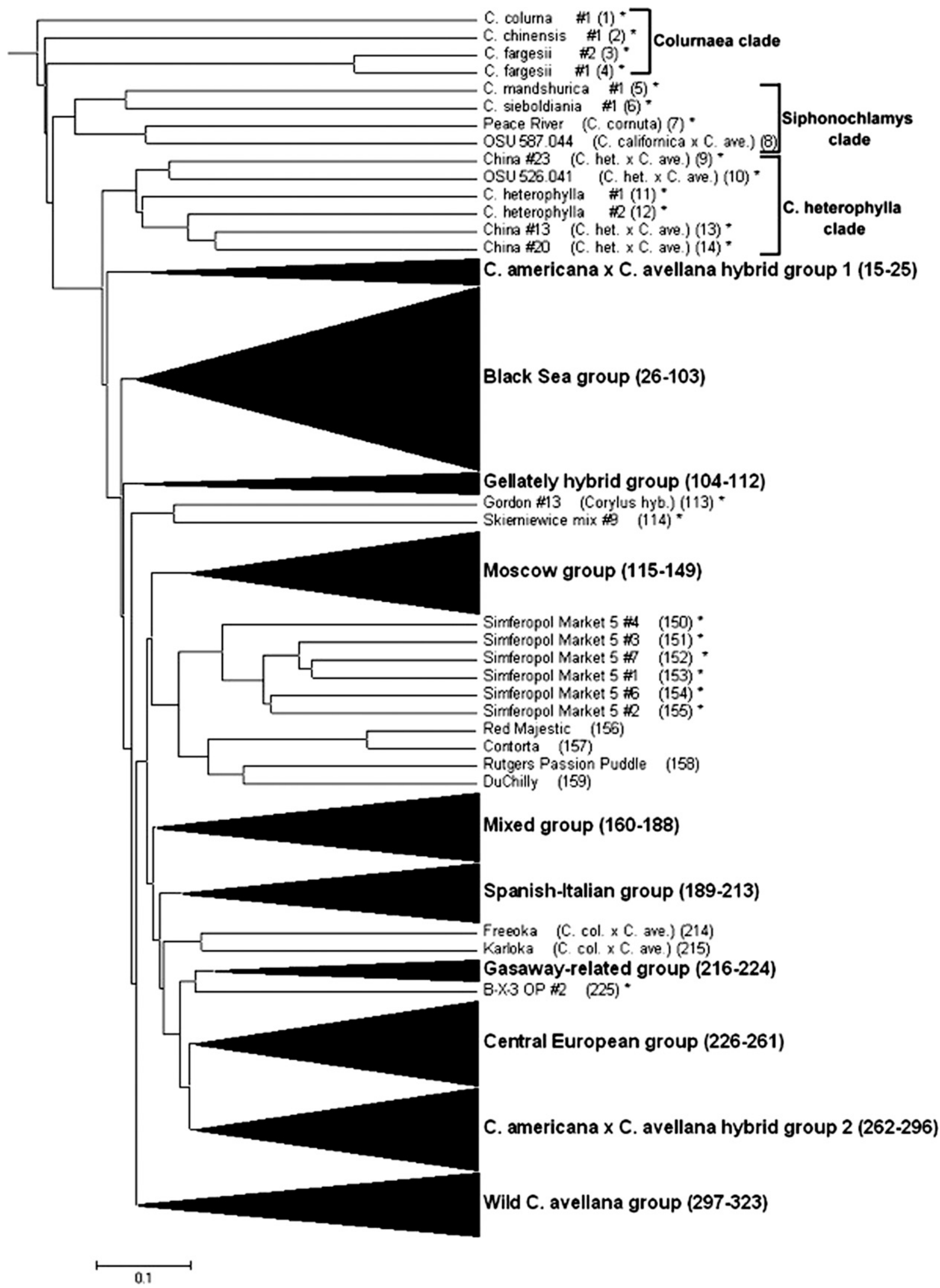

Fig. 1. Unweighted pair group method using arithmetic averages (UPGMA) dendrogram with 10 of the major groups, excluding outgroups, collapsed. All accessions are Corylus avellana unless otherwise noted. In reference to the hybrid accessions, C. ave., C. het., C. amer., and C. col. correspond to C. avellana, C. heterophylla, C. americana, and C. colurna, respectively. The abbreviations hyb. and OP indicate hybrid and open-pollinated, respectively. Accessions marked with an asterisk (*) are resistant to eastern filbert blight. 


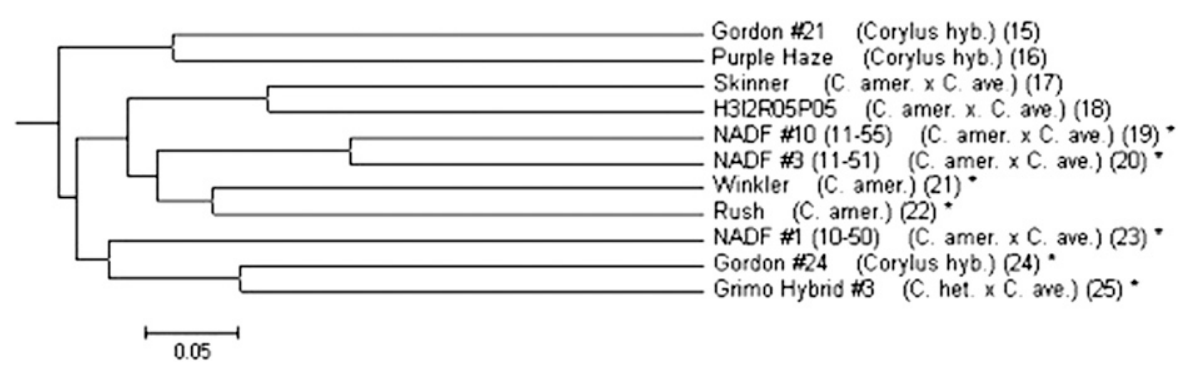

Fig. 2. Uncollapsed Corylus americana $\times$ C. avellana hybrid Group 1 node of the unweighted pair group method using arithmetic averages (UPGMA) dendrogram. C. ave., C. amer., and C. het. correspond to C. avellana, $C$. americana, and $C$. heterophylla, respectively. The abbreviation hyb. indicates hybrid. Accessions marked with an asterisk (*) are resistant to eastern filbert blight.

(Capik and Molnar, 2012) and are included in this study. Thus, the placement of Gordon's selections in the group with 'Rush' is supported by knowledge of his original breeding material.

Grimo Hybrid \#3 is an OP seeding of an OP C. heterophylla selection. E. Grimo of Niagara-on-the-Lake, Ontario, Canada, grew many 'Rush' hybrid selections on his farm, including seedlings of NY 1329 (Grimo, 2011; E. Grimo, personal communication). This led to the selection and release of Grimo 208P. Thus, Grimo Hybrid \#3 could be the result of hybridization with a 'Rush' seedling, providing support for its inclusion in this group. No prior information is available for 'Purple Haze', a red-leaf selection from McKay Nursery, Waterloo, WI.

Black Sea group. A large group $(n=78)$ holding nearly all of the reference cultivars originating from the Black Sea region (Turkey, the Republic of Georgia, Azerbaijan, and southern Russia) was revealed by the UPGMA clustering analysis (Fig. 3). This grouping of cultivars is similar to that shown in Gökirmak et al. (2009), although their dendrogram showed a separation of cultivars into two respective groups, Black Sea Group 1 and Black Sea Group 2. These two groups were not clearly resolved in our study. However, two distinct subgroups, one large and one small, were resolved within our Black Sea group.

The larger subgroup holds most of the Black Sea reference cultivars as well as most of the seedlings from Holmskij and Sochi. It was divided into seven distinct clades with the EFBresistant clonal selection OSU 495.072 [believed to have originated from southern Russia (Sathuvalli et al., 2010)] placed in its most basal position.

The clade placed lowest in the dendrogram (Clade 1) contains the reference cultivars Ata Baba and Ashrafi from Azerbaijan as well as OSU 759.010 from the Republic of Georgia. It also holds the seedling accessions 'Ata Baba' OP \#1, which originated from the Russian Academy of Agricultural Science Institute of Floriculture and Subtropical Cultures, Sochi, Russia (referred to subsequently as the "Sochi Institute"), Sochi Market $5 \# 1$, \#5, and \#6, and Holmskij Market $6 \# 3$.

The clade placed directly above the aforementioned clade (Clade 2) is the largest of the seven and contains Cherkesskii II (the most widely grown cultivar in southern Russia), seven seedlings originating from markets in Holmskij, eight seedlings from Sochi, and nine OP seedlings of Zugdui, a cultivar from the Sochi Institute that is unfamiliar to the authors. The third clade (Clade 3) holds the seedlings 'Adighei' OP \#1, from the Chişinău Botanical Garden of the Academy of Sciences of
Moldova, and Sochi Market $2 \# 1$ and \#4. The fourth clade (Clade 4) holds the reference cultivars from Turkey-Kalinkara, Kudryavchik, Palaz, Sivri Ghiaghli, Tombul (Akcacoca), and Tombul Ghiaghli as well as Ganja from Azerbaijan and two OP seedlings of Abhazki originating from the Sochi Institute. The fifth clade (Clade 5) holds four seedlings from Holmskij markets and 'Kavkas' OP \#2, originating from the Sochi Institute. The sixth clade (Clade 6) within the larger Black Sea subgroup holds the reference cultivar Pioneer from southern Russia and four seedlings of President, a cultivar also originating from southern Russia and held at the Sochi Institute. The final clade (Clade 7) within the larger Black Sea subgroup holds the reference cultivar Skorospelka from southern Russia and the EFB-resistant $C$. avellana clonal accession from the Rutgers University collection (Unknown-EFB res.) whose identity was lost. Although the identity of unknown-EFB res. remains unclear, it is valuable to know its origins are also most likely southern Russia. The seedling selections ZC1, ZC4, and ZC6 were also placed in this group. They are from seed believed to have been collected from the Caucuses region (southern Russia), although the exact location is not known (D. Zaurov, personal communication). The final three seedlings placed in this clade originate from Sochi.

The smaller subgroup of the Black Sea group was placed above and adjacent to the branch point that holds the larger subgroup. It holds the reference cultivars Imperial de Trebizonde from Turkey and Losovskoi Sharovdnii from Harkiv, Ukraine. It also holds four seedlings originating from the Nikita Botanical Gardens, Yalta, Ukraine, and two originating from markets in Simferopol, Ukraine. The remaining three seedlings include one from Holmskij and two from Sochi. This smaller subgroup, while holding several seedlings from southern Russia (Holmskij and Sochi), is the only group within the Black Sea group that holds accessions from Ukraine.

Also included in the Black Sea group is one small cluster of seedling accessions placed in a basal position to the two major Black Sea subgroups described previously. This cluster holds B-X-3 OP \#1 and 'Kavkas' OP \#1, originating from the Sochi Institute, and 'Badem' OP \#3, originating from the Research Institute for Horticulture and Viticulture, Krasnodar, Russia. Their origins, like with all of the accessions placed in the large Black Sea group described previously, support their inclusion in this group.

GellatLY HYBRID GROUP. Placed below the Black Sea group and above the Moscow group (discussed in the following section) is a small, distinct group of nine accessions (Fig. 4). The known cultivars and clonal selections in this group include the putative $C$. colurna $\times C$. avellana hybrids Morrisoka, Laroka, and Eastoka and the EFB-resistant Gellatly Chinese Trazel \#6 and \#11 (also C. colurna despite being named "Chinese" trazel). These five accessions were developed by J.U. Gellatly in Westbank, British Columbia, Canada (Gellatly, 1950, 1956, 1964, 1966). Also included are two EFB-resistant OP seedlings of Gellatly Chinese Trazel \#6 selected at Rutgers University. The final two accessions in this group are Gordon hybrids \#23 and \#32. Although their pedigrees are unknown, 


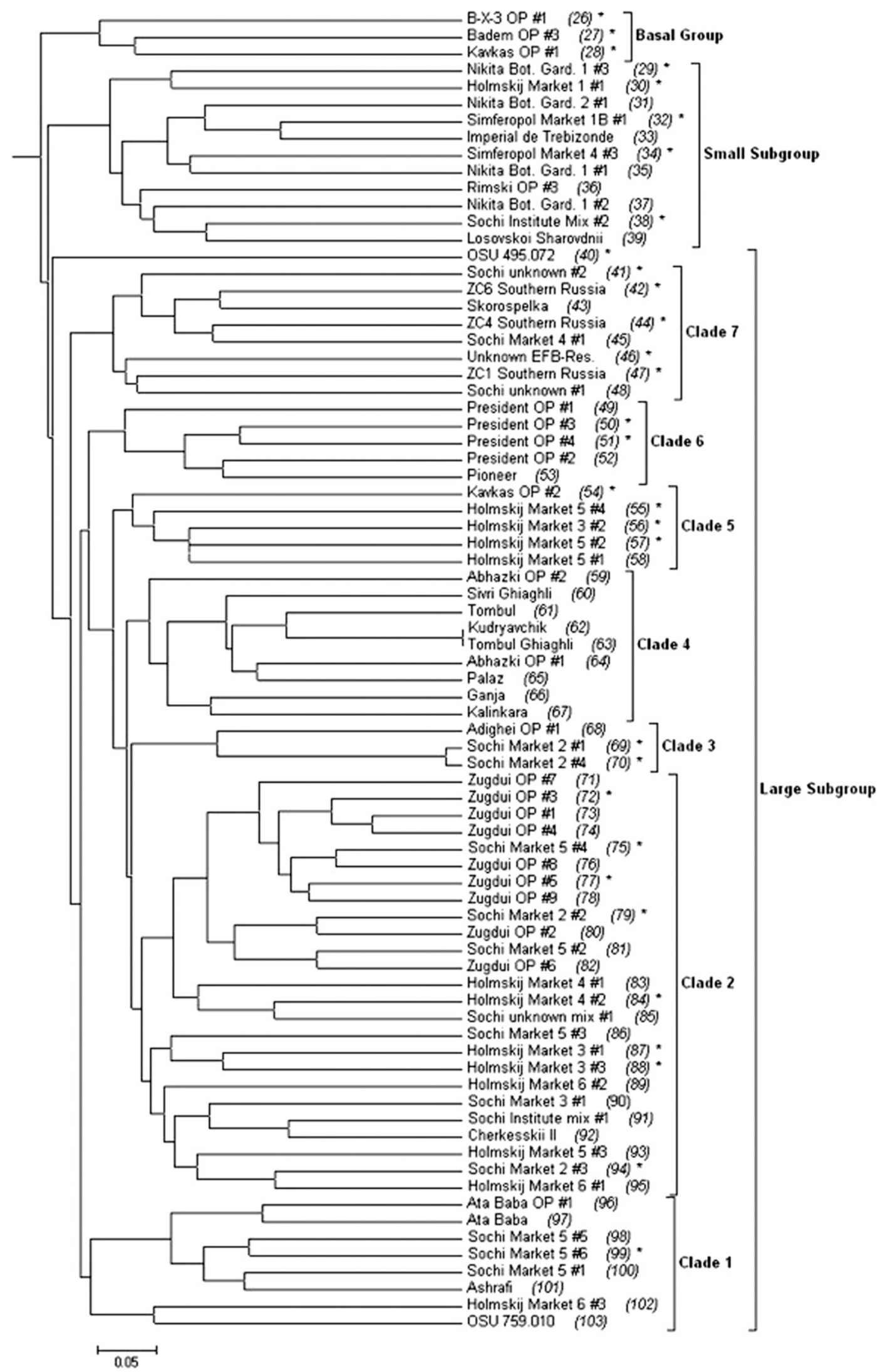

Fig. 3. Uncollapsed Black Sea group node of the unweighted pair group method using arithmetic averages (UPGMA) dendrogram. All accessions are Corylus avellana. The abbreviation OP indicates open-pollinated, Res. indicates resistant, EFB indicates eastern filbert blight, and Nikita Bot. Gard. indicates Nikita Botanical Garden (Yalta, Ukraine). Accessions marked with an asterisk $\left(^{*}\right)$ are resistant to eastern filbert blight. 
the inclusion of these two selections may be because, in addition to the 'Rush' hybrids described earlier, in the 1980s, Gordon used 'Morrisoka', 'Laroka', 'Faroka', and the $C$. cornuta hybrid Gellatly 502 as parents (Gordon, 1993; J. Gordon, personal communication).

Moscow GROuP. Placed below the Gellatly hybrid group and a single disparate cluster holding Gordon \#13 and Skierniewice mix \#9 is the Moscow group. This group is also adjacent to a cluster holding 'Contorta' and seedlings from Simferopol, Ukraine (Fig. 5). This group of 35 plants holds the reference cultivars Early Long Zellernuss (EFB-susceptible), from England, and Auger, the second named OP selection from Gordon, with the remaining accessions believed to have originated from Moscow, Russia. The last clonal accession in the group is the EFBresistant, red-leaf Moscow \#2, which originated from scions imported to OSU from the Russian Research Institute of Forestry and Mechanization, Moscow (Sathuvalli et al., 2010). The remaining 32 accessions are EFB-resistant OP seedlings of the red-leaf 'Moskovskii Rubin' or red-leaf 'Kudashovski'. Seeds from both cultivars were collected at the Sochi Institute, although in different years, with both cultivars believed to have originated near Moscow (Capik et al., 2013).

Adjacent to the Moscow group is an unnamed cluster containing the ornamental hazelnut 'Contorta', its offspring 'Red Majestic', and the reference cultivar DuChilly (synonym 'Kentish Cob'), which fell in the Central European group (German section) of Gökirmak et al. (2009) (Fig. 1). The accession Rutgers Passion Puddle, an old, EFB-tolerant $C$. avellana seedling growing on the Rutgers University Cook Campus, New Brunswick, NJ, was also included in this group. The final six accessions placed in this group are EFB-resistant OP seedlings from Simferopol, Ukraine (Simferopol Market 5).

Mixed Group. Placed below the Moscow group is the Mixed group. This group comprises an assortment of 29 accessions that are divided into two subgroups, each of which contain plants from a variety of origins (Fig. 6). The subgroup located basally and placed at the bottom of the Mixed group (Subgroup 1) eastern filbert blight. holds the reference cultivar Faroka, a putative hybrid of C. colurna developed by J. Gellatly (Gellatly, 1966), and two of its known EFB-resistant offspring: 'Grand Traverse' (Farris, 1989) and Grimo 186M (Grimo, 2011). Also placed in this subgroup are Gordon \#1, \#31, \#33, and \#34; 'Estrella \#1', a hybrid of $C$. heterophylla var. sutchuensis $\times C$. avellana 'Holder' (Farris, 1974); and the EFB-resistant seedling

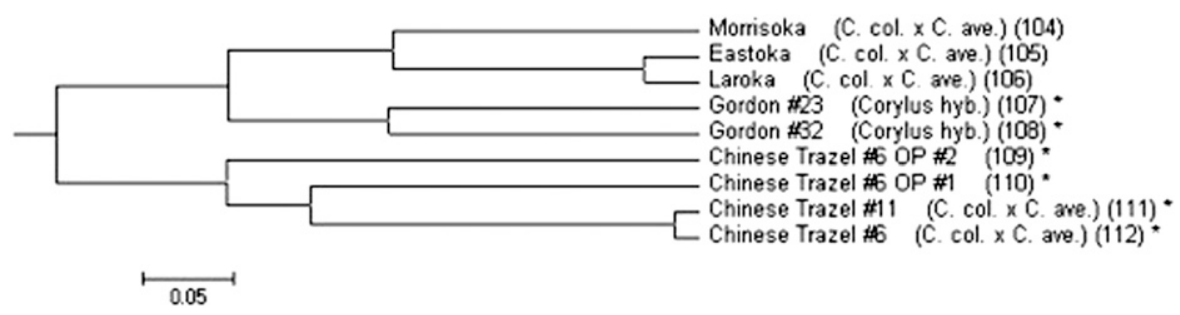

Fig. 4. Uncollapsed Gellately hybrid group node of the unweighted pair group method using arithmetic averages (UPGMA) dendrogram. In reference to the hybrid accessions, Corylus avellana and C. colurna are represented by $C$. ave. and C. col., respectively. The abbreviation hyb. indicates hybrid. Accessions marked with an asterisk $(*)$ are resistant to eastern filbert blight.

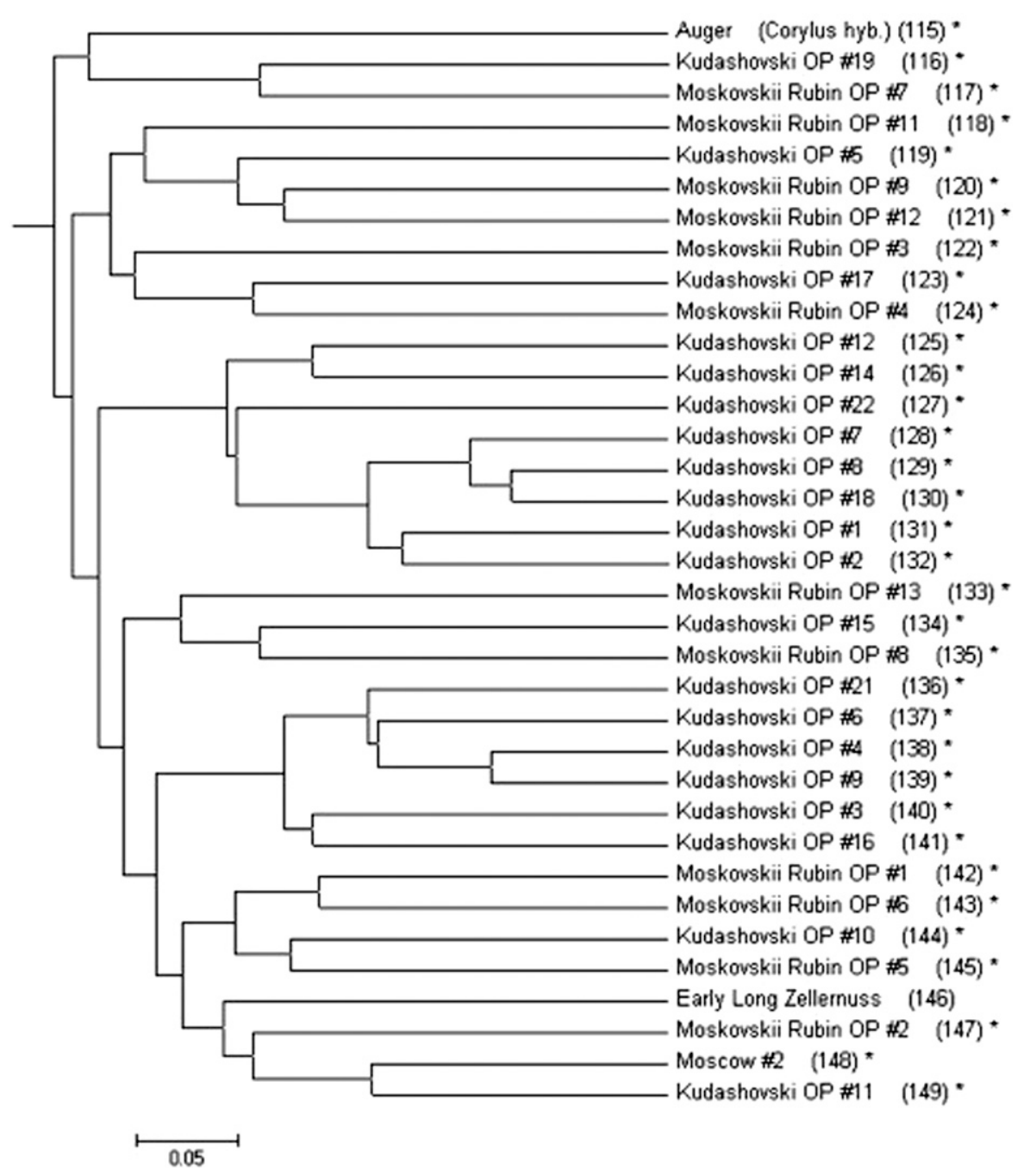

Fig. 5. Uncollapsed Moscow group node of the unweighted pair group method using arithmetic averages (UPGMA) dendrogram. All accessions are Corylus avellana unless otherwise noted. The abbreviations hyb. and OP indicate hybrid and open-pollinated, respectively. Accessions marked with an asterisk (*) are resistant to 
'Kudashovski' OP \#13. Besides the 'Kudashovski' OP \#13, the accessions in this group share ties through their developers being members of the NNGA who were known to have exchanged germplasm (Capik and Molnar, 2012).

Located interior to and above Subgroup 1 is a larger group (Subgroup 2) that contains the reference cultivars Karol from Poland [Central European group (Gökirmak et al., 2009)], 'Badem' from Turkey [Spanish-Italian group (Gökirmak et al., 2009)], 'Istrski Duguljasti' from Croatia [Black Sea Group 1 (Gökirmak et al., 2009)], Bulgaria X1-8 from Bulgaria [Black Sea Group 1 (Gökirmak et al., 2009)], and 'Barr's Zellernuss' from England [Central European group (Gökirmak et al., 2009)]. Also placed in this subgroup are accessions with uncertain origins, such as 'Henneman 3', 'Ugbrooke', and 'Jeans', as well as a number of additional putative C. colurna $\times$ C. avellana hybrids developed by Gellatly, including Turkish Trazel \#3, 'Chinoka', and 'Erioka', and his C. cornuta hybrid 'Manoka'. Other clonal accessions with unknown origins placed in this group include Morris 32-1379A, an EFB-resistant $C$. avellana accession from the Morris Arboretum, Philadelphia, PA; Home Ec Building, an EFBtolerant seedling located on the Rutgers University Cook campus, New Brunswick, NJ; and Gordon \#30. In addition, the seedling accessions placed in this group include four from Skierniewice, Poland, and one from Simferopol, Crimea, Ukraine.

Although some of the accessions placed in this UPGMA group have clear English or central European origins, others span regions from eastern Europe to the Black Sea region. As such, the reasons for their grouping in the same clade are unclear. Thus, we label this group the Mixed group.

SPANish-Italian GROUP. Placed interior to and below the Mixed group in the dendrogram is the Spanish-Italian group. Similar to the findings of Gökirmak et al. (2009), nearly all of our reference cultivars previously placed in their Spanish-Italian group were placed in one large group by our UPGMA clustering analysis. These cultivars include Barcelona, Casina, Closca Molla, Culpla (EFB-resistant), Negret, Ratoli (EFB-resistant), Restiello, Sant Juame, Segorbe, Tonda di Giffoni, Tonda Gentile delle Langhe, and Tonda Romana (Fig.
7). Also included in the group, although previously placed in English Group 2 by Gökirmak et al. (2009), are 'Butler', 'Daviana', 'Ennis', 'Gem', 'Royal', and 'Zimmerman'. All of these cultivars besides Daviana (from England), which was placed at the bottom of the group adjacent to Ennis, are believed to share Barcelona as a common parent. Furthermore, 'Butler' and 'Ennis' were shown to be offspring of 'Barcelona' $\times$ 'Daviana' (Gökirmak et al., 2009). Several cultivars released from the OSU breeding program with Spanish-Italian cultivars in their pedigrees were also placed in this group. These include

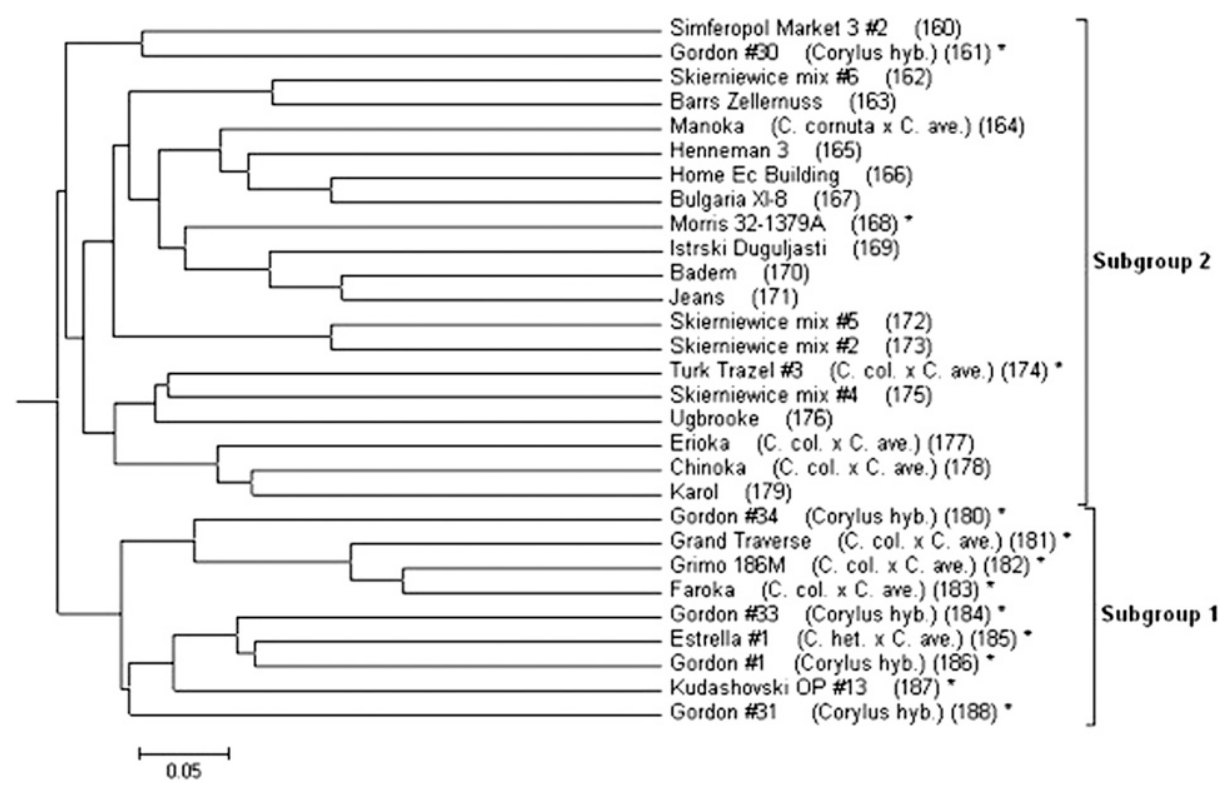

Fig. 6. Uncollapsed Mixed group node of the unweighted pair group method using arithmetic averages (UPGMA) dendrogram. All accessions are Corylus avellana unless otherwise noted. In reference to the hybrid accessions, C. ave., $C$. het., and $C$. col. correspond to C. avellana, C. heterophylla, and C. colurna, respectively. The abbreviations hyb. and OP indicate hybrid and open-pollinated, respectively. Accessions marked with an asterisk (*) are resistant to eastern filbert blight.

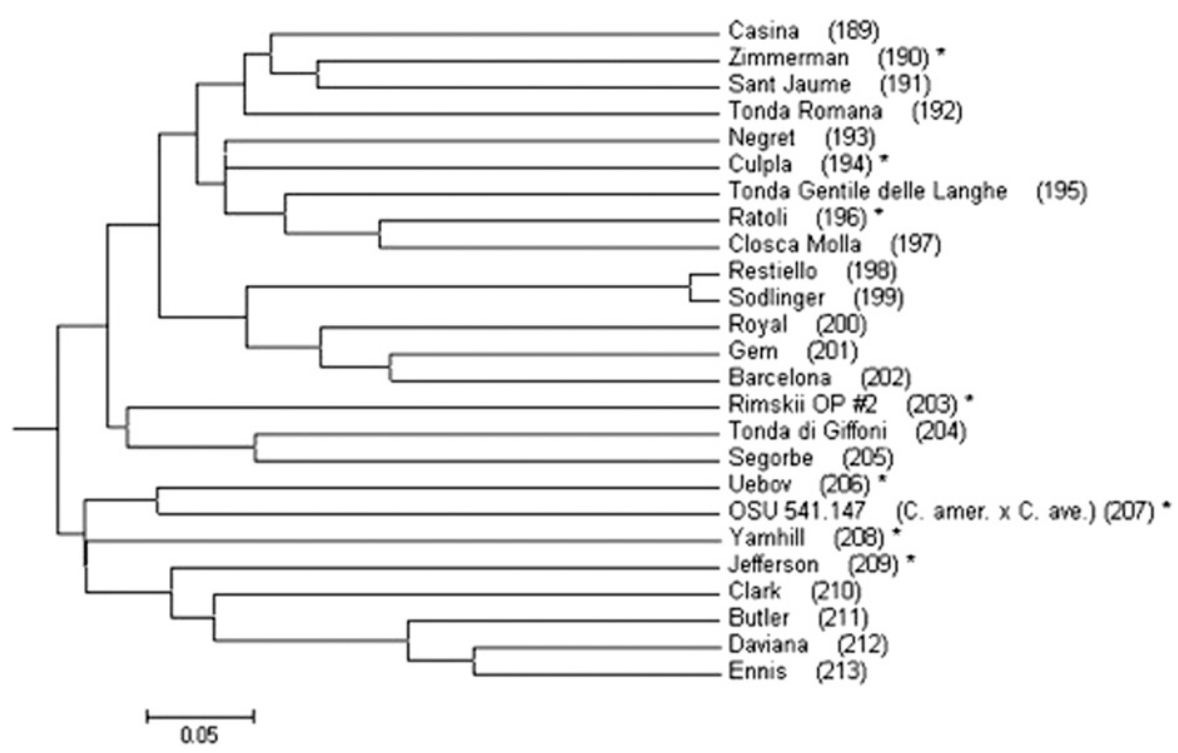

Fig. 7. Uncollapsed Spanish-Italian group node of the unweighted pair group method using arithmetic averages (UPGMA) dendrogram. All accessions are Corylus avellana unless otherwise noted. In reference to the hybrid accessions, C. ave. and C. amer. correspond to C. avellana and C. americana, respectively. The abbreviation OP indicates open-pollinated. Accessions marked with an asterisk $(*)$ are resistant to eastern filbert blight. 
'Clark' (Mehlenbacher et al., 2001), 'Jefferson' (Mehlenbacher et al., 2011), and 'Yamhill' (Mehlenbacher et al., 2009), which each have 'Barcelona' and 'Montebello' (synonym 'Siciliana') in their pedigrees. Although 'Clark' is susceptible to EFB, 'Jefferson' and 'Yamhill' are resistant as a result of a resistance allele from 'Gasaway'. Also included in the group was OSU 541.147, a breeding selection from OSU carrying EFB resistance from $C$. americana 'Rush' (through NY 110) that also has 'Montebello' and 'Barcelona' in its pedigree (S.A. Mehlenbacher, personal communication); EFB-resistant 'Uebov' from Serbia (Sathuvalli et al., 2010); and 'Sodlinger' from the former Yugoslavia. Interestingly, only one seedling accession was placed in this group, EFB-resistant 'Rimski' OP \#2, which was selected from OP seedlings of 'Rimski' originating from the Sochi Institute.

GASAWAY-RELATED GROUP. Placed interior to the SpanishItalian group, along with a disparate group of the two accessions 'Freeoka' and 'Karloka', is a group of nine EFBresistant accessions that includes the reference cultivar Gasaway and its offspring VR 20-11 and Santiam (Fig. 8). This group also contains the EFB-resistant clonal accessions Farris 88 BS (a purported OP seedling of the $C$. colurna hybrid 'Faroka'), Farris Box 1 (unknown pedigree), and Farris G-17 (unknown pedigree). It should be noted that Box 1 and G-17 may be the same genotype because they share common alleles at all 17 loci. Additionally, three seedling accessions with uncertain parentage were included in this group: 'Badem' OP \#1 and \#2, which were both selected from OP seedlings of 'Badem' originating from the Research Institute for Horticulture and Viticulture, and 'Moskovskii Rubin' OP \#10, originating from the Sochi Institute.

'Gasaway' is a grower selection of R. Gasaway from Battleground, WA, although little is known of its origin (Thompson et al., 1996). It was not placed in any of the four geographic groups identified by Gökirmak et al. (2009). Its relationship to the Farris selections is unclear, although Farris did use OSU germplasm in his breeding efforts, including plants carrying the 'Gasaway' R-gene (Farris, 2000).

Central European Group. Most of the reference cultivars of Polish and German origin were placed together in one large group similar to the Central European group described in Gökirmak et al. (2009). However, our group was divided into two subgroups (Fig. 9), which did not precisely match the Polish and German sections defined in their study. The lower subgroup (Subgroup 1) held the Polish cultivars Acorn Hazel, Little Poland, Lenka 3, and Maria and the "red-leaf" cultivars

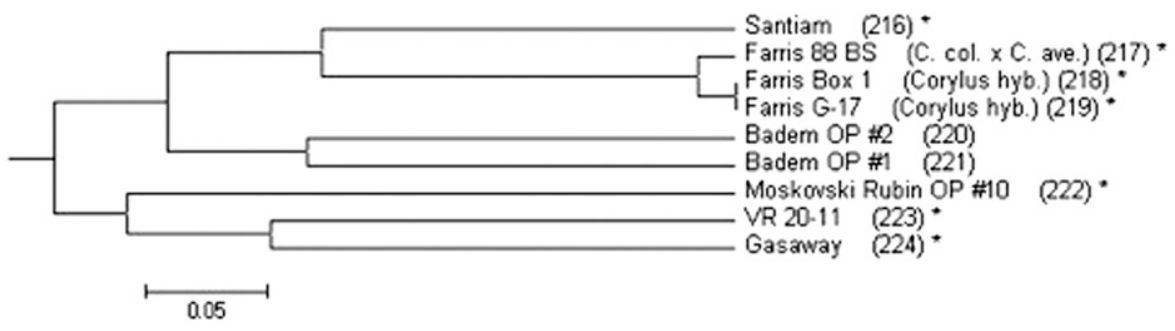

Fig. 8. Uncollapsed Gasaway group node of the unweighted pair group method using arithmetic averages (UPGMA) dendrogram. All accessions are $C$. avellana unless otherwise noted. In reference to the hybrid accessions, C. ave. and C. col. correspond to C. avellana and C. colurna, respectively. The abbreviations hyb. and $\mathrm{OP}$ indicate hybrid and open-pollinated, respectively. Accessions marked with an asterisk (*) are resistant to eastern filbert blight.
Rote Zellernuss (German), Red Fortrin, Goc (Poland), and Annie's Compact Red. This cluster of four red-leaf cultivars suggests they share a common lineage and reinforces the report in Gökirmak et al. (2009) that 'Rote Zeller' is a parent of 'Goc'. The red leaf color in hazelnut is transmitted in a dominant manner (Thompson, 1985). It is also interesting to note that these red-leaf accessions are placed distant from the UPGMA Moscow group that holds a number of other red-leaf accessions, suggesting a possible unrelated origin for the central European red leaf color compared with that from Moscow.

Several accessions with uncertain parentage are also included in the lower Central European subgroup. These include NY 616 OP \#1 [a red-leaf OP seedling of NY 616 (C. americana 'Rush' $\times$ C. avellana 'Barcelona') selected at Rutgers University], 'Slagel' (a named OP selection released by Gordon), and Gordon \#19. The inclusion of NY 616 OP \#1, which has red leaves from an unknown pollen parent, likely reflects a common lineage with the other red-leaf $C$. avellana accessions in this group. The reasons for inclusion of 'Slagel' and Gordon \#19 in this subgroup are unclear.

The upper subgroup (Subgroup 2) holds a mix of Polish [Frango 2, Lech, Syrena (red leaf), and Volski] and German [Gustav's Zellernuss, its synonym Italian Red (which shares identical alleles at all loci), and Hall's Giant] cultivars as well as Aveline d'Angleterre, which is believed to have originated in France (Gökirmak et al., 2009). Seedlings from Poland were also placed in this group (11 of 21), which includes those grown from OP nuts collected in markets and research stations in Warsaw, Skierniewice, and Konskowli, Poland (Capik et al., 2013). It should be noted that cultivars from the Central European group are known for their cold-hardiness (Thompson et al., 1996). Some of the EFB-resistant and -tolerant Polish seedlings may also express this valuable trait, which warrants investigation. Also included in this subgroup are Gordon \#17 and \#26. Gordon's use of NY 200 ('Rush' $\times$ C. avellana 'Hall's Giant') as an early breeding parent provides a link to his selections being placed in this subgroup that holds 'Hall's Giant'.

C. AMERICANA $\times \boldsymbol{C}$. AVELLANA HYBRID Group 2. The UPGMA analysis resolved a second group holding known accessions of $C$. americana $\times C$. avellana origin (Fig. 10). This group was placed adjacent to the Central European group. It holds the reference accessions NY 398 (C. americana 'Rush' $\times C$. avellana 'Red Lambert') and $C$. avellana 'Frango 5' from Poland (Gökirmak et al., 2009). Other clonal accessions placed in this group, although with less certain parentage, are 'Medium Long' from the New York Agricultural Experiment Station, which was previously shown to cluster with 'Rush' in a nuclear and chloroplast SSR analysis by Bassil et al. (2013); Grimo 208P, which is an OP seedling of NY 1329 ('Rush' $\times$ C. avellana 'Cosford') (Grimo, 2011); and NY 616 OP \#2, an OP seedling of NY 616 ('Rush' $\times C$. avellana 'Barcelona') selected at Rutgers University.

The remaining accessions in this group have unknown parentages. These accessions include a majority of the Gordon hybrids ( 25 of 40) as 


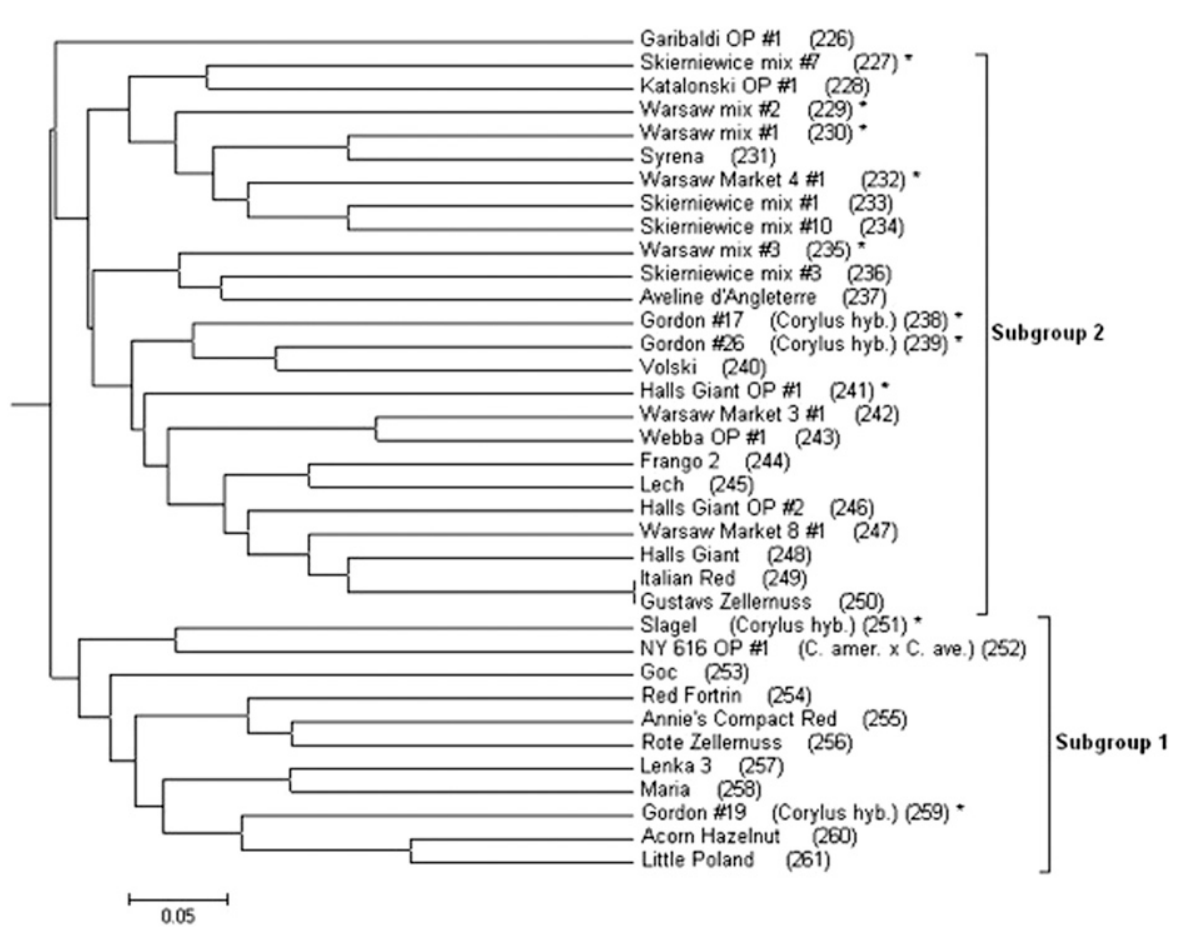

Fig. 9. Uncollapsed Central European group node of the unweighted pair group method using arithmetic averages (UPGMA) dendrogram. All accessions are Corylus avellana unless otherwise noted. In reference to hybrid accessions, $C$. ave and C. amer. correspond to C. avellana and C. americana, respectively. The abbreviations hyb. and OP indicate hybrid and open-pollinated, respectively. Accessions marked with an asterisk (*) are resistant to eastern filbert blight.

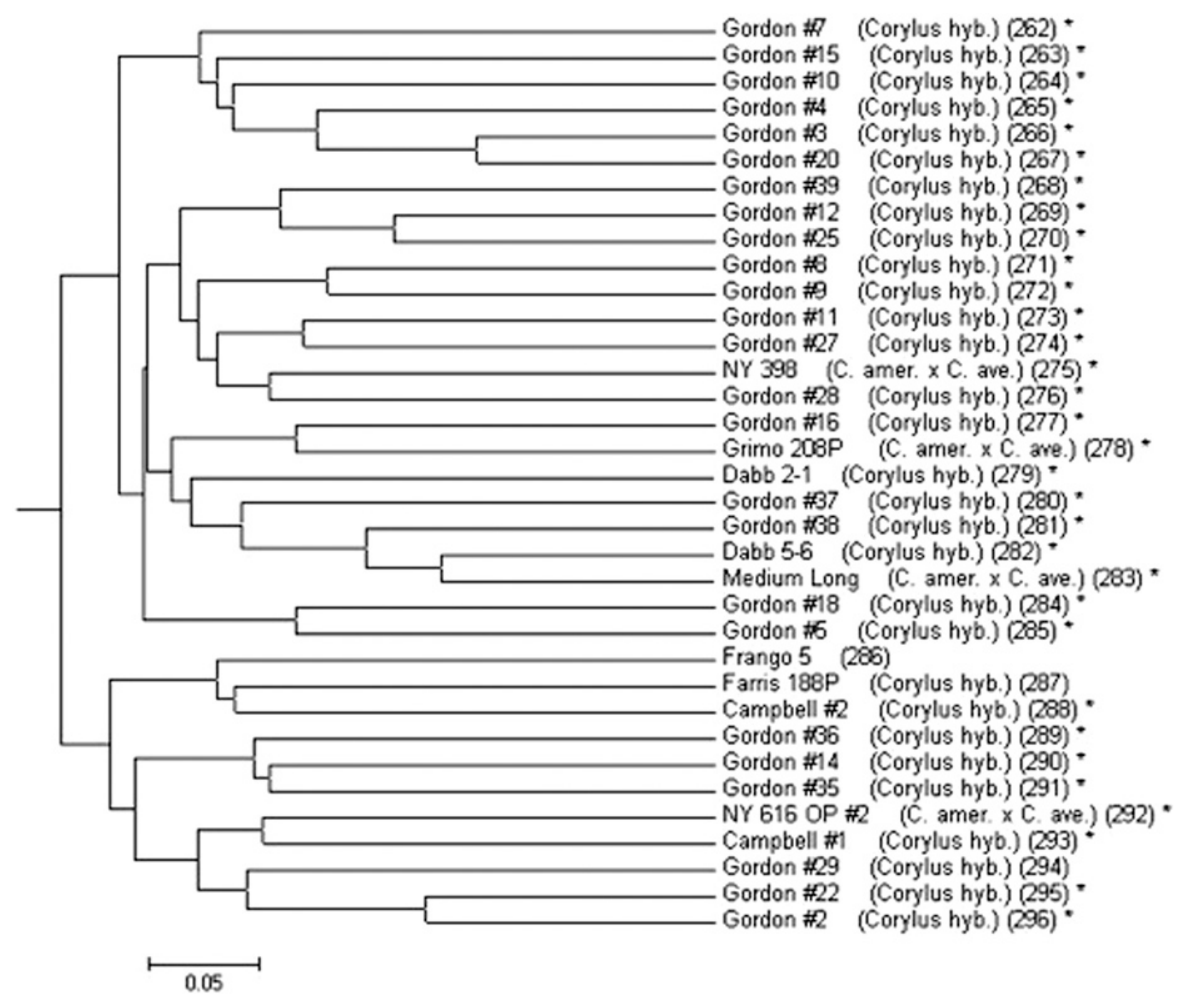

Fig. 10. Uncollapsed Corylus americana $\times$ C. avellana hybrid Group 2 node of the unweighted pair group method using arithmetic averages (UPGMA) dendrogram. All accessions are C. avellana unless otherwise noted. In reference to the hybrid accessions, $C$. ave and $C$. amer. correspond to $C$. avellana and $C$. americana, respectively. The abbreviations hyb. and OP indicate hybrid and open-pollinated, respectively. Accessions marked with an asterisk $\left(^{*}\right)$ are resistant to eastern filbert blight. well as Campbell \#1 and Campbell \#2, which were selected at Rutgers University as being EFB-resistant from a larger group of seedlings purchased from Douglas Campbell Nursery, Niagra-on-the-Lake, Ontario, Canada, under the name "Turkish tree hazel hybrid seedlings." The final three accessions include Farris 188P, an EFB-tolerant clonal selection from C. Farris, and Dabb 2-1 and Dabb 5-6, both EFB-resistant clonal selections obtained from $\mathrm{C}$. Dabb in Ogden, UT. Little is known of their origin. However, Dabb was an active member of the NNGA (as were C. Farris, J. Gordon, and E. Grimo), and he was known to have exchanged nut tree germplasm with members of this organization (Dabb, 1971; L. Dabb, personal communication).

As discussed earlier, the fact that Gordon used 'Rush' hybrids in his breeding pool provides support for a majority of his EFB-resistant selections being included in this group, which holds NY 398 and other accessions known to be related to 'Rush'. Molnar and Capik (2012) suggest that the $R$-gene from 'Rush' is controlled by a single dominant allele in the heterozygous state, which supports the recovery of a large number of related resistant plants from Gordon's efforts. Furthermore, Gordon's use of NY 200 ('Rush' $\times$ C. avellana 'Hall's Giant'), as discussed earlier, may also provide support for why $C$. americana $\times$ C. avellana hybrid Group 2 is located adjacent to the Central European group. D. Campbell was an active member of the NNGA (Campbell, 1996), participating in germplasm exchange along with Gordon, Farris, Grimo, and Dabb, which provides a link for the inclusion of his plant material in this group.

WiLd C. aVELLANa group. A second mixed group of cultivars and seedlings that is notable for holding the only wild $C$. avellana accessions in the study as well as a majority of the seedlings from Simferopol, Ukraine (10 out of 19) (Fig. 11) was placed at the very bottom of the dendrogram. This group is divided into three distinct clusters. The cluster placed lowest in the group (Subgroup 1) holds four 
OP seedlings from Simferopol and one seedling originating from the Vavilov Research Institute of Plant Industry (VIR) in Maykop, Russia (Maykop VIR \#1).

The middle cluster (Subgroup 2) holds the reference cultivar Aurea (C. avellana var. aurea), a yellow-leaf ornamental hazelnut believed to be from France; Fusco Rubra, a red-leaf cultivar from Germany; Finland CCOR 187, an EFBtolerant wild accession from Finland (Chen et al., 2007); and OSU 408.040, an EFB-resistant seedling selection from Minnesota (Chen et al., 2005). None of these accessions were placed in any of the four major geographic groups by Gökirmak et al. (2009). Subgroup 2 also holds two clonal selections from the Russian Research Institute of Forestry and Mechanization, Moscow (Moscow \#28 and a Moscow selection from the same group of introduced plants whose specific accession number was lost at Rutgers University), and an EFB-resistant seedling of 'Kudashovski', which, as mentioned previously, is also believed to have originated from Moscow. The other seedling accessions placed in this group include two wild C. avellana accessions from Estonia (Estonia \#1 from Agusalu and Estonia \#2 from Tartu), six seedlings from Simferopol, one from Maykop, Russia, and one from Poland.

The final cluster (Subgroup 3), placed in a more basal position within this wild C. avellana group, holds the reference cultivars Bianca from Italy and Cutleaf from England. It also holds three C. heterophylla $\times C$. avellana hybrids-China \#1, China \#14, and China \#18. It should be noted that China \#14 and China \#18 shared the same alleles at all 17 loci, making it likely that they are the same genotype. Although 'Bianca' was placed in the Spanish-Italian subgroup by Gökirmak et al. (2009), 'Cutleaf' was not assigned to one of their four major subgroups. Furthermore, little is known about the background of the hybrid accessions originating from the Economic Forestry Institute of Liaoning Province, Dalian, China (Capik and Molnar, 2012), to help support their placement in this group.

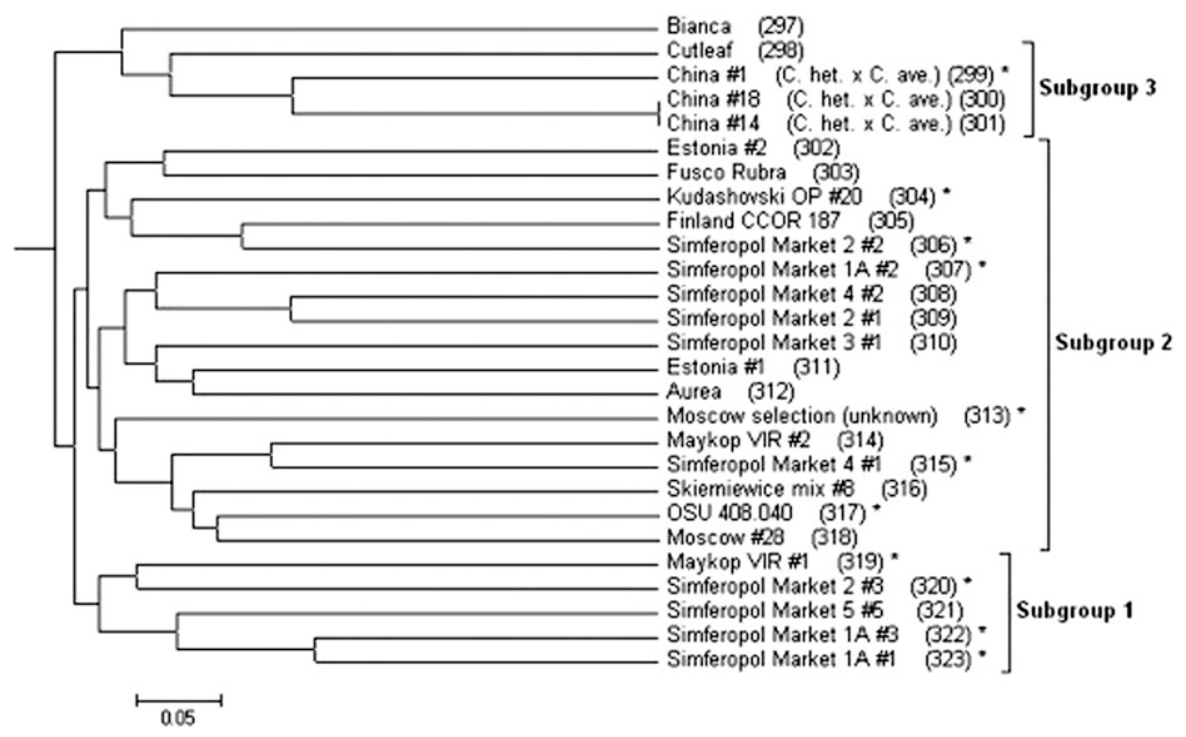

Fig. 11. Uncollapsed wild Corylus avellana group node of the unweighted pair group method using arithmetic averages (UPGMA) dendrogram. All accessions are $C$. avellana unless otherwise noted. In reference to the hybrid accessions, $C$. ave. and $C$. het. correspond to C. avellana and C. heterophylla, respectively. The abbreviation OP indicates open-pollinated. Accessions marked with an asterisk (*) are resistant to eastern filbert blight.
Overall, the UPGMA wild $C$. avellana group contains a mixture of accessions spanning different origins. However, it is the only group that holds known wild accessions of $C$. avellana (Finland CCOR 187 and the two seedlings from Estonia). In addition, the three accessions from Moscow are believed to be from a breeding program that used local wild $C$. avellana in crosses with southern cultivars to develop coldhardy selections, as discussed in Molnar (2011). Furthermore, OSU 408.040 is a seedling selection derived from an unknown C. avellana plant growing in Minnesota, which denotes a level of cold-hardiness not found in most cultivated C. avellana. Thus, the UPGMA group was named the wild $C$. avellana group, in part for lack of better resolved genetic associations.

\section{STRUCTURE analysis}

The results of the Bayesian model-based clustering analysis (STRUCTURE) are shown in Figure 12. Genotyping data for all samples were imported for STRUCTURE analysis in the order displayed in the UPGMA dendrogram; thus, the first (top) accession in the UPGMA tree is labeled as Accession 1 in the STRUCTURE analysis, etc. The maximum value for the first plateau of the graphical representation of the average estimated log probability $\operatorname{Pr}(X \mid K)$ curve [used to identify the most parsimonious number of clusters/populations $(K)]$ was $(K)=$ 11. Additional $(K)$ values were considered, but $(K)=11$ correlated best with the breeding histories, countries of origin, and the results of the UPGMA clustering analysis.

In general, the STRUCTURE results strongly support the groupings depicted in the UPGMA dendrogram. Notable exceptions occurred within the Black Sea group, which is depicted as one large group in the UPGMA clustering analysis that holds two subgroups (large and small) and one basal clade. In the STRUCTURE analysis, the Black Sea group was divided into two genetic groups; however, they did not clearly follow the groupings displayed in the UPGMA dendrogram. Furthermore, the $C$. americana $\times C$. avellana hybrid Groups 1 and 2, which are separated by a relatively wide margin in the UPGMA dendrogram, were combined into one large population in the STRUCTURE analysis. An additional divergence between the UPGMA and STRUCTURE analysis was shown for the Mixed group. Although depicted as one large group in the UPGMA analysis, the Mixed group was dissolved by the STRUCTURE analysis with the included entries subsequently placed in other STRUCTURE groups. Greater details and discussion on the results of the STRUCTURE model-based clustering analysis in comparison with the UPGMA cluster analysis are described for each original UPGMA group below.

Outgroups. The STRUCTURE analysis assigned nearly all of the wild species accessions into unique populations distinct from a great majority of the other accessions in 

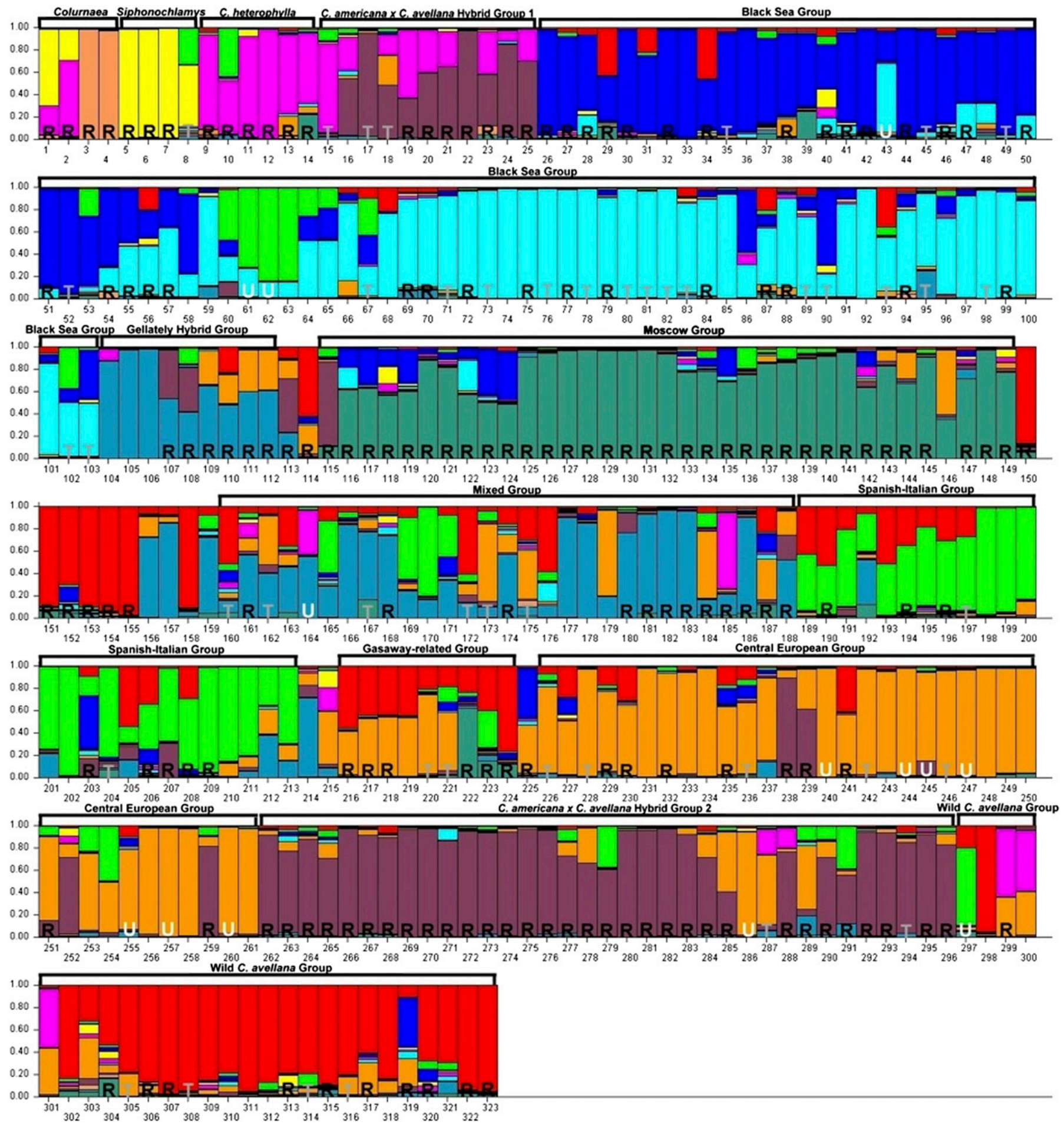

Fig. 12. STRUCTURE analysis output resulting in the most parsimonious number of populations $(\mathrm{K})=11$ (Falush et al., 2003; Pritchard et al., 2000). Accessions are susceptible to eastern filbert blight (EFB) unless otherwise marked where R represents EFB-resistant accessions, T represents EFB-tolerant accessions, and U represents unknown EFB resistance. The STRUCTURE accessions are labeled in accordance with their placement in the unweighted pair group method using arithmetic averages (UPGMA) dendrogram (Fig. 1), where Accession 1 is placed at the very top of the UPGMA dendrogram.

the study. Interestingly, three distinct outgroup populations were resolved, which did not necessarily reflect the groupings revealed by the UPGMA dendrogram. For example, the four accessions placed in the Colurnaea clade of the UPGMA dendrogram were now divided up across three STRUCTURE groups. STRUCTURE Outgroup 1 holds $C$. colurna \#1, which was originally placed at the very top of the UPGMA dendrogram in the Colurnaea clade. However, now also placed within this STRUCTURE group are the accessions previously placed within the Siphonochlamys clade of the UPGMA dendrogram $(C$. mandshurica \#1, C. sieboldiana \#1, C. cornuta 'Peace River', and OSU 587.044). Next, the two C. fargesii accessions were 
classified as their own STRUCTURE group (Outgroup 2). Finally, $C$. chinensis \#1, the last UPGMA Colurnaea member, was placed in STRUCTURE Outgroup 3, which now also holds accessions primarily of $C$. heterophylla origin. It should be noted that four additional $C$. heterophylla hybrid accessions were placed in this group that were not originally included in the $C$. heterophylla UPGMA clade (China \#1, \#14, \#18, and Estrella \#1), as well as the hybrid accessions Gordon \#21 and NADF \#10 (Table 1).

C. AMERICANA $\times$ C. AVELLANA HYBRID GROUPS. The STRUCTURE analysis grouped nearly all of the accessions of the UPGMA C. americana $\times C$. avellana hybrid Groups 1 and 2 into one large population (Table 1). Only six accessions were moved out from these two UPGMA groups, including 'Frango 5', Farris 188P, and Gordon \#5 and \#36, which were moved to the Central European group. The accessions Gordon \#21 and NADF \#10 were both moved to STRUCTURE Outgroup 3. Six accessions were added to the STRUCTURE C. americana $\times$ C. avellana hybrid group, which are also putative $C$. americana $\times$ C. avellana hybrids. These include NY 616 OP \#1 and five Gordon accessions.

Overall, a majority of the accessions placed in this STRUCTURE group can be linked to $C$. americana 'Rush' either directly through known pedigree or indirectly based on germplasm used by their developers. In some cases, their breeding histories corroborate their placement in both their respective UPGMA group and this STRUCTURE population, which provides support for the validity of both analyses. For example, the Gordon hybrids \#17, \#19, and \#26 were previously grouped near $C$. avellana 'Hall's Giant' in the UPGMA Central European group (Fig. 9). This placement supports the report that NY 200 ('Rush' $\times C$. avellana 'Hall's Giant') was a component of Gordon's starting material and constitutes part of the genetic background of some of his selections. The fact that the STRUCTURE analysis moved these Gordon accessions into the $C$. americana $\times C$. avellana population may suggest that the $C$. americana genetic background is more prominent in them than that of $C$. avellana 'Hall's Giant'. It is interesting to note that when admixture is present in the accessions placed within the $C$. americana $\times C$. avellana hybrid group, the colors indicate a strong contribution from the Central European group (Fig. 12).

Nearly all of the accessions in this group are further linked by a shared phenotypic characteristic-resistance or high tolerance to EFB. EFB resistance is a relatively rare trait that is not always transmitted at a high level from parents showing resistance (Capik and Molnar, 2012; Molnar and Capik, 2012; Thompson et al., 1996). The presence of a potential dominant $R$-gene from 'Rush' in germplasm frequently exchanged and accessible to members of the NNGA for more than 50 years would likely lead to a large number of related, EFB-resistant plants being selected by amateur breeders living where the fungus is endemic.

Black Sea groups. The STRUCTURE analysis largely followed the placement of the known Black Sea accessions resolved in the UPGMA analysis, although it showed deeper resolution of relationships among the accessions in the different subgroups (Table 1). For example, within the UPGMA Black Sea group, two distinct subgroups (one large and one small) and one basal clade were resolved. In the STRUCTURE analysis, a majority of the accessions in the large UPGMA subgroup were placed into one STRUCTURE group (henceforth named
STRUCTURE Black Sea Group 1). This group of accessions remained well defined with no additional accessions moved into it by the STRUCTURE analysis. However, a total of 22 accessions were moved out of the UPGMA large subgroup by the STRUCTURE analysis, and of those, 17 were placed into a separate, distinct STRUCTURE group that includes all of the accessions originally found in the small UPGMA Black Sea subgroup and the basal clade (henceforth named the STRUCTURE Black Sea Group 2). The remaining five accessions were moved to the STRUCTURE Spanish-Italian group, discussed subsequently (comprised of the Turkish references cultivars Sivri Ghiaghli, Tombul, Kudryavchik, Tombul Ghiaghli, and Kalinkara). Only three accessions, 'Rimski' OP \#2, Maykop VIR \#1, and B-X-3 OP \#2, were moved into Black Sea Group 2 from across the study.

Although the reason for the differentiation between the two STRUCTURE Black Sea groups is unclear, it should be noted that Black Sea Group 1 holds most of the reference cultivars from the Black Sea region and many seedling accessions from Holmskij and Sochi. While holding some accessions with origins in southern Russia, STRUCTURE Black Sea Group 2 also holds 'Losovskoi Sharovdnii' from Harkiv, Ukraine (northern Ukraine), and seedlings originating from Simferopol and Yalta (Crimean Peninsula), Ukraine. No accessions of Ukrainian origin are found in STRUCTURE Black Sea Group 1.

Gellatly hybrid group. The STRUCTURE analysis placed all nine of the UPGMA Gellatly hybrid group accessions in one distinct group, most of which are known $C$. colurna $\times C$. avellana hybrids. The analysis also placed an additional 19 accessions in this group, most of which trace their origin directly or indirectly to hybrids developed by Gellatly (Table 1).

Moscow GRouP. The STRUCTURE analysis placed nearly all of the Moscow seedlings ('Kudashovski' OP and 'Moskovskii Rubin' OP) in a distinct group that is nearly identical to that resolved by the UPGMA dendrogram. The only divergence was that 'Early Long Zeller' (which showed admixture with several other groups) was moved to the Central European group (discussed subsequently) and the Gordon hybrid 'Auger' was moved to the STRUCTURE $C$. americana $\times C$. avellana group. Furthermore, only one accession was moved into the STRUCTURE Moscow group, 'Moskovskii Rubin' OP \#10, which joins the vast majority of its half-sibs included in the study.

Mixed Group. The STRUCTURE analysis dissolved the large UPGMA Mixed group into several other STRUCTURE groups, some of which are discussed in more detail subsequently. In respect to the two original subgroups of the Mixed group revealed by the UPGMA analysis, differing levels of admixture was observed within them, which merits some discussion. Six of the nine total accessions in UPGMA Subgroup 1 show only minor admixture with other groups and were clearly placed in the Gellatly hybrid STRUCTURE group. The three remaining accessions show a much greater level of admixture. These include the $C$. heterophylla hybrid 'Estrella \#1', which was placed in STRUCTURE Outgroup 3, and 'Kudashovski' OP \#13 and Gordon \#33, which were placed in the STRUCTURE Central European group.

Subgroup 2 of the UPGMA Mixed group holds accessions from a variety of origins with many exhibiting significant amount of admixture across multiple STRUCTURE groups 
(Fig. 12). Of the 20 total accessions, eight were also placed in the STRUCTURE Gellatly hybrid group. Of the remaining 12 accessions, 'Karol' (from Poland) and three seedlings from Skierniewice, Poland, were placed in the STRUCTURE Central European group. 'Karol' was placed in a similar group in Gökirmak et al. (2009). Furthermore, 'Ugbrooke', 'Barrs Zellernuss', Skierniewice mix \#5, and Simferopol Market 3 \#2 were placed in the STRUCTURE wild C. avellana group. Lastly, 'Henneman 3', 'Istrski Duguljasti', 'Jeans', and 'Badem' were placed in the STRUCTURE Spanish-Italian group; of these, only 'Badem' was placed in a similar group in Gökirmak et al. (2009).

SPANISH-ITALIAN GROUP. The STRUCTURE analysis largely followed the placement of the known Spanish-Italian accessions resolved in the UPGMA analysis. Of the 25 accessions held in the UPGMA Spanish-Italian group, only five were moved to different STRUCTURE groups. These include 'Negret', 'Segorbe', and 'Zimmerman', which were placed in the wild $C$. avellana group, as well as 'Tonda Romana' and 'Rimski' OP \#2, which were placed in the Gellately hybrid group and Black Sea Group 2, respectively. 'Segorbe' and 'Negret' are from Spain and were placed in the Spanish-Italian group in Gökirmak et al. (2009). Thus, it is not clear why they were moved in our study; however, the STRUCTURE analysis shows they both contains significant admixture between a number of groups [Fig. 12 (Accession 205)], which may have led to its new placement. 'Tonda Romana' and 'Rimski' OP \#2 both also show a high level of admixture between several groups [Fig. 12 (Accessions 192 and 203, respectively)].

Accessions moved into the STRUCTURE Spanish-Italian group from other UPGMA groups include 'Sivri Ghiaghli', 'Tombul', Kudryavchik', 'Tombul Ghiaghli', 'Kalinkara', 'Henneman 3', 'Istrski Duguljasti', 'Badem', 'Jeans', and 'Bianca' (Table 1).

Gasaway-Related group. The STRUCTURE analysis dissolved the UPGMA Gasaway-related group. Although all nine accessions showed kinship with the STRUCTURE wild $C$. avellana group (discussed subsequently), only 'Gasaway', VR 20-11, and Santiam were placed there. The three Farris accessions (88 BS, Box 1, and G-17) and the two 'Badem' OP accessions (\#1 and \#2) were moved into the STRUCTURE Central European group (also discussed subsequently). As a result of a lack of pedigree information, it is unclear why these accessions would be placed in either the UPGMA 'Gasaway' or Central European groups. The final accession, 'Moskovskii Rubin' OP \#10, was moved into the STRUCTURE Moscow group as mentioned earlier.

Central European group. The STRUCTURE analysis largely followed the placement of the known Central European accessions resolved in the UPGMA analysis. Of the 36 accessions originally placed in this group, only four were moved to other groups. However, the STRUCTURE analysis moved 18 additional accessions into the Central European group (Table 1). These include six accessions originally from the dissolved UPGMA Mixed group, five from the dissolved Gasaway group, one from the Moscow group, four from the C. americana $\times$ C. avellana hybrid group, one from the wild C. avellana group, and finally 'Karloka', which was not included in a UPGMA group. A common thread found in nearly all of the 18 added accessions is a relatively high degree of admixture per each accession, which may help explain their divergent placements between the two analyses (Fig. 12).
Wild $\boldsymbol{C}$. avellana group. The STRUCTURE analysis largely followed the placement of the wild $C$. avellana group accessions resolved in the UPGMA analysis. Of the 27 accessions placed in the UPGMA group, only six were placed elsewhere by the STRUCTURE analysis. Three $C$. heterophylla hybrid accessions (China \#1, \#14, and \#18) were moved to STRUCTURE Outgroup 3; 'Fusco Rubra' was moved to the Central European group; Maykop VIR \#1 was moved to STRUCTURE Black Sea Group 2; and 'Bianca' was moved to the STRUCTURE Spanish-Italian group.

Eighteen additional accessions were moved into the wild $C$. avellana group by the STRUCTURE analysis. Most notably, this includes 'Gasaway' and its offspring 'Santiam', VR 20-11, and 'Zimmerman'. Also now included are 'Segorbe', Skierniewice mix \#9, 'Ugbrooke', 'Barrs Zellernuss', Simferopol Market $3 \# 2$, and Skierniewice mix \#5. It is hard to draw conclusions on the inclusion of these accessions in the $C$. avellana wild group. However, as mentioned in the UPGMA discussion, a number of the included reference accessions placed in this group fell outside of the major groups in Gökirmak et al. (2009) and were labeled in their study as the most genetically divergent. This also included 'Gasaway', which is now placed in this group. However, the STRUCTURE analysis for these reference accessions and the rest of the somewhat unknown accessions placed in the group shows a relatively uniform genetic relationship despite a number of them having disparate origins. For example, the group includes accessions spanning France ('Aurea'), England ('Cutleaf'), Finland (CCOR 187), Estonia (two seedlings), Russia (two clonal accessions), and Ukraine (17 seedlings), all with limited admixture with other STRUCTURE groups (Fig. 12).

\section{Restructured (consensus) populations}

The results of the UPGMA and STRUCTURE analysis are broadly similar to previous research on hazelnut genetic resources (e.g., Bassil et al., 2013; Gökirmak et al., 2009; Gürcan et al., 2010b) and are generally well supported by the known breeding histories and collection origins of a vast majority of the accessions. Overall, the reference cultivars provide a useful framework on which to place the unknown grower selections and OP seedlings from foreign germplasm collections. Seedlings from similar collection origins tend to group closely together with the collection origins of a majority of them corresponding to that of the reference cultivars with which they were grouped. Although the UPGMA clustering analysis and STRUCTURE results are largely in agreement with each other, the STRUCTURE results seem to better reflect the known, biologically relevant major and minor details of relationships between and among the accessions in the study, including their species background, reported breeding histories, and/or geographic origins.

Thus, based primarily on the STRUCTURE results, most accessions were decisively placed into one of 11 consensus groups/populations. However, the results of the STRUCTURE analysis were inconclusive for some accessions as a result of high levels of admixture between multiple groups, sometimes resulting in less than $50 \%$ identity for any single group. This occurred for the following entries: 'Fusco Rubra', 'Jeans', 'Tonda Romana', 'Kalinkara', 'Uebov', 'Daviana', 'Barrs Zellernuss', VR 20-11, OSU 495.072, Gordon \#32, Holmskij 
Market 3 \#2, B-X-3 OP \#2, Nikita Botanical Garden 1 \#3, 'Kudashovski' OP \#13, and Skierniewice mix \#6. In these cases, group assignment for AMOVA was based on a combination of the UPGMA clustering and STRUCTURE results as well as known breeding histories and/or geographic origins of the accessions. Using this approach, all of the accessions in the study were then clearly assigned into 11 consensus groups for the AMOVA.

The AMOVA showed that $89 \%$ of the genetic variation of the accessions was attributable to within-population variance, whereas $11 \%$ was attributed to among-population variance. The within-population variance was then partitioned into each of the 11 populations, and the percentage of variance contributed by each population was calculated using the total withinpopulation variance. The consensus populations, excluding the outgroups, had variance percentages ranging from $\approx 9.05 \%$ to $15.22 \%$, indicating a range of levels of variation found across populations. The highest within-population variance was found in the STRUCTURE Central European group $(15.22 \%)$ followed by the $C$. americana $\times C$. avellana hybrid group (14.29\%). Comparatively, the lowest withinpopulation variance was found in the STRUCTURE Gellatly hybrid group $(9.05 \%)$ followed by the Spanish-Italian group $(9.15 \%)$ (Table 4).

The pairwise $F_{S T}$ values derived from the AMOVA indicate a large degree of genetic differentiation between consensus groups/populations. The AMOVA results also denote that each consensus group is statistically different from every other consensus group $(P<0.05)$ (Table 5). These results indicate that the consensus groups constitute an accurate representation of the genetic relationships between the groups/populations.

\section{Presence of eastern filbert blight-resistant accessions}

As shown in Table 1 and Figure 12, each of the 11 final consensus groups holds accessions known to express resistance or tolerance to EFB, providing strong evidence that EFB resistance is a relatively widespread phenomenon across the Corylus genus. Although this study cannot address whether there are different resistance genes present in the different groups, it does show that EFB resistance is present in hazelnuts of many different genetic backgrounds. Furthermore, a number of the EFB-resistant OP seedling accessions from the new germplasm introductions were placed in groups where none or very few of the known EFB-resistant reference accessions were placed, suggesting that they represent new pools of resistant plant material. Thus, these new plants may represent potential targets for revealing novel $R$-genes in future studies, of which a first step would be investigating inheritance of resistance in progeny and mapping $R$-genes to the hazelnut linkage map (Mehlenbacher et al., 2006). For example, the final Black Sea Group 2 holds eight resistant and two tolerant OP seedling accessions with no EFB-resistant reference accessions placed in this group (Fig. 1; Table 1). The Moscow group holds 33 new EFB-resistant OP seedling selections and is only joined by one EFB-resistant clonal selection, Moscow \#2, a new introduction from the Russian Research Institute of Forestry and Mechanization, Moscow, Russia, of which little pedigree background is known. Furthermore, seven EFB-resistant OP seedling accessions were placed in the large Central European group, which holds no EFB-resistant reference accessions besides 'Slagel', a named hybrid selection from Gordon of whose pedigree is unknown. Also placed in the Central European group were several clonal, EFB-resistant, interspecific hybrid accessions from Farris and Gordon that have unclear origins. Based on these examples and others represented in this study, it is reasonable to assume that further collection and disease screening efforts from different regions of the world may lead to the identification of additional resistant plants, possibly from different genetic populations than those included in our study. Having access to a very wide diversity of EFB-resistant germplasm should help breeders maintain genetic diversity in their breeding lines as they strive to develop broad-based, durable resistance to infection by $A$. anomala in combination with many other important traits of commercial and ecological value.

The results of this study also provide a substantial reference tool to help manage and reduce the population size of EFBresistant seedling plants and clonal accessions held in the Rutgers University germplasm collection. For example, before this study, seedling and clonal germplasm accessions at Rutgers University were organized and maintained in rows in the field largely by collection origin (e.g., John Gordon Nursery) or by individual seed lot of introduced germplasm. In an attempt to maintain the potential genetic diversity present, the best plants of every seed lot (in terms of EFB-resistance and nut and kernel characteristics) were maintained (Capik et al., 2013). A similar approach was used for preserving clonal accessions obtained from private breeders and plant enthusiasts. This approach resulted in the generation of a field collection of more than 200 large (over $4 \mathrm{~m}$ ) trees from just a few collection trips and private

Table 4. Population partitioning of total within population variance across 323 Corylus accessions.

\begin{tabular}{|c|c|c|c|c|c|}
\hline Source & No. & $\mathrm{df}$ & $\begin{array}{c}\text { Sum of squares within } \\
\text { populations }\end{array}$ & $\begin{array}{l}\text { Variance components } \\
\text { within populations }\end{array}$ & $\begin{array}{l}\text { Proportion of total } \\
\text { variance }(\%)\end{array}$ \\
\hline Outgroup 1 & 10 & 9 & 65 & 7.22 & 1.63 \\
\hline Outgroup 2 & 4 & 3 & 6.75 & 2.25 & 0.169 \\
\hline C. americana $\times$ C. avellana hybrid group & 94 & 93 & 570.64 & 6.14 & 14.29 \\
\hline Black Sea Group 1 & 84 & 83 & 493.04 & 5.94 & 12.35 \\
\hline Black Sea Group 2 & 68 & 67 & 443.88 & 6.63 & 11.12 \\
\hline Wild $C$. avellana group & 78 & 77 & 510.01 & 6.62 & 12.77 \\
\hline Spanish-Italian group & 60 & 64 & 365.68 & 5.71 & 9.15 \\
\hline Moscow group & 68 & 67 & 407.71 & 6.09 & 10.21 \\
\hline Central European group & 100 & 99 & 607.61 & 6.14 & 15.22 \\
\hline
\end{tabular}


Table 5. Matrix of pairwise analysis of molecular variation $F_{S T}$ values (below the diagonal) and probability values above the diagonal with variation within each group of Corylus accessions along the principle diagonal.

\begin{tabular}{|c|c|c|c|c|c|c|c|c|c|c|c|}
\hline Group & G1 & G2 & G3 & G4 & G5 & G6 & G7 & G8 & G9 & G10 & G11 \\
\hline$\overline{\mathrm{G} 1^{\mathrm{z}}}$ & - & 0.001 & 0.001 & 0.001 & 0.001 & 0.001 & 0.001 & 0.001 & 0.001 & 0.001 & 0.001 \\
\hline $\mathrm{G}^{\mathrm{y}}$ & 0.326 & $\overline{-}$ & $\overline{0.001}$ & $\overline{0.001}$ & $\overline{0.001}$ & $\overline{0.001}$ & $\overline{0.001}$ & $\overline{0.001}$ & $\overline{0.001}$ & $\overline{0.001}$ & $\overline{0.001}$ \\
\hline $\mathrm{G}^{x}$ & 0.104 & 0.308 & $\overline{-}$ & $\overline{0.001}$ & $\underline{0.001}$ & $\overline{0.001}$ & $\overline{0.001}$ & $\overline{0.001}$ & $\overline{0.001}$ & $\overline{0.001}$ & $\overline{0.001}$ \\
\hline$\overline{\mathrm{G} 5}^{\mathrm{v}}$ & 0.179 & 0.356 & 0.133 & 0.173 & $\overline{-}$ & $\overline{0.001}$ & $\overline{0.001}$ & $\overline{0.001}$ & $\overline{0.001}$ & $\overline{0.001}$ & $\overline{0.001}$ \\
\hline$\overline{\mathrm{G}}^{\mathrm{u}}$ & 0.138 & 0.300 & 0.076 & 0.121 & 0.069 & $\overline{-}$ & $\overline{0.001}$ & $\overline{0.001}$ & $\overline{0.001}$ & $\overline{0.001}$ & $\overline{0.001}$ \\
\hline$\overline{\mathrm{G}}^{\mathrm{t}}$ & 0.129 & 0.308 & 0.084 & 0.099 & 0.129 & 0.090 & - & $\overline{0.001}$ & $\overline{0.001}$ & $\overline{0.001}$ & $\overline{0.001}$ \\
\hline$\overline{\mathrm{G} 10^{\mathrm{q}}}$ & 0.182 & 0.342 & 0.122 & 0.123 & 0.173 & 0.112 & 0.101 & 0.086 & 0.142 & $\overline{-}$ & $\overline{0.001}$ \\
\hline$\overline{\mathrm{G} 11}^{\mathrm{p}}$ & 0.178 & 0.356 & 0.101 & 0.061 & 0.154 & 0.096 & 0.072 & 0.057 & 0.0914 & 0.102 & - \\
\hline
\end{tabular}

${ }^{\mathrm{z}}$ Outgroup 1.

y Outgroup 2.

${ }^{\mathrm{x}}$ Outgroup 3.

${ }^{\mathrm{w}} \mathrm{C}$. americana $\times$ C. avellana hybrid group.

'Black Sea Group 1.

"Black Sea Group 2.

${ }^{\mathrm{t}}$ Gellatly hybrid group.

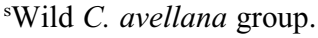

${ }^{r}$ Spanish-Italian group.

${ }^{\mathrm{q}}$ Moscow group.

${ }^{\mathrm{p} C e n t r a l ~ E u r o p e a n ~ g r o u p . ~}$

breeder contributions (Capik et al., 2013; Capik and Molnar, 2012; Molnar et al., 2007), which uses a large area of field space and is expensive to maintain. Fortunately, the SSR results provide the ability to use the consensus groups, in addition to phenotypic traits, as a decision tool to reduce the number of accessions held in field collections and to better target breeding and research efforts. For example, 34 OP seedling accessions spanning 12 different seed lots, all of which are currently being maintained in the field, were merged into Black Sea Group 1. Using the new genetic relationship information and phenotypic data (as discussed in Capik et al., 2013), the number of trees can be substantially reduced, where each seed lot need not be represented while still maintaining adequate representation from this genetic group. As a further example, the 40 total John Gordon hybrid clones were placed into four of the consensus groups, although a majority (29 of 40) were placed in the final C. americana $\times$ C. avellana hybrid group. This large number of accessions can be substantially reduced based on this finding by maintaining the best two to three accessions from each of the genetic groups represented, effectively reducing 40 large trees down to less than 10. Following this approach, a more refined, select group of EFB-resistant accessions can be used as the foundation for breeding genetically diverse, new, EFB-resistant cultivars for the creation of genetic mapping populations and advanced molecular genetic research projects aimed at the discovery of novel $R$-genes, etc. We expect that selecting plants for use in breeding based on their SSR-derived relationships in addition to other traits should prove much more effective in terms of maintaining genetic diversity than selecting accessions based on phenotype or collection origin alone.

\section{Conclusions}

As discussed previously, the results of the UPGMA cluster and STRUCTURE analysis are largely similar and are also congruent with previous research on hazelnut genetic resources.
Overall, the results support the known breeding histories and collection origins of a vast majority of the accessions. Furthermore, the reference cultivars, especially those selected to represent the groupings resolved in Gökirmak et al. (2009), provide a useful framework on which to place the unknown accessions.

EFB-resistant or -tolerant accessions were found in each of the final 11 consensus groups resolved in the study, providing strong evidence that EFB resistance is widespread across the Corylus genus. This finding provides support that breeding for resistance to EFB need not be equated with the narrowing of genetic diversity in future breeding. Furthermore, the SSR results, in combination with phenotypic characteristics, will allow us to narrow our germplasm collection at Rutgers University to the most interesting and unique accessions within each of the consensus populations, saving considerable field space and reducing maintenance expenses. As future evaluations and improvement goals dictate, the remaining pool of accessions can be used to enhance breeding efforts to develop commercial-quality, EFB-resistant cultivars while striving to maintain a high level of genetic diversity. Some of these new accessions should also be preserved in the USDA National Clonal Germplasm Repository, as resources and field space permit. Finally, this project contributes to the growing body of evidence showing that the Corylus genus is very diverse and that hazelnut breeders have access to a substantial gene pool from which to continue genetic improvement efforts for EFB resistance and a multitude of other traits of commercial value and scientific and ecological interest.

\section{Literature Cited}

Ashworth, F. 1970. Notes on the less important hardy nuts. Annu. Rpt. Northern Nut Growers Assn. 61:133-136.

Bassil, N., P. Boccacci, R. Botta, J. Postman, and S. Mehlenbacher. 2013. Nuclear and chloroplast microsatellite markers to assess 
genetic diversity and evolution in hazelnut species, hybrids and cultivars. Genet. Resources Crop Evol. 60:543-568.

Bassil, N.V., R. Botta, and S.A. Mehlenbacher. 2005a. Microsatellite markers in hazelnut: Isolation, characterization and cross-species amplification. J. Amer. Soc. Hort. Sci. 130:543-549.

Bassil, N.V., R. Botta, and S.A. Mehlenbacher. 2005b. Additional microsatellite markers of the european hazelnut. Acta Hort. 686:105110.

Boccacci, P., A. Akkak, N.V. Bassil, S.A. Mehlenbacher, and R. Botta. 2005. Characterization and evaluation of microsatellite loci in european hazelnut (Corylus avellana L.) and their transferability to other Corylus species. Mol. Ecol. Notes 5:934-937.

Boccacci, P., A. Akkak, and R. Botta. 2006. DNA-typing and genetic relationships among european hazelnut (Corylus avellana L.) cultivars using microsatellite markers. Genome 49:598-611.

Boccacci, P., R. Botta, and M. Rovira. 2008. Genetic diversity of hazelnut (Corylus avellana L.) germplasm in northeastern Spain. HortScience 43:667-672.

Brooks, R.M. and H.P. Olmo. 1997. Register of fruit \& nut varieties. 3rd Ed. ASHS Press, Alexandria, VA.

Brownstein, M.J., J.D. Carpten, and J.R. Smith. 1996. Modulations of non-templated nucleotide addition by Taq DNA polymerase: Primer modifications that facilitate genotyping. Biotechniques 20:1004 1010.

Cameron, H.R. 1976. Eastern filbert blight established in the Pacific Northwest. Plant Dis. Rptr. 60:737-740.

Campbell, D. 1996. Observations of eastern filbert blight. Annu. Rpt. Northern Nut Growers Assn. 87:12-14.

Capik, J.M. and T.J. Molnar. 2012. Assessment of host (Corylus sp.) resistance to eastern filbert blight in New Jersey. J. Amer. Soc. Hort. Sci. 137:157-172.

Capik, J.M., M. Muehlbauer, A. Novy, J.M. Honig, and T.J. Molnar. 2013. Eastern filbert blight resistant hazelnuts from Russia, Ukraine, and Poland. HortScience 48:466-473.

Chen, H., S.A. Mehlenbacher, and D.C. Smith. 2005. AFLP markers linked to eastern filbert blight resistance from OSU 408.040 hazelnut. J. Amer. Soc. Hort. Sci. 30:412-417.

Chen, H., S.A. Mehlenbacher, and D.C. Smith. 2007. Hazelnut accessions provide new sources of resistance to eastern filbert blight. HortScience 42:466-469.

Chen, Z., S.R. Manchester, and H. Sunday. 1999. Phylogeny and evolution of the Betulaceae as inferred from DNA sequences, morphology, and paleobotany. Amer. J. Bot. 86:1168-1181.

Coyne, C.J., S.A. Mehlenbacher, and D.C. Smith. 1998. Sources of resistance to eastern filbert blight. J. Amer. Soc. Hort. Sci. 124:253257.

Crane, H.L., C.A. Reed, and M.N. Wood. 1937. Nut breeding, p. 835 844. In: Hambidge, G. and E.S. Bressman (eds.). 1937 Yearbook of agriculture. U.S. Govt. Printing Office, Washington, DC.

Cullings, K.W. 1992. Design and testing of a plant-specific PCR primer for ecological and evolutionary studies. Mol. Ecol. 1:233240.

Dabb, C. 1971. Be active, let us all take part. The Nutshell Qrtly. Nwsl. Northern Nut Growers Assn. 19:3.

Davison, A.D. and R.M. Davidson. 1973. Apioporthe and Monchaetia canker reported in western Washington. Plant Dis. Rptr. 57:522523.

Doyle, J.J. and J.L. Doyle. 1987. A rapid DNA isolation procedure for small quantities of fresh leaf tissue. Phytochem. Bul. 19:11-15.

Erdogan, V. and S.A. Mehlenbacher. 2000. Phylogenetic relationships of Corylus species (Betulaceae) based on nuclear ribosomal DNA ITS region and chloroplast matK gene sequences. Syst. Bot. 25:727737.

Falush, D., M. Stephens, and J.K. Pritchard. 2003. Inference of population structure using multilocus genotype data: Linked loci and correlated allele frequencies. Genetics 164:1567-1587.

Farris, C.W. 1974. An introduction to the stars-A new family of filbert hybrids. Ann. Rpt. Northern Nut Growers Assn. 67:80-82.
Farris, C.W. 1989. Two new introductions: The 'Grand Traverse' hazelnut and 'Spartan Seedless' grape. Annu. Rpt. Northern Nut Growers Assn. 80:102-103.

Farris, C.W. 2000. The hazel tree. Northern Nut Growers Assn., East Lansing, MI.

Food and Agriculture Organization of the United Nations. 2013. Agricultural production, crops primary. 8 July 2013 . $<$ http://faostat. fao.org/site $/ 567 /$ default.aspx\#ancor $>$.

Fuller, A.S. 1908. The nut culturist. Orange Judd, New York, NY. Gellatly, J.U. 1950. Description of Filazel varieties. Annu. Rpt. Northern Nut Growers Assn. 41:116-117.

Gellatly, J.U. 1956. Filazels. Annu. Rpt. Northern Nut Growers Assn. 47:112-113.

Gellatly, J.U. 1964. Filazels. Annu. Rpt. Northern Nut Growers Assn. 55:153-155.

Gellatly, J.U. 1966. Tree hazels and their improved hybrids. Annu. Rpt. Northern Nut Growers Assn. 57:98-101.

Gökirmak, T., SA. Mehlenbacher, and N.V. Bassil. 2009. Characterization of european hazelnut (Corylus avellana L.) cultivars using SSR markers. Genet. Resources Crop Evol. 56:147-172.

Gordon, J. 1993. Nut growing Ontario style. Soc. Ontario Nut Growers, Niagara-on-the-Lake, Ontario, Canada.

Gottwald, T.R. and H.R. Cameron. 1980. Infection site, infection period, and latent period of canker caused by Anisogramma anomala in european filbert. Phytopathology 70:1083-1087.

Grimo, E. 2011. Nut tree Ontario, A practical guide. Soc. Ontario Nut Growers, Niagara-on-the-Lake, Ontario, Canada.

Gürcan, K. and S.A. Mehlenbacher. 2010a. Development of microsatellite marker loci for european hazelnut (Corylus avellana L.) from ISSR fragments. Mol. Breed. 26:551-559.

Gürcan, K. and S.A. Mehlenbacher. 2010b. Transferability of microsatellite markers in the Betulaceae. J. Amer. Soc. Hort. Sci. 135:159-173.

Gürcan, K., S.A. Mehlenbacher, R. Botta, and P. Boccacci. 2010a. Development, characterization, segregation, and mapping of microsatellite markers for european hazelnut (Corylus avellana L.) from enriched genomic libraries and usefulness in genetic diversity studies. Tree Genet. Genomes 6:513-531.

Gürcan, K., S.A. Mehlenbacher, and V. Erdogan. 2010b. Genetic diversity in hazelnut cultivars from Black Sea countries assessed using SSR markers. Plant Breed. 129:422-434.

Hammond, E. 2006. Identifying superior hybrid hazelnut plants in southeast Nebraska. MS thesis, Univ. Nebraska, Lincoln, NE.

Johnson, K.B. and J.N. Pinkerton. 2002. Eastern filbert blight, p. 44 46. In: Teviotdale, B.L., T.J. Michailides, and J.W. Pscheidt (eds.). Compendium of nut crop diseases in temperate zones. APS Press, St. Paul, MN.

Johnson, K.B., J.N. Pinkerton, S.A. Mehlenbacher, J.K. Stone, and J.W. Pscheidt. 1996. Eastern filbert blight of european hazelnut: It's becoming a manageable disease. Plant Dis. 80:1308-1316.

Julian, J.W., C.F. Seavert, and J.L. Olsen. 2008. Orchard economics: The costs and returns of establishing and producing hazelnuts in the Willamette Valley. Oregon State Univ. Ext. Serv. Bul. EM 8748-E.

Julian, J., C.F. Seavert, and J.L. Olsen. 2009. An economic evaluation of the impact of eastern filbert blight resistant cultivars in Oregon, U.S.A. Acta Hort. 845:725-732.

Kalinowski, S.T., M.L. Taper, and T.C. Marshall. 2007. Revising how the computer program CERVUS accommodates genotyping error increases success in paternity assignment. Mol. Ecol. 16:10991106.

Liu, K. and S.V. Muse. 2005. PowerMarker: Integrated analysis environment for genetic marker data. Bioinformatics 21:2128-2129.

Lunde, C.F., S.A. Mehlenbacher, and D.C. Smith. 2000. Survey of hazelnut cultivars for response to eastern filbert blight inoculation. HortScience 35:729-731.

Mehlenbacher, S.A. 1991. Hazelnuts (Corylus), p. 789-836. In: Moore, J.N. and J.R. Ballington (eds.). Genetic resources of temperate fruit and nut crops. Intl. Soc. Hort. Sci., Wageningen, The Netherlands. 
Mehlenbacher, S.A., A.N. Azarenko, D.C. Smith, and R. McCluskey. 2001. 'Clark' hazelnut. HortScience 36:995-996.

Mehlenbacher, S.A., A.N. Azarenko, D.C. Smith, and R.L. McCluskey. 2007. 'Santiam' hazelnut. HortScience 42:715-717.

Mehlenbacher, S.A., R.N. Brown, E.R. Nouhra, T. Gökirmak, N.V. Bassil, and T.L. Kubisiak. 2006. A genetic linkage map for hazelnut (Corylus avellana L.) based on RAPD and SSR markers. Genome 49:122-133.

Mehlenbacher, S.A., D.C. Smith, and R.L. McCluskey. 2009. 'Yamhill' hazelnut. HortScience 44:845-847.

Mehlenbacher, S.A., D.C. Smith, and R.L. McCluskey. 2011. 'Jefferson' hazelnut. HortScience 46:662-664.

Mehlenbacher, S.A., D.C. Smith, and R.L. McCluskey. 2013. 'Dorris' hazelnut. HortScience 48:796-799.

Mehlenbacher, S.A., M.M. Thompson, and H.R. Cameron. 1991. Occurrence and inheritance of immunity to eastern filbert blight in 'Gasaway' hazelnut. HortScience 26:442-443.

Molnar, T. 2011. Corylus L., p. 15-48. In: Kole, C. (ed.). Wild crop relatives: Genomic and breeding resources of forest trees. Vol. 10. Springer-Verlag Berlin, Heidelberg, Germany.

Molnar, T.J. and J.M. Capik. 2012. Eastern filbert blight susceptibility of american $\times$ european hazelnut progenies. HortScience 47:1412-1418. Molnar, T.J., J.C. Goffreda, and C.R. Funk. 2005. Developing hazelnuts for the eastern United States. Acta Hort. 68:609-617.

Molnar, T.J., S.A. Mehlenbacher, D.E. Zaurov, and J.C. Goffreda. 2007. Survey of hazelnut germplasm from Russia and Crimea for response to eastern filbert blight. HortScience 42:51-56.

Northern Nut Growers Association. 2013. NNGA-Northern Nut Growers Association, Inc. 10 Oct. 2013. <http:// www.nutgrowing.org $>$.

Peakall, R. and P.E. Smouse. 2006. GENALEX 6: Genetic analysis in Excel. Population genetic software for teaching and research. Mol. Ecol. Notes 6:288-295.

Peakall, R. and P.E. Smouse. 2012. GenAlEx 6.5: Genetic analysis in Excel. Population genetic software for teaching and research-An update. Bioinformatics 28:2537-2539.

Pritchard, J.K., M. Stephens, and P. Donnelly. 2000. Inference of population structure from multilocus genotype data. Genetics 155:945-959.

Reed, C.A. 1936. New filbert hybrids. J. Hered. 27:427-431.

Rutter, P.A. 1987. Badgersett research farm-Plantings, projects, and goals. Annu. Rpt. Northern Nut Growers Assn. 78:173-186.
Rutter, M. 1991. Variation in resistance to eastern filbert blight in hybrid hazels. Annu. Rpt. Northern Nut Growers Assn. 82:159-162.

Sathuvalli, V., S.A. Mehlenbacher, and D.C. Smith. 2010. Response of hazelnut accessions to greenhouse inoculation with Anisogramma anomala. HortScience 45:1116-1119.

Sathuvalli, V.R., H.L. Chen, S.A. Mehlenbacher, and D.C. Smith. 2011a. DNA markers linked to eastern filbert blight resistance in 'Ratoli' hazelnut. Tree Genet. Genomes 7:337-345.

Sathuvalli, V., S.A. Mehlenbacher, and D.C. Smith. 2011b. DNA markers linked to eastern filbert blight resistance from a hazelnut selection from the Republic of Georgia. J. Amer. Soc. Hort. Sci. 136:350-357.

Sathuvalli, V.R. and S.A. Mehlenbacher. 2012. Characterization of american hazelnut (Corylus americana) accessions and Corylus americana $\times$ Corylus avellana hybrids using microsatellite markers. Genet. Resources Crop Evol. 59:1055-1075.

Sathuvalli, V.R., S.A. Mehlenbacher, and D.C. Smith. 2012. Identification and mapping of DNA markers linked to eastern filbert blight resistance from OSU 408.040 hazelnut. HortScience 47:570 573.

Schuelke, M. 2000. An economic method for the fluorescent labeling of PCR fragments. Nat. Biotechnol. 18:233-234.

Slate, G.L. 1961. The present status of filbert breeding. Annu. Rpt. Northern Nut Growers Assn. 52:24-26.

Tamura, K., D. Peterson, N. Peterson, G. Stecher, M. Nei, and S. Kumar. 2011. MEGA5: Molecular evolutionary genetics analysis using maximum likelihood, evolutionary distance, and maximum parsimony methods. Mol. Biol. Evol. doi: 10.1093/molbev/msr121.

Thompson, M.M. 1985. Linkage of the incompatibility locus and red pigmentation genes in hazelnut. J. Hered. 76:119-122.

Thompson, M.M., H.B. Lagerstedt, and S.A. Mehlenbacher. 1996. Hazelnuts, p. 125-184. In: Janick, J. and J.N. Moore (eds.). Fruit breeding. Vol. 3. Nuts. Wiley, New York, NY.

Weschcke, C. 1954. Growing nuts in the north. Webb, St. Paul, MN. Weschcke, C. 1970. A little nut history. Annu. Rpt. Northern Nut Growers Assn. 61:113-116.

Xu, Y.X. and M.A. Hanna. 2010. Evaluation of Nebraska hybrid hazelnuts: Nut/kernel characteristics, kernel proximate composition, and oil protein properties. Ind. Crops Prod. 31:84-91.

Yoo, K. and J. Wen. 2002. Phylogeny and biogeography of Carpinus and subfamily Coryloideae (Betulaceae). Intl. J. Plant Sci. 163:641650 . 


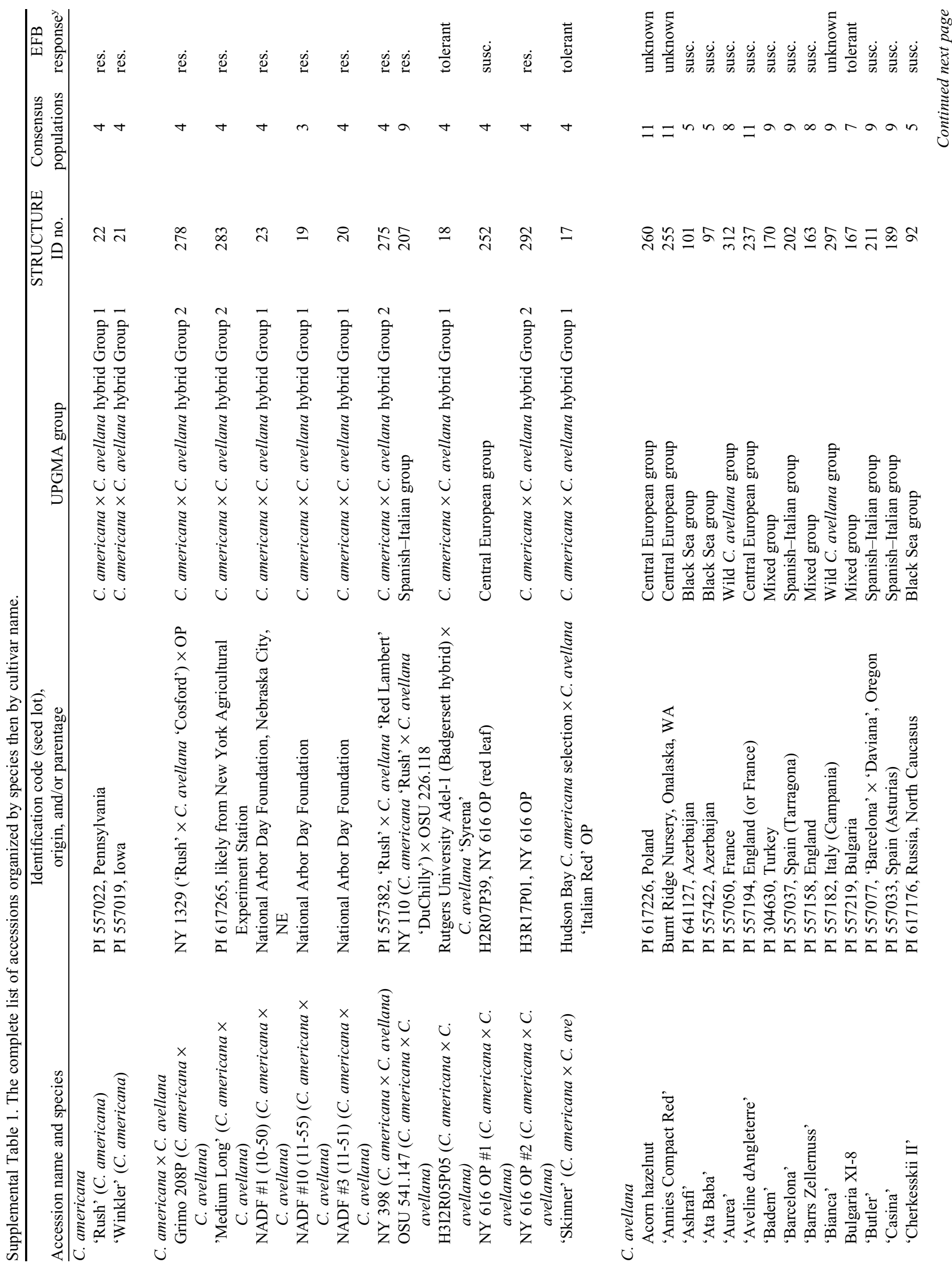




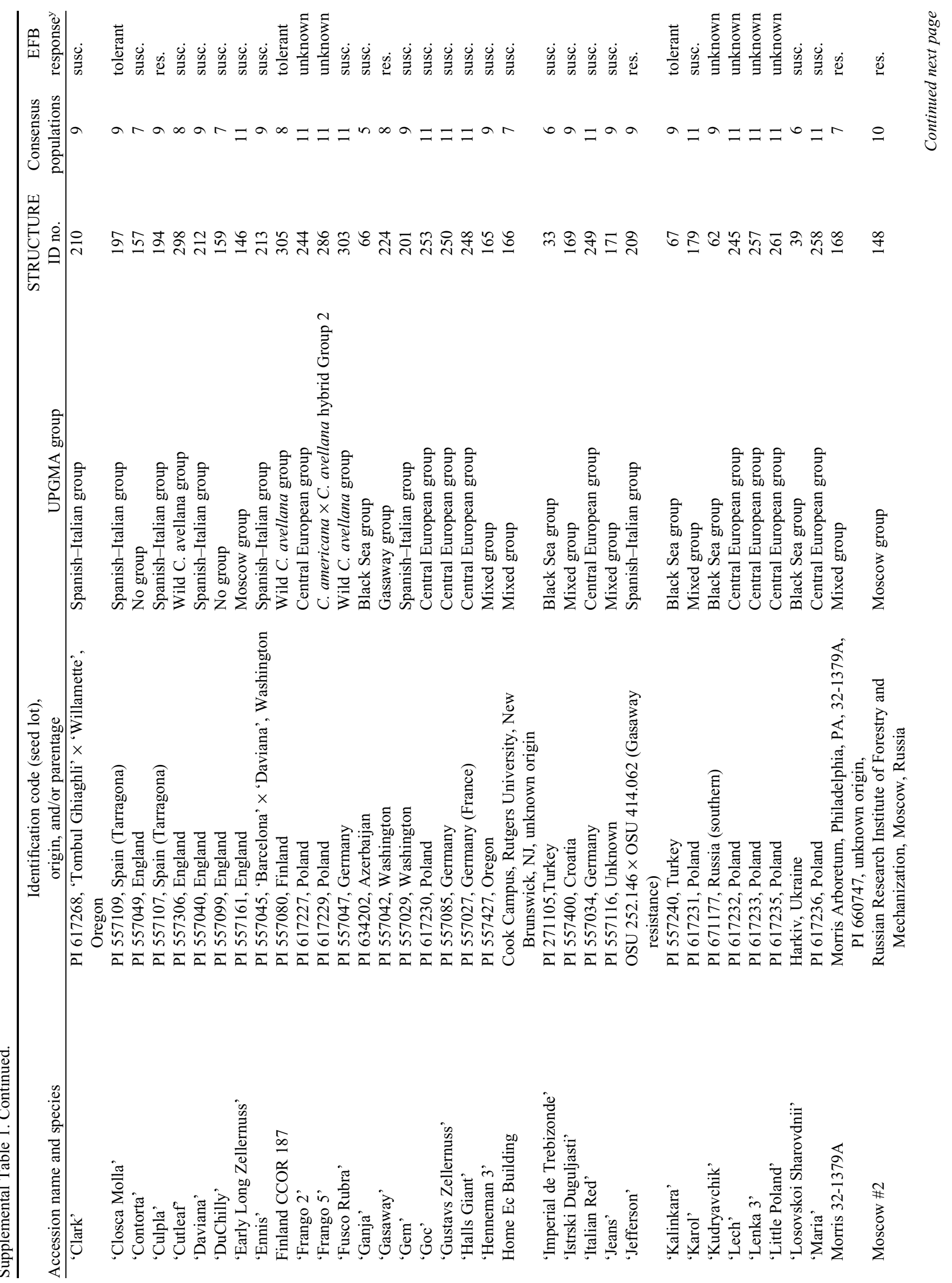




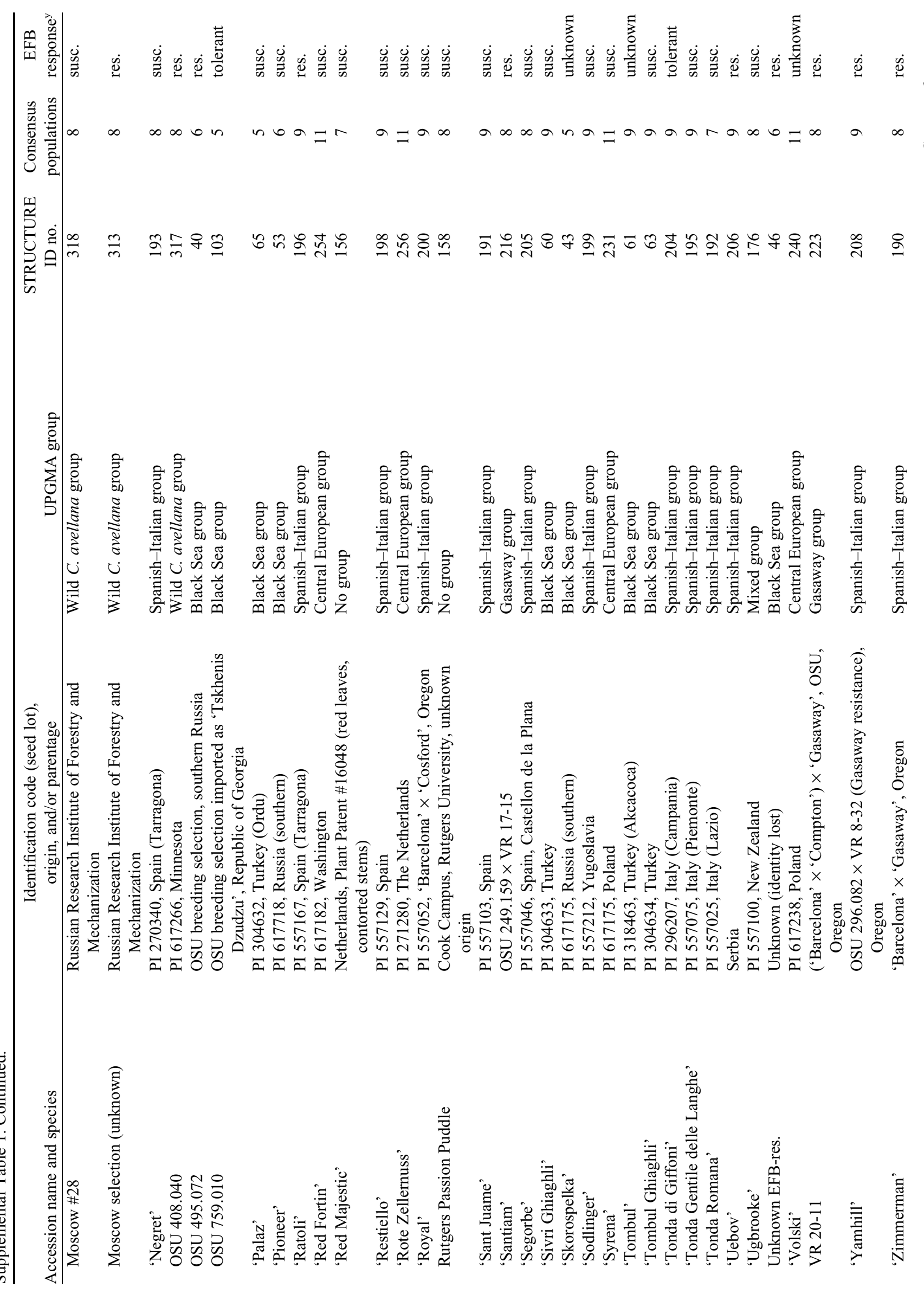




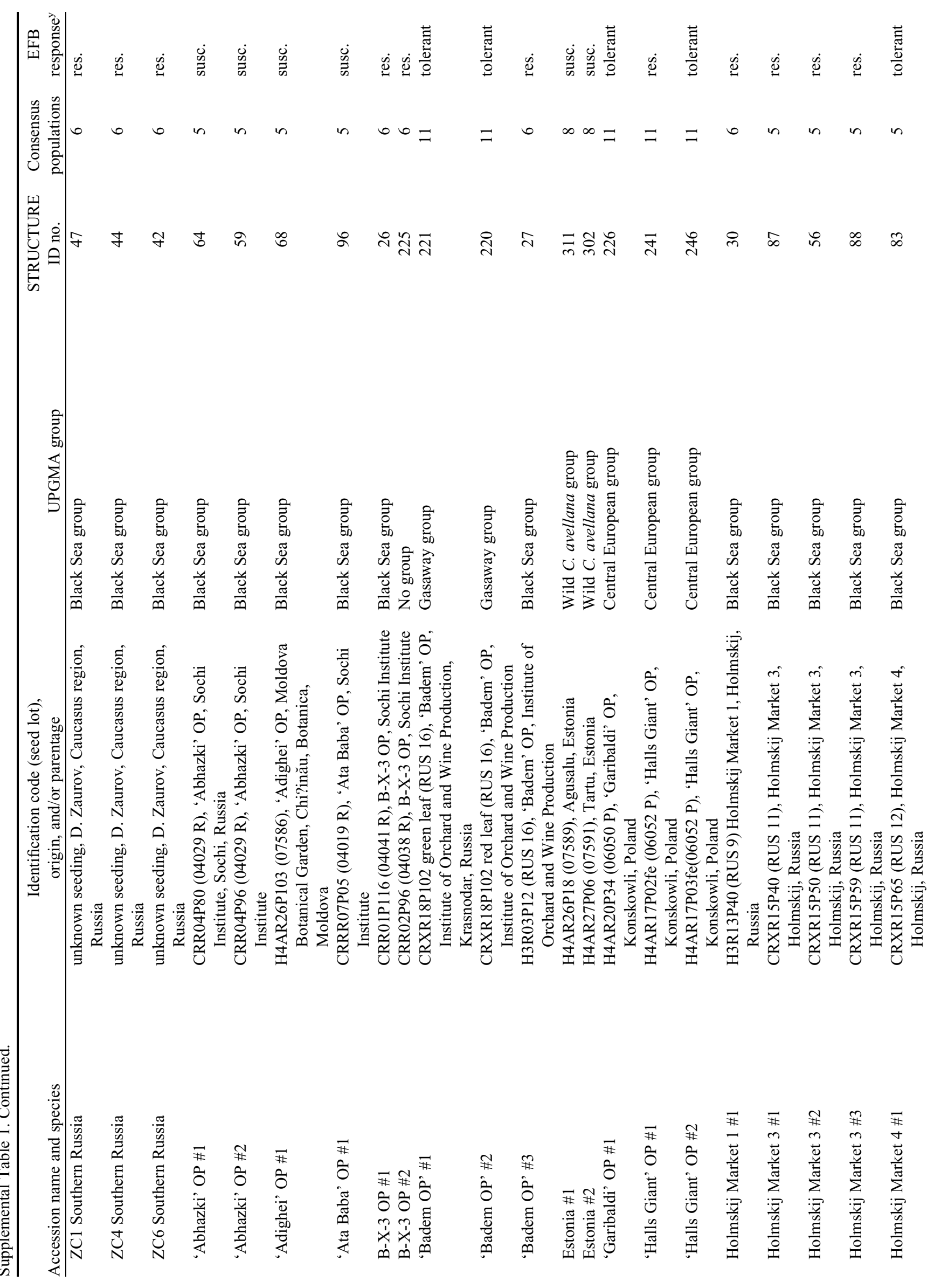




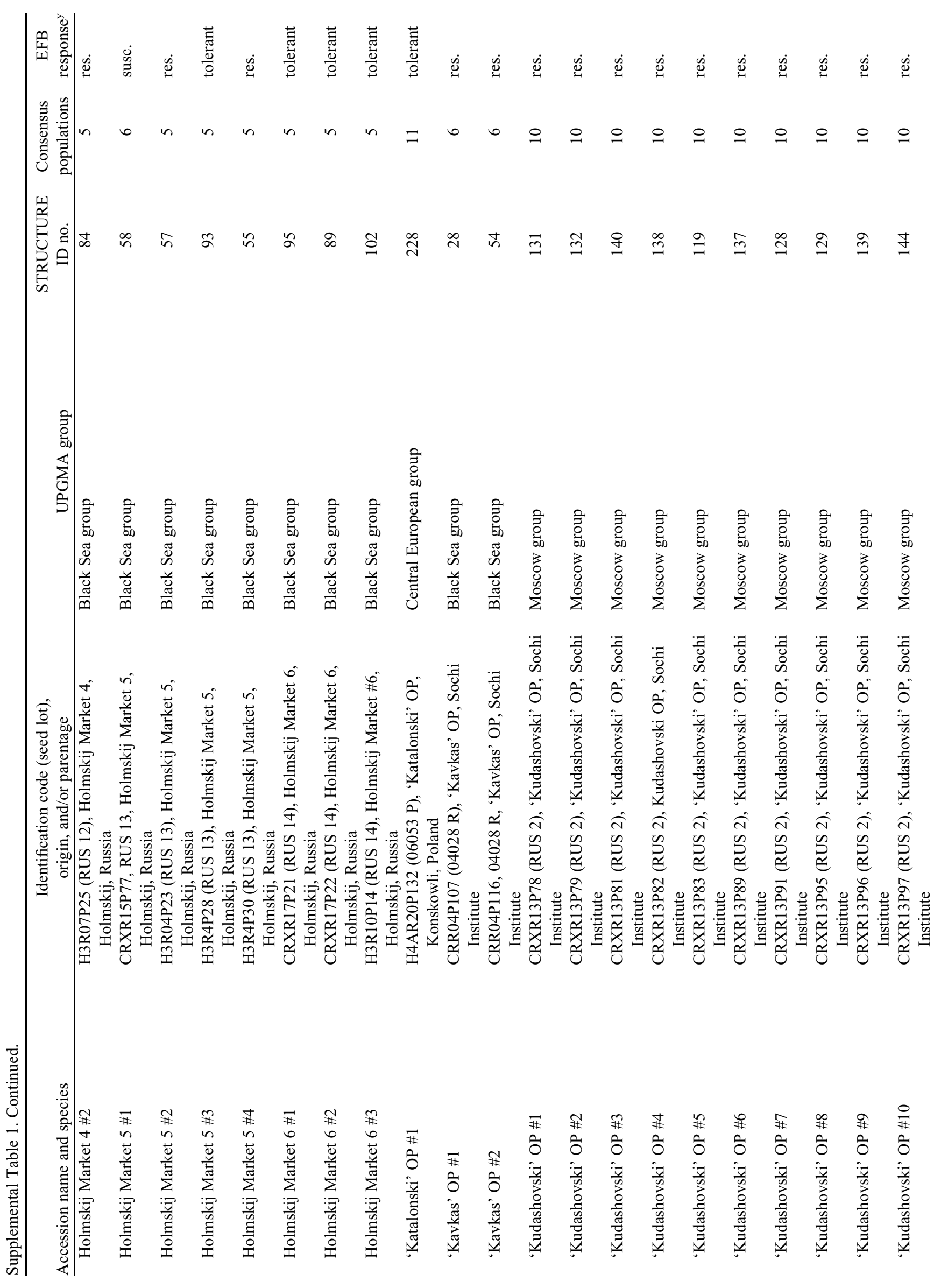




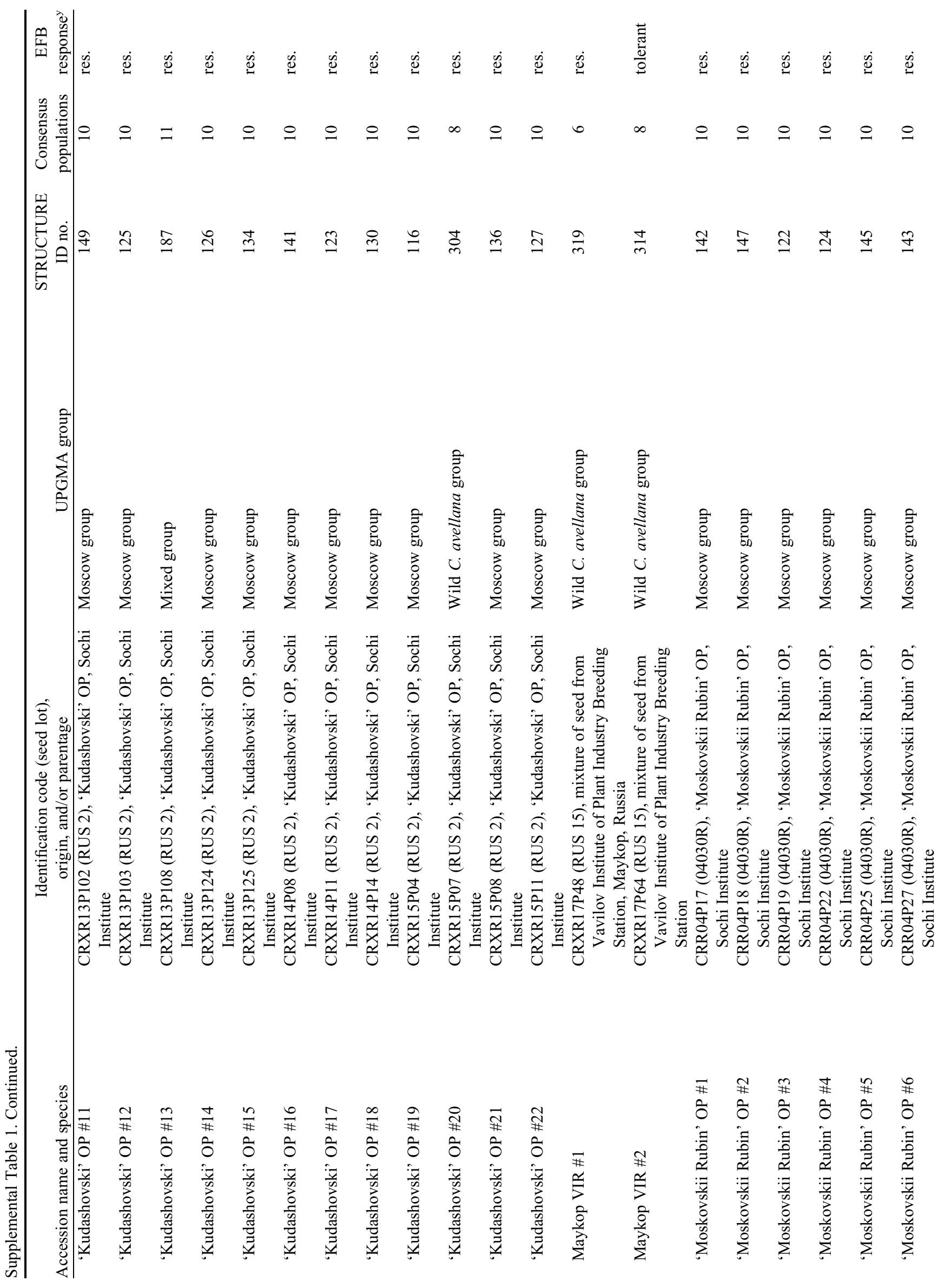




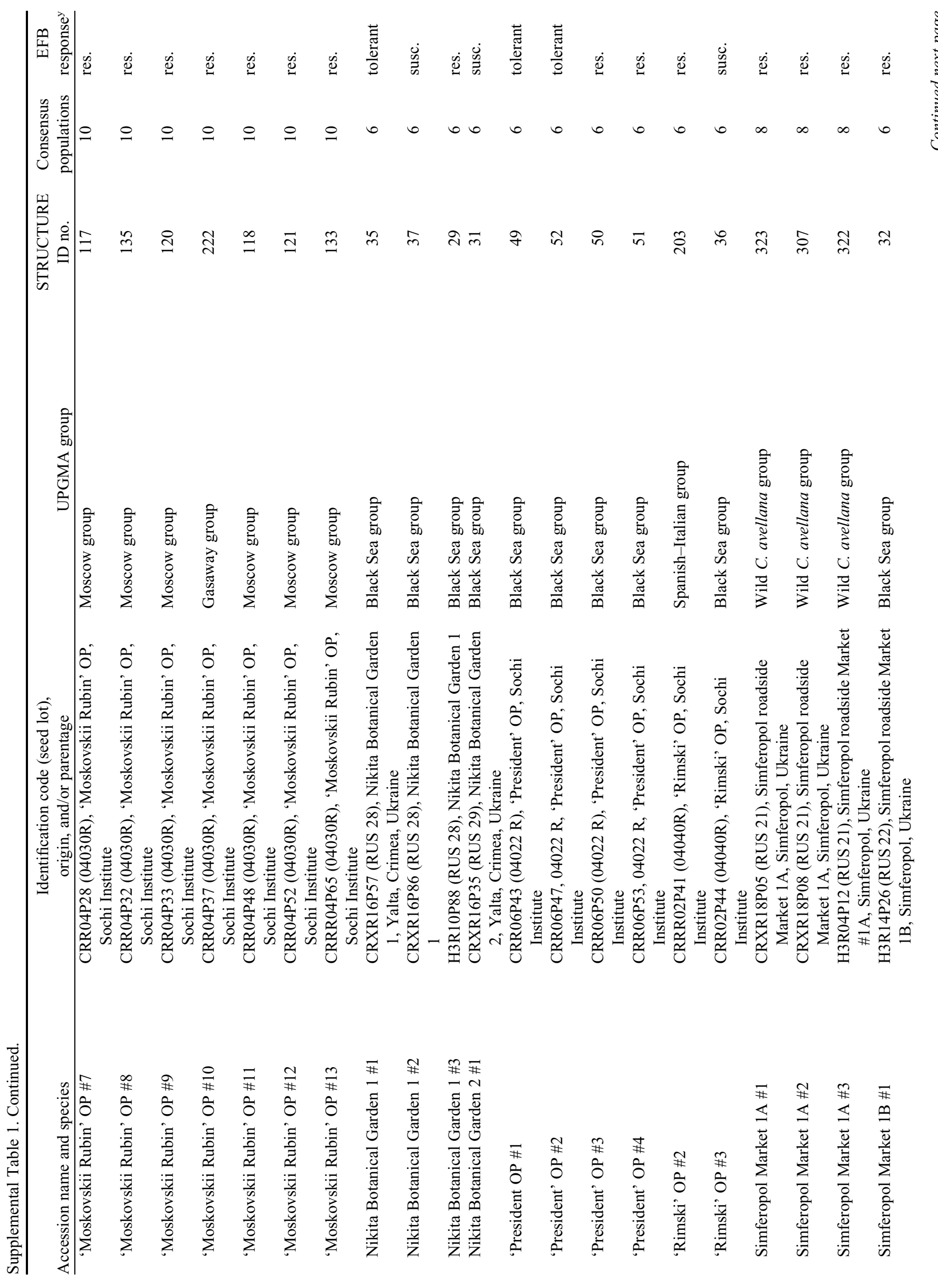




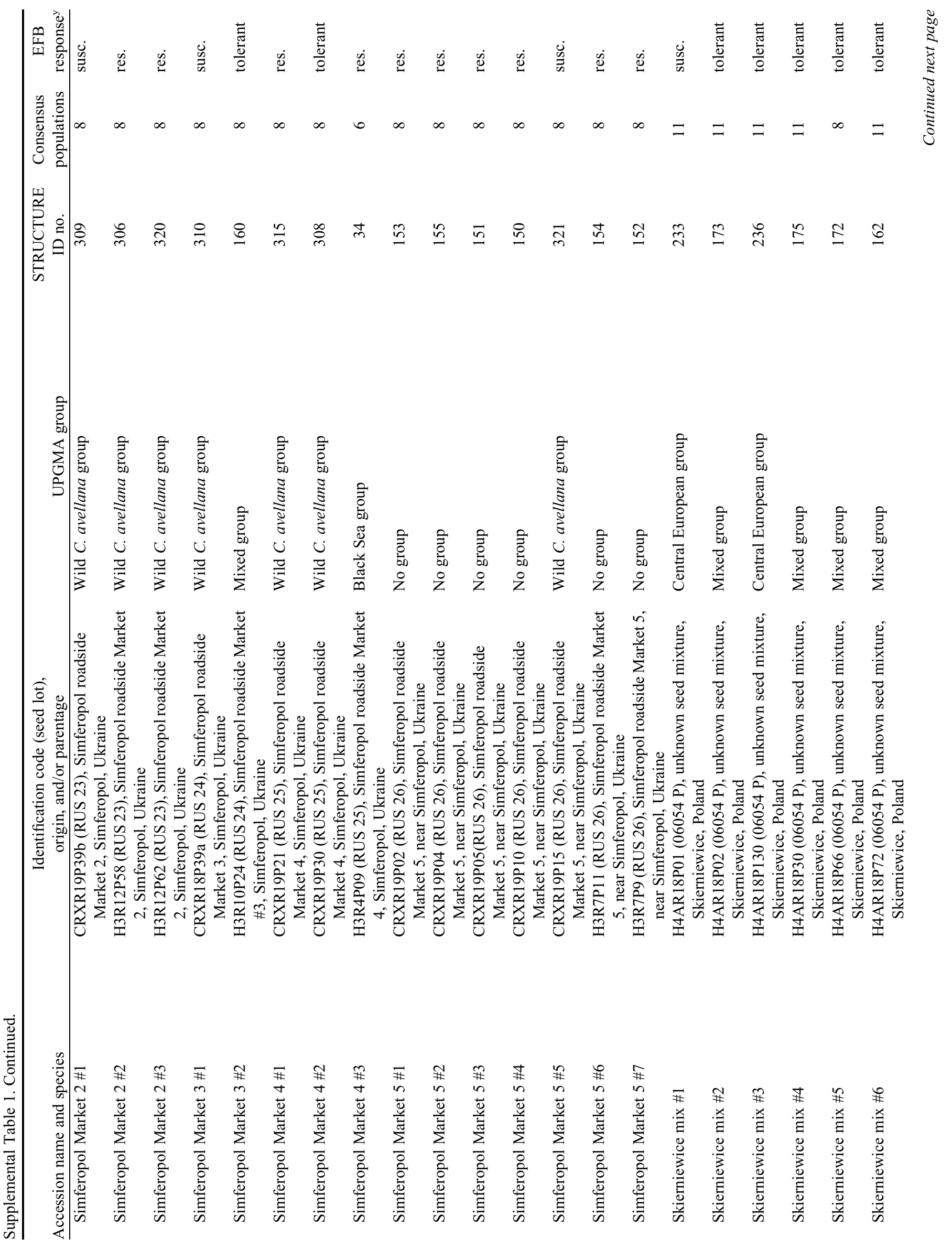




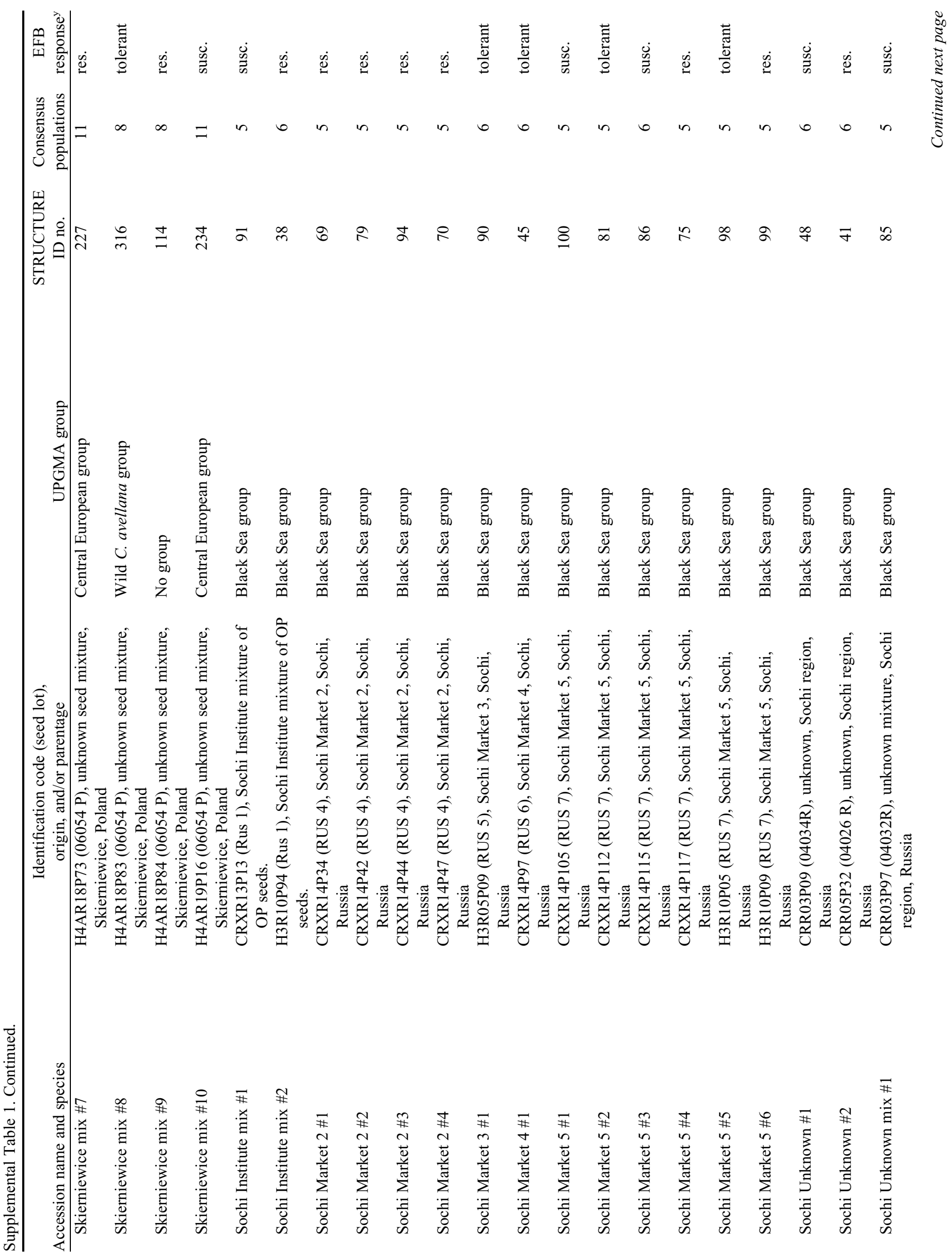




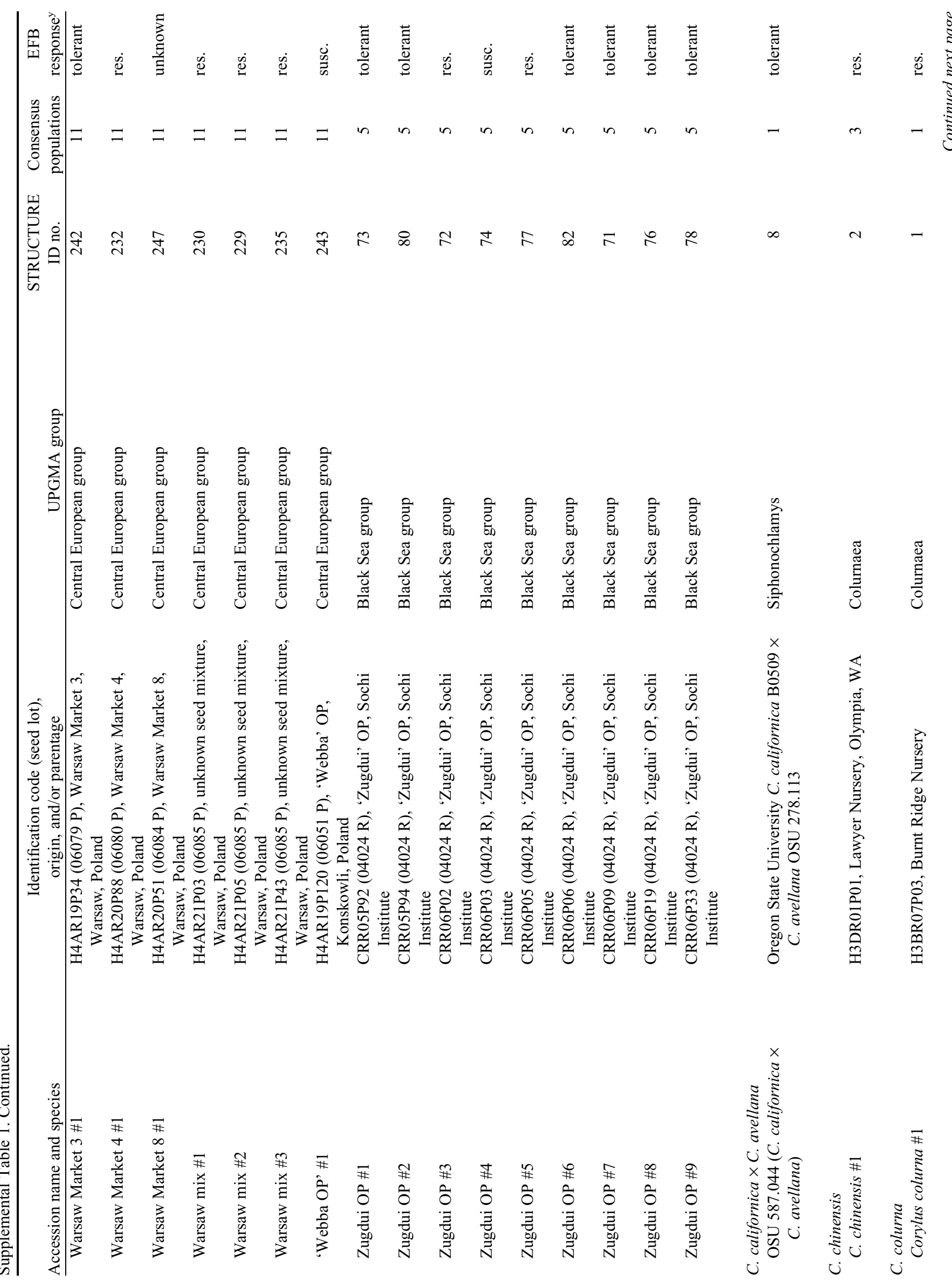




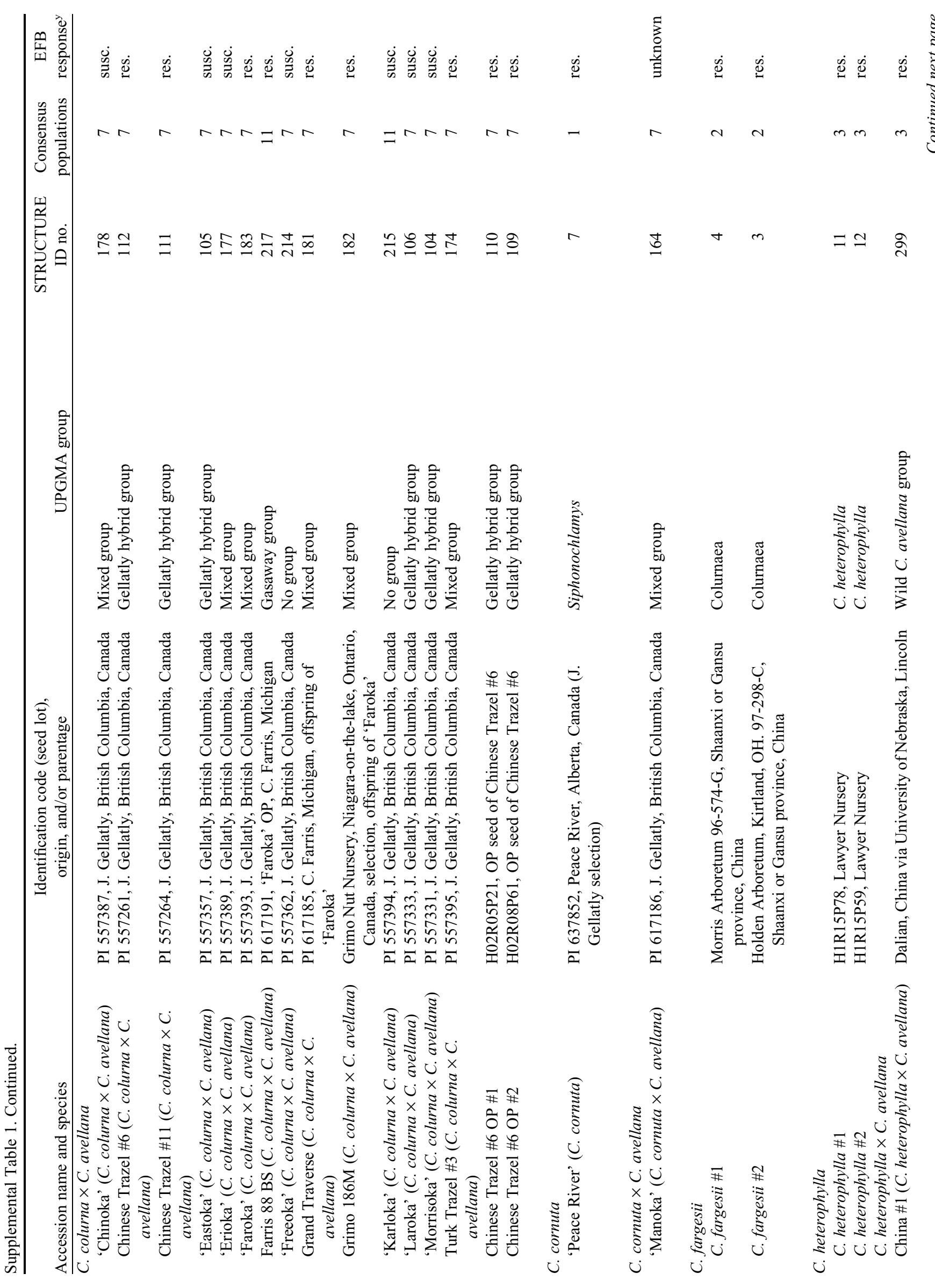




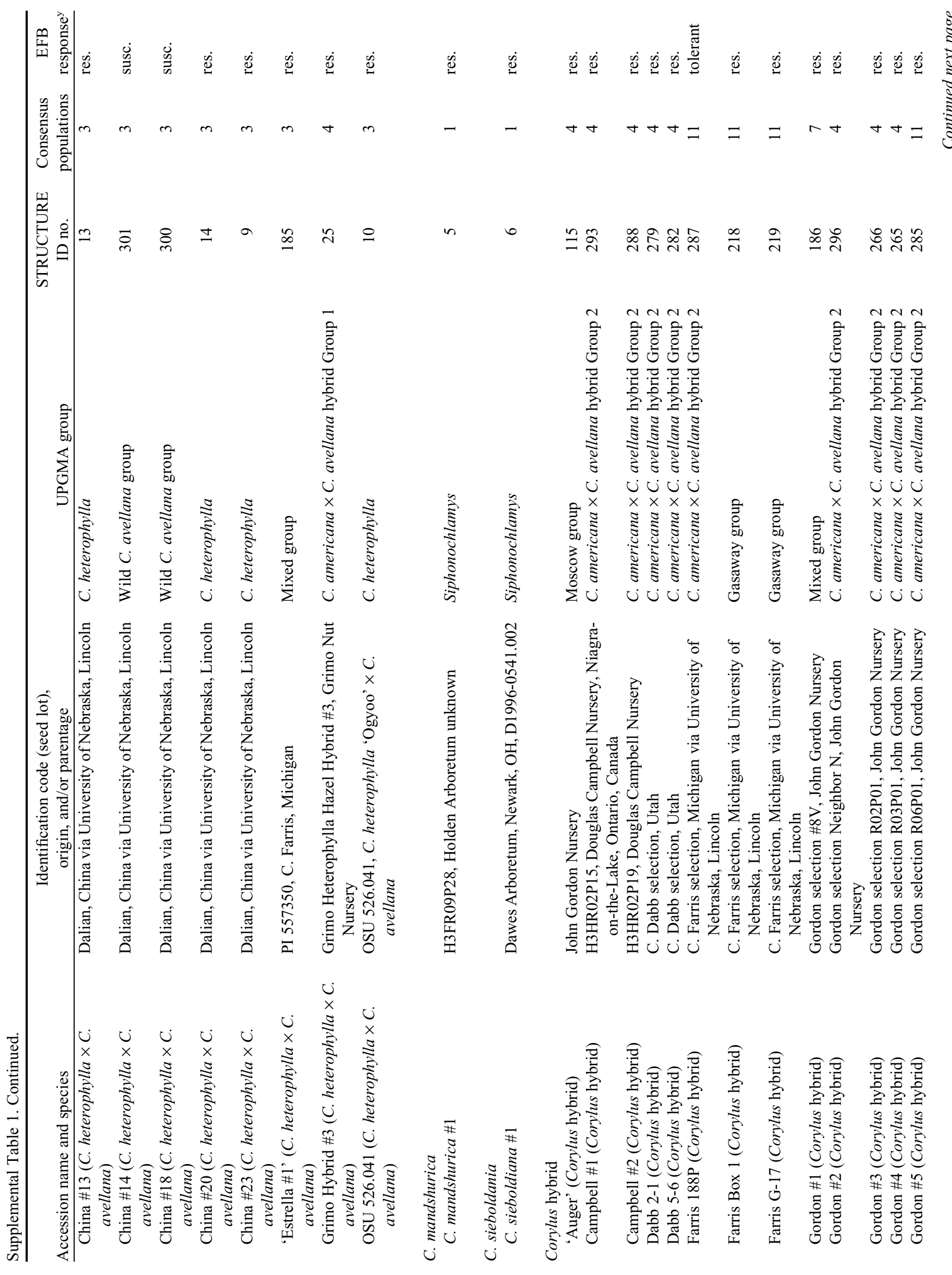




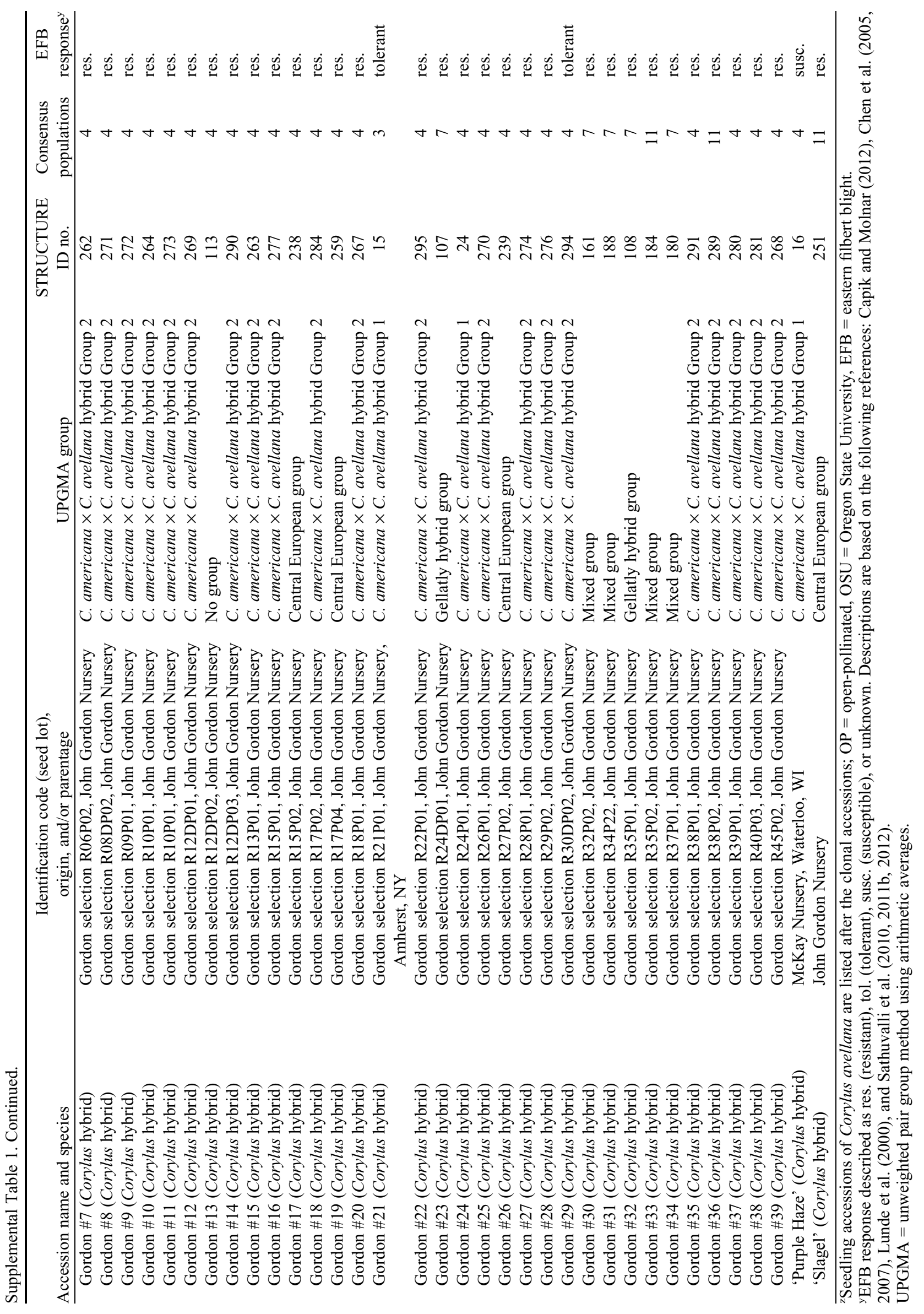

